\author{
Aus der Abteilung Neurologie \\ (Prof. Dr. med. M. Bähr) \\ im Zentrum Neurologische Medizin \\ der Medizinischen Fakultät der Universität Göttingen
}

\title{
Der Einfluss der Therapie mit Dornase alfa auf Beatmungsdauer und Entzündungsmediatoren bei beatmeten neurologischen Patienten
}

\author{
INAUGURAL-DISSERTATION \\ zur Erlangung des Doktorgrades \\ der Medizinischen Fakultät \\ der Georg-August-Universität zu Göttingen
}

\author{
vorgelegt von \\ Maria Grigoryev \\ aus \\ Charkow/Ukraine
}

Göttingen 2008 
Dekan: $\quad$ Prof. Dr. med. C. Frömmel

I. Berichterstatter: Prof. Dr. med. H. Prange

II. Berichterstatter / in:

III. Bericherstatter / in:

Tag der mündlichen Prüfung: 


\section{Inhaltsverzeichnis}

1 Einleitung 1

$1.1 \quad$ Epidemiologie der nosokomialen Pneumonie 1

1.2 Die Rolle von Risikofaktoren 3

1.3 Die Rolle der mukoziliären Clearance 4

1.4 Die Rolle von Atemwegsinfektionen 6

1.4.1 Immunologischer Ablauf der Atemwegsinfektion 6

$\begin{array}{lll}\text { 1.4.1.1 Interleukin-1 } \beta & 7\end{array}$

$\begin{array}{lll}\text { 1.4.1.2 } & \text { Interleukin-6 }\end{array}$

1.4.1.3 Interleukin-8 8

1.4.1.4 Interleukin-10 8

1.4.1.5 Lipopolysaccharidbindendes Protein 9

1.4.1.6 Granulozyten-Makrophagen-Kolonienstimulierender Faktor 9

1.5 Andere Faktoren mit Einfluss auf die Clearance 10

1.6 Warum spielt die Vermeidung von Atelektasen eine bedeutende $\begin{array}{ll}\text { Rolle? } & 10\end{array}$

1.7 RhDNase - Dornase alfa 11

1.7.1 Klinische Erfahrungen 11

$\begin{array}{lll}\text { 1.7.2 Produktion und chemische Charakteristika } & 12\end{array}$

1.7.3 Zu erwartende Wirkung des Medikaments 13

$\begin{array}{lll}\text { 1.7.4 Nebenwirkungen } & 14\end{array}$

1.7.5 Überdosierung 15

$1.8 \quad$ Besonderheit der neurologischen Patienten 15

$2 \quad$ Fragestellung 17

$3 \quad$ Material und Methoden 19

$\begin{array}{lll}3.1 & \text { Patienten } & 19\end{array}$ 


$\begin{array}{lll}3.2 & \text { Allokation } & 20 \\ 3.3 & \text { Studiendesign } & 20 \\ 3.4 & \text { Prüfpräparat } & 23 \\ 3.5 & \text { Placebo } & 24 \\ 3.6 & \text { Trachealsekretentnahme } & 24 \\ 3.7 & \text { Erfassung des klinischen Patientenzustandes } & 24 \\ 3.8 & \text { Applikationsmodus } & 24 \\ 3.8 .1 & \text { Beschreibung der Verum-Behandlung } & 25 \\ 3.8 .2 & \text { Beschreibung der Placebo-Behandlung } & 25 \\ 3.9 & \text { Methoden zur Erfassung der Wirksamkeit und Sicherheit } & 25 \\ 3.9 .1 & \text { Erfassung der klinischen Wirksamkeit } & 25 \\ 3.9 .2 & \text { Erfassung der Wirksamkeit in vitro } & 26 \\ 3.9 .2 .1 & \text { Verringerung der DNA-Konzentration } & 26 \\ 3.9 .2 .2 & \text { Verkürzung der DNA-Kettenlänge } & 27 \\ 3.9 .2 .3 & \text { Zytokinkonzentration im Trachealsekret } & 27 \\ 3.10 & \text { Statistik und Auswertung } & 28 \\ 3.10 .1 & \text { Fallzahl } & 28 \\ 3.10 .2 & \text { Datenauswertung } & 28\end{array}$

4 Ergebnisse 30

$\begin{array}{lll}4.1 & \text { Patientenkollektiv } 30\end{array}$

$\begin{array}{lll}4.1 .1 & \text { Altersverteilung } & 30\end{array}$

$\begin{array}{lll}\text { 4.1.2 Geschlechtsverteilung } & 30\end{array}$

4.1.3 Neurologische Grunderkrankungen 30

4.1.4 Pneumonologische Erkrankungen 32

4.1.5 Systemisches Entzündungsstadium 32

4.1.6 Tracheotomie 33

4.1.7 Reintubation 33

4.1.8 Beatmungsparameter 34

4.2 Erfassung der klinischen Wirksamkeit 34

$\begin{array}{lll}4.2 .1 & \text { Beatmungsdauer } & 34\end{array}$ 
4.2.2 Verbesserung der Lungenfunktionsparameter 35

4.2.2.1 Sauerstofffraktions-Bedarf 35

4.2.2.2 Atemminutenvolumen 36

4.2.3 Verkürzung des Aufenthaltes auf der Intensivstation 37

4.2.4 Verkürzung der Krankenhausaufenthaltsdauer 38

4.3 Erfassung der Wirksamkeit von rhDNase in vitro 39

4.3.1 Verringerung des DNA-Gehaltes und Verkürzung der

DNA-Kettenlängen im Trachealsekret 39

4.3.1.1 DNA-Konzentration im Trachealsekret 39

4.3.1.2 DNA-Fragmente im Trachealsekret 40

4.3.2 Verminderung der Inflammation 41

4.3.2.1 Anzahl der Leukozyten im Trachealsekret 41

4.3.2.2 Senkung der Zytokinkonzentration im Trachealsekret 42

4.3.2.2.1 Interleukin-1 $\beta \quad 42$

4.3.2.2.2 Interleukin-6 43

4.3.2.2.3 Interleukin-8 44

4.2.2.2.4 Interleukin-10 45

4.3.2.2.5 Lipopolysaccharidbindendes Protein 46

4.3.2.2.6 Granulozyten-Makrophagen-Kolonienstimulierender Faktor 47

4.4 Erfassung der klinischen Wirksamkeit von rhDNase im Vergleich zur modifizierten Gruppe 3 der Lufit-Studie $\quad 48$

4.4.1 Beatmungsdauer 49

4.4.2 Verbesserung der Lungenfunktionsparameter 51

4.4.2.1 Sauerstofffraktions-Bedarf 51

4.4.2.2 Atemminutenvolumen 53

4.4.3 Verkürzung des Aufenthaltes auf der Intensivstation 55

4.4.4 Verkürzung der Krankenhausaufenthaltsdauer 57

4.5 Erfassung der Wirksamkeit von rhDNase in vitro im Vergleich zur modifizierten Gruppe 3 der Lufit-Studie $\quad 59$

4.5.1 Verringerung des DNA-Gehaltes und Verkürzung der DNA-

Kettenlängen im Trachealsekret im Vergleich 59 
4.5.1.1 DNA-Konzentration im Trachealsekret 59

4.5.1.2 DNA-Fragmente im Trachealsekret 61

4.5.2 Verminderung der Inflammation 63

4.5.2.1 Die Anzahl der Leukozyten im Trachealsekret 63

4.5.2.2 Senkung der Zytokinkonzentration im Trachealsekret 65

4.5.2.2.1 Interleukin-1 $\beta \quad 65$

$\begin{array}{lll}\text { 4.5.2.2.2 Interleukin-6 } & 67\end{array}$

$\begin{array}{lll}\text { 4.5.2.2.3 Interleukin-8 } & 69\end{array}$

4.5.2.2.4 Interleukin-10 71

4.5.2.2.5 Lipopolysaccharidbindendes Protein 73

4.5.2.2.6 Granulozyten-Makrophagen-Kolonienstimulierender Faktor 75

5 Diskussion 77

$\begin{array}{lll}5.1 & \text { Basischarakteristika } & 77\end{array}$

5.2 Erfassung der klinischen Wirksamkeit 78

$\begin{array}{lll}\text { 5.2.1 Beatmungsdauer } & 78\end{array}$

5.2.1.1 Verlust des kinozilientragenden Epithels 79

5.2.1.2 Effekt der Mukusmenge, rhDNase-Dosis und

$\begin{array}{ll}\text { Viskosität auf Sputumtransportrate } & 80\end{array}$

5.2.1.3 Die Non-Responder 81

$\begin{array}{lll}\text { 5.2.1.4 Medikamenteneinfluss } & 81\end{array}$

5.2.1.5 $\mathrm{O}_{2}$-Fraktion 82

5.2.1.6 Lokalisation der Trachealsekretansammlung 82

5.2.1.7 Zeitpunkt der Applikation 82

5.2.2 Verbesserung der Lungenfunktionsparameter 83

5.2.3 Verkürzung des Aufenthaltes auf der Intensivstation 84

5.2.4 Verkürzung der Krankenhausaufenthaltsdauer 84

5.3 Erfassung der Wirksamkeit von rhDNase in vitro 84

5.3.1 Verringerung des DNA-Gehaltes und Verkürzung der DNA-

Kettenlängen im Trachealsekret $\quad 84$

5.3.1.1 DNA-Konzentration im Trachealsekret 84 
5.3.1.2 DNA-Fragmente im Trachealsekret 85

5.3.2 Verminderung der Entzündungsreaktion 86

5.3.2.1 Anzahl der Leukozyten im Trachealsekret 86

5.3.2.2 Senkung der Zytokinkonzentration im Trachealsekret 86

5.3.2.2.1 Veränderungen der Zytokinbalance durch

die jeweilige Grunderkrankung $\quad 87$

5.3.2.2.2 Einfluss der Antibiotika und des

$\begin{array}{ll}\text { Erregerspektrums auf den Zytokinspiegel } & 88\end{array}$

5.3.2.2.3 Einfluss der Beatmung auf den

Zytokinspiegel $\quad 89$

5.3.2.2.4 Einfluss des Alters auf den Zytokinspiegel 89

5.3.2.3 Interleukin-1 $\beta \quad 89$

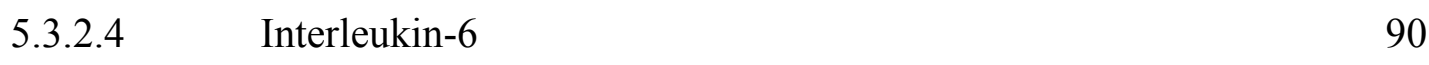

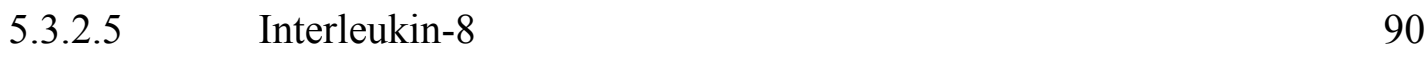

5.3.2.6 Interleukin-10 91

5.3.2.7 Lipopolysaccharidbindendes Protein 91

5.3.2.8 Granulozyten-Makrophagen-Kolonienstimulierender Faktor 92

$\begin{array}{lll}5.4 & \text { Schlussfolgerung } & 93\end{array}$

$6 \quad$ Zusammenfassung 94

$\begin{array}{lll}7 & \text { Literaturverzeichnis } & 96\end{array}$ 


\section{Abkürzungsverzeichnis}

\begin{tabular}{|l|l|}
\hline ACTH & Adrenokortikotropes Hormon \\
\hline AF & Atemfrequenz \\
\hline AMV & Atemminutenvolumen \\
\hline ARAS & Aufsteigendes retikuläres Aktivierungssystem \\
\hline ARDS & Acute respiratory distress syndrome \\
\hline BE & Base Excess \\
\hline BIPAP & Biphasic positive airway pressure \\
\hline C5a & Komplementfaktor 5a \\
\hline CD & Cluster of differentiation \\
\hline CF & Zystische Fibrose \\
\hline CHO & Chinese Hamster Ovary \\
\hline COPD & Chronic obstructive pulmonary disease \\
\hline CPAP & Continuous positive airway pressure \\
\hline CRP & C-reaktives Protein \\
\hline DHFR & Dihydrofolatreduktase \\
\hline DNA & Desoxyribonucleic acid \\
\hline DNase & Desoxyribonuklease \\
\hline DTT & Dithiotreitol \\
\hline ELISA & Enzyme-linked immunosorbent assay \\
\hline FiO 2 & Fraction of inspired oxygen \\
\hline F/VT & Atemfrequenz/Tidalvolumen-Verhältnis \\
\hline GCS & Glasgow Coma Scale \\
\hline G-CSF & Granulozyten-Kolonienstimulierender Faktor \\
\hline GM-CSF & Granulozyten-Makrophagen-Kolonienstimulierender Faktor \\
\hline HSV & Herpes-simplex-Virus \\
\hline IFN- $\gamma$ & Interferon- $\gamma$ \\
\hline Ig & Immunoglobulin \\
\hline IL & Interleukin \\
\hline kb & Kilobase \\
\hline KISS & Krankenhaus-Infektions-Surveillance-System \\
\hline LPS & Lipopolysaccharid \\
\hline LTB4 & Leukotrien B4 \\
\hline
\end{tabular}




\begin{tabular}{|c|c|}
\hline $\mathrm{MHC}$ & Major histocompatibilty complex \\
\hline $\mathrm{P}$ & Druck \\
\hline $\mathrm{PaO}_{2}$ & Sauerstoffpartialdruck \\
\hline$\overline{\mathrm{pCO}_{2}}$ & Kohlenstoffdioxidpartialdruck \\
\hline PDGF & Platelet derived growth factor \\
\hline PEEP & Positive endexpiratory pressure \\
\hline PNS & Peripheres Nervensystem \\
\hline rhDNase & Rekombinante humane Desoxyribonuklease \\
\hline RSV & Respiratory-syncytial-Virus \\
\hline $\mathrm{SaO}_{2}$ & Fraktionelle arterielle Sauerstoffsättigung \\
\hline SAPS II & Simplified Acute Physiology Score II \\
\hline SIRS & Systemic inflammatory response syndrom \\
\hline SOFA & Sepsis-related Organ Failure Assessment \\
\hline TIA & Transitorische ischämische Attacke \\
\hline TNF & Tumornekrosefaktor \\
\hline ZNS & Zentrales Nervensystem \\
\hline
\end{tabular}


Abb. 3.3/1.

21

Abb. 4.1.3/1.

Abb. 4.1.5/1.

Abb. 4.2.1/1.

Abb. 4.2.2.1/1.

Abb. 4.2.2.2/1.

Abb. 4.2.3/1.

Abb. 4.2.4/1.

Abb. 4.3.1.1/1.

Abb. 4.3.1.2/1.

Abb. 4.3.2.1/1.

Abb. 4.3.2.2.1/1.

Abb. 4.3.2.2.2/1.

Abb. 4.3.2.2.3/1.

Abb. 4.3.2.2.4/1.

Abb. 4.3.2.2.5/1.

Abb. 4.3.2.2.6/1.

Abb. 4.4.1/1.

Abb. 4.4.1/2.

Abb. 4.4.2.1/1.

Abb. 4.4.2.1/2.

Abb. 4.4.2.2/1.

Abb. 4.4.2.2/2.

Abb. 4.4.3/1.

Abb. 4.4.3/2.

Abb. 4.4.4/1.

Abb. 4.4.4/2.

Abb. 4.5.1.1/1.

Abb. 4.5.1.1/2.

Abb. 4.5.1.2/1.

Abb. 4.5.1.2/2.

Abb. 4.5.2.1/1.

Abb. 4.5.2.1/2.

Abb. 4.5.2.2.1/1.

Abb. 4.5.2.2.1/2.

Abb. 4.5.2.2.2/1.

Abb. 4.5.2.2.2/2.

Abb. 4.5.2.2.3/1.

Abb. 4.5.2.2.3/2.

Abb. 4.5.2.2.4/1.

Abb. 4.5.2.2.4/2.

Abb. 4.5.2.2.5/1.

Abb. 4.5.2.2.5/2.

Abb. 4.5.2.2.6/1.

Abb. 4.5.2.2.6/2.

Abb. 5.1/1

Abb. 5.3.2.2.1/1
33

34

35

36

37

38

39

40

41

42

43

44

45

46

47

49

50

51

52

53

54

55

56

57

58

59

60

61

62

63

64

65

66

67

68

69

70

71

72

73

74

75

76

77

87
Tabelle 4.1.3/1. 31

Tabelle 4.1.4/1. 32

Tabelle 4.1.5/1. 33 


\section{1. $\quad$ Einleitung}

\subsection{Epidemiologie der nosokomialen Pneumonie}

In den westlichen Industrieländern ist die nosokomiale Pneumonie die zweithäufigste Hospitalinfektion. Deutsche Ergebnisse des Krankenhaus-Infektions-Surveillance-Systems (KISS) aus dem Jahre 2003 stellen die nosokomiale Pneumonie an die erste Stelle. 89\% aller nosokomialen Pneumonien treten bei intubierten und beatmeten Patienten auf (Bodmann et al. 2003).

Die nosokomiale Pneumonie ist definiert als neu diagnostizierte Pneumonie $\geq 48$ Std. nach Hospitalisierung, bei Patienten ohne klinische Pneumoniesymptome bei der Krankenhausaufnahme. Sollte der Patient/ die Patientin zum Zeitpunkt der Diagnose $\geq 48$ Std. beatmet sein, wird sie als beatmungsassozierte Pneumonie bezeichnet (de Lange und Bonten 2005).

In einer europäischen Analyse aus dem Jahre 1995 betrug die Prävalenz nosokomialer Infektionen im intensivmedizinischen Bereich insgesamt etwa 20,6\%. Die beatmungsbedingte Pneumonie nimmt mit einer Inzidenz von 46,9\% darunter den ersten Platz ein, gefolgt von Infektionen der unteren Atemwege mit 17,8\% (Vincent et al. 1995). Nach Safdar et al. (2005), dessen Erhebung 10 Jahre nach der oben genannten europäischen Analyse erfolgte, scheint die Inzidenz der nosokomialen Pneumonie bei über 48 Std. beatmeten Patienten in einem Bereich zwischen $10 \%$ und $20 \%$ zu liegen.

Die nosokomiale Pneumonie ist die häufigste Todesursache unter den Krankenhausinfektionen (Bodmann et al. 2003). Jährlich versterben auf deutschen Intensivstationen ca. 1200 bis 2400 Patienten an den Folgen einer auf der Intensivstation erworbenen Pneumonie oder primären Sepsis (Gastmeier et al. 2005). Safdar et al. (2005) führen in ihrem ausführlichen Studienvergleich eine pneumoniebedingte Mortalität mit Werten von $16-76 \%$ auf.

Eine Reihe von expositionellen Faktoren und klinischen Konstellationen, denen der Patient auf einer Intensivstation ausgesetzt ist, stellen ein besonderes Risiko der nosokomialen Pneumonie dar. $\mathrm{Zu}$ ihnen zählen: Beatmung, schlechter neurologischer Status (ZNSErkrankungen), überkalorische parenterale Ernährung, Operation, pulmonale Vorschädigung, 
Leukozytose, nasogastrische Sonde mit enteraler Ernährung, Antazida (Protonenpumpenhemmer, Antihistaminika $>$ Sucralfat), Patientengewicht 10-20\% unter dem Idealgewicht, Verbrennung, Trauma, kardiale Erkrankungen, gesicherte Aspiration, muskelrelaxierende Substanzen, iatrogene Immunsuppression durch Kortikosteroide, sowie > 7 Tage vorbestehende antimikrobielle Therapie in beliebiger Indikation (Cook et al. 1998a, Salemi et al. 1993, Ewig et al. 2000, Kampf et al. 1998, Prod'hom et al. 1994, Cook et al. 1998b).

Unter allen intensivpflichtigen Patienten nehmen solche der neurologischen Intensivstationen eine gesonderte Stellung ein (Zolldann et al. 2005). Die Unterscheidung zwischen Patienten mit neurologischen und nicht-neurologischen Diagnosen ist deshalb von Bedeutung, weil neurologische Patienten im Vergleich $\mathrm{zu}$ sonstigen Intensivpatienten einen höheren Krankheitsschweregrad, insbesondere im Hinblick auf zentrale oder periphere Ventilationsstörungen, Schluckstörungen, Bewusstseinseintrübungen und damit verbundene längere Phasen der Immobilität aufweisen und somit eine längere stationäre Verweildauer haben (Fagon et al. 1996, Heckmann et al. 1999). Die zentrale Ventilationsstörung ist durch den "brainstem shock" oder "retikulären Schock", wie ihn Baumgartner 1979 bezeichnete, bedingt, der bei einer größeren Anzahl der Patienten mit hemisphärischen Schlaganfällen unterschiedlichen Ausmaßes, mit Blutungen oder Infektionen anzunehmen ist. Dieser globale neurologische Zustand entsteht auf dem Boden intermittierender oder anhaltender Verschlechterung einer oder mehrerer Vitalfunktionen: Beeinträchtigung des aufsteigenden retikulären Aktivierungssystem (ARAS), des Atemantriebs oder des laryngealen Hustenreflexes. Eine funktionelle Störung des ARAS hat in der Regel eine Vigilanzstörung zur Folge. Häufig bedürfen die Patienten einer Intubation aufgrund des gestörten Atemantriebs. Wie schnell sich ein Patient aus dem "brainstem shock" erholt, ist nicht vorhersehbar, deshalb steigt mit Prolongation dieses Zustandes das Morbiditäts- und Mortalitätsrisiko an (Addington et al. 2005).

Entsprechend schätzen Cook et al. (1998a) das Risiko der Patienten mit akuten ZNSErkrankungen, eine beatmungsbedingte Pneumonie zu entwickeln, mit 3,4-fachem Anstieg gegenüber unkomplizierten Behandlungsverläufen ein. Die Inzidenz der beatmungsbedingten Pneumonie liegt bei intensivpflichtigen neurologischen Patienten bei 31,4\%. Des Weiteren ist das relative Risiko, eine Pneumonie pro Beatmungstag zu entwickeln, bei diesen Patienten um das 1,3-fache erhöht (Kraus et al. 2002). 


\subsection{Die Rolle von Risikofaktoren}

Das Risiko einer nosokomialen Pneumonie bei einem neurologischen Patienten kann man in für ihn spezifische und unspezifische Risikobereiche aufteilen.

An erster Stelle ist die durch ZNS-Traumen ausgelöste sekundäre Immuninkompetenz als spezifischer Risikofaktor zu erwähnen. Dieser Zustand, genannt als CIDS (CNS injury induced immunodepression), entsteht als Folge der aus traumatisiertem ZNS freigesetzten Neuromodulatoren. Im Rahmen der CIDS kommt es zum Zusammenbruch der immunologischen Barrieren und anschließender Infektionsneigung (Meisel et al. 2005).

Das Risiko einer Pneumonie steigt beim Vorliegen von mit der ZNS-Läsion assoziierten Begleitphänomenen noch mehr an. Demnach scheint eine initiale Bewusstseinsstörung ein entscheidender Faktor für die Entwicklung einer nosokomialen Pneumonie zu sein (Kraus et al. 2002, Kampf et al. 1998). Darüber hinaus hängt das Risiko einer nosokomialen Pneumonie von dem Schweregrad der ZNS-Schädigung (z.B. Ausmaß des neurologischen Defizits beim Schlaganfall), Lokalisation und Anzahl der infarzierten Hirnareale ab (Heuschmann et al. 2004, Hilker et al. 2003, Kraus et al. 2002). Wie am Beispiel des Schlaganfalls dargestellt, sind ebenfalls andere neurologische Erkrankungen in ihrem Risikopotenzial sehr heterogen (Kraus et al. 2002, Addington et al. 2005).

Die Aspiration stellt einen weiteren Risikofaktor der beatmungsbedingten Pneumonie dar (Cook et al. 1998a, Hilker et al. 2003, Schmidt et al. 1994, Kidd et al. 1995, Lundy et al. 1999). Beeinträchtigte Atemschutzreflexe und neuromuskuläre Erkrankungen, die zu einmaliger oder chronischer Aspiration führen, haben sich in einer heterogenen Gruppe von spontan atmenden und beatmeten Patienten als Risikofaktoren für die nosokomiale Pneumonie erwiesen (Hilker et al. 2003, Kidd et al. 1995, Lundy et al. 1999, Chevret et al. 1993, Mosconi et al. 1991, Kardos et al. 2004). Die Schlaganfallpatienten stellen unter diesem Aspekt eine besondere Risikogruppe dar, da sie oft unter Dysphagie und stillen Aspirationen leiden. Die Inzidenz von Dysphagie bei diesen Patienten beträgt in den ersten zwei Wochen nach dem Infarktereignis zwischen 30\% und 50\% und bei mehr als der Hälfte der Patienten mit Dysphagie wird diese von Aspiration begleitet (Hilker et al. 2003, Daniels et al. 1998, Kidd et al. 1995, Lundy et al. 1999). 
Mit Abstand der wichtigste unspezifische Risikofaktor für das Auftreten einer nosokomialen Pneumonie ist dabei die Intubation (Estes und Meduri 1995).

Die internistischen Grunderkrankungen aus dem kardio-vaskulären und pulmonalen Bereich tragen ebenfalls bei intensivpflichtigen neurologischen Patienten zu Erhöhung des Risikos bei. Kampf et al. (1998) und Kraus et al. (2002) fanden ein signifikant häufigeres Auftreten einer nosokomialen Pneumonie bei Patienten mit vorbekannten Herz-Kreislauf- und Lungenerkrankungen.

\subsection{Die Rolle der mukoziliären Clearance}

Die Clearance des tracheobronchialen Baums erfolgt durch zwei Hauptmechanismen, nämlich durch Zilienaktivität und Husten (Clarke 1989). Bei intubierten Patienten bleibt die mukoziliäre Clearance als einziger signifikanter nicht spezifischer protektiver Mechanismus des Atemapparates (Konrad et al. 1994, Chilvers und O’ Callaghan 2000).

Die mukoziliäre Clearance wird durch den rachenwärts gerichteten Zilienschlag gewährleistet. Sie entspricht der Befreiung von Atemwegen von selbst produziertem Trachealsekret und den in ihnen haften gebliebenen Partikeln (Leith 1968). Für das Zustandekommen des Gemisches sorgen a) alveolare Flüssigkeit, b) sekretorische Produkte von verschiedenen Zellen entlang der Atemwege, c) sekretorische Produkte der submukösen Drüsen, d) Serumtranssudat, e) Zellmembran- und Zytoplasma-Komponenten aus dem epithelialen Zellumsatz (Boat et al. 1994). Bei dem Trachealsekret handelt es sich um ein viskoelastisches Gel, das Wasser und eine hochmolekulare Masse von quervernetzten Glykoproteinen gemischt mit Albumin, Enzymen, Immunoglobulinen (v.a. IgA), Lactoferrin und Lipiden enthält (Creeth 1978, Clamp 1978). Im Falle pathologischer Bedingungen häufen sich in ihm ebenfalls die DNA-Moleküle aus den abgestorbenen neutrophilen Granulozyten und Epithelien an (Creeth 1978, Lethem et al. 1990, Goodman et al. 1978). Prozentual betrachtet, besteht das Trachealsekret zu etwa 1\% aus Salzen und anderen dialysierbaren Komponenten, 0,5-1\% freien Proteinen, einer gleichen Prozentzahl von Mukoproteinen (zuckerreiche Glykoproteinen) und $\geq 95 \%$ Wasser (Creeth 1978).

Die pathogenetische Bedeutung der Sekretbildung ist in Bezug auf die mukoziliäre Clearance intensiv untersucht. In der Literatur existieren zwei Modelle der mukoziliären Clearance. Das traditionelle Konzept beschreibt, dass sofern das Trachealsekret einmal entstanden ist, dieses aus Sol-Schicht und Gel-Schicht besteht, die im Äquilibrium vorliegen. Die Zilien bewegen 
sich bzw. schlagen in der Sol-Schicht (periziliäre Flüssigkeit), deren Dichte für den effektiven Trachealsekretsport kritisch ist. Die Gel-Schicht liegt in den proximalen Atemwegen auf der Sol-Schicht. Diese Tatsache erlaubt den Zilien mit ihrem Schlag in der Sol-Schicht die darüber liegende Gel-Schicht oralwärts zu transportieren (Clarke 1989). Ein neueres Konzept geht von einer anderen Anordnung der Sekretmoleküle aus. Die Muzine formen ein Maschenwerk, das sich komplett von der Sekretoberfläche bis zu Zelloberfläche ausstreckt mit Verdichtung an der Luft-Flüssigkeitsgrenze (Verdugo 1991, Boucher 1994). Im ersten Modell wird die Viskoelastizität des Trachealsekrets durch Veränderungen in der chemischen Zusammensetzung der Glykoproteine reguliert (Houtmeyers et al. 1999 b). Auf diese Weise erhöht die aus den neutrophilen Granulozyten freigesetzte DNA durch Ausbildung von Komplexen mit den Trachealsekret-Glykoproteinen und Phospholipiden in der Gel-Schicht die Sekretviskosität (Zahm et al. 1998).

Im Kontrast dazu werden die rheologischen Eigenschaften des Trachealsekrets, nämlich die Viskoelastizität und Spinnbarkeit, im zweiten Modell des mukoziliären Mechanismus durch Hydratation via Flüssigkeits-, Protein- und Elektrolyttransport über die Zellmembran eingestellt (Girod et al. 1992, Verdugo 1991). Dieses Modell wird durch negative bzw. positive Einflüsse von Medikamenten, die in den Ionentransport eingreifen, unterstützt (Kondo et al. 2002, App et al. 1990, Knowles et al. 1986).

Mit der Notwendigkeit der prolongierten Beatmung treten häufig Alterationen der Bronchialschleimhaut auf; die natürliche Atemphysiologie und die Mechanismen der mukoziliären Clearance werden gestört. In Tierversuchen mit Hunden wird alleine durch die Blockung des Trachealtubus die Transportgeschwindigkeit des Sekrets in der Trachea reduziert (Sackner et al. 1975). Bereits in den ersten 24-48 Std. nach Beatmungsbeginn treten die entzündlichen Veränderungen der Bronchialschleimhaut in Erscheinung. Sie nehmen bis $\mathrm{zu}$ einer Beatmungsdauer von 150-200 Std. rasch zu und schreiten bei weiter anhaltender Beatmung dann nicht mehr fort (Worth et al. 1982). Außerdem schädigen häufige Bronchialtoilette und durchgeführte fiberoptische Bronchoskopien mechanisch das respiratorische Epithel (Landa et al. 1980, Lundgren et al. 1983). Begleitend führt inadäquate Befeuchtung des Gasgemisches zu morphologischen Veränderungen des Flimmerepithels (Tsuda et al. 1977). Die Beatmung mit hohen Sauerstoffkonzentrationen, inspiratorischen Drücken bzw. hohen Tidalvolumina hat ebenfalls eine morphologische Schädigung des Epithels zu Folge (Tsuda et al. 1977, Laurenzi et al. 1968). 


\subsection{Die Rolle von Atemwegsinfektionen}

Akute Atemwegsinfektionen nehmen Einfluss auf die mukoziliäre Clearance bzw. ihre Komponenten und spielen in diesem Zusammenhang eine besondere Rolle, da sie bei intubierten beatmeten Patienten eine hohe Inzidenz aufweisen (Zolldann et al. 2005, Vincent et al. 1995). Konrad et al. (1994) bewiesen in ihrer Arbeit, dass die gestörte mukoziliäre Clearance bzw. die Transportgeschwindigkeit von dem Verlust des kinozilientragenden Epithels abhängt. Allerdings bleibt es unklar, ob die erfolgte Schädigung durch zytotoxische Effekte und durch bakterielle Produkte, z.B. Pyocyanin, die eine Beeinträchtigung der mukoziliären Clearance bedingt (Dormehl et al. 1991, Munro et al. 1989, Read et al. 1992, Nahori et al. 1992, Wilson et al. 1985, Pavia 1987), oder ob schon vorher bestehende Läsionen des Epithels und verminderte mukoziliäre Clearance $\mathrm{zu}$ einer erleichterten bakteriellen Besiedlung beitragen (Konrad et al. 1995). Zusätzlich zu dem Verlust des kinozilientragenden Epithels vermindern die aus den neutrophilen Granulozyten freigesetzten Proteinasen, wie Elastase, in der periziliären Flüssigkeit die Schlagfrequenz der Kinozilien in vitro (Smallman et al. 1984). Durch die bakterielle Besiedlung ausgelöste Entzündungsprozesse beeinträchtigen desgleichen eine andere Komponente der mukoziliären Clearance, nämlich die Trachealsekretzusammensetzung. Chemotaktisch angelockt, wandern neutrophile Granulozyten in den Entzündungsherd kontinuierlich ein und unterhalten damit die Entzündung. Anschließend gehen die neutrophilen Granulozyten nekrotisch zugrunde und setzen dabei ihre DNA frei. Die frei gewordene DNA sowohl aus neutrophilen Granulozyten als auch aus epithelialem Zelldetritus erhöht die Viskosität des Trachealsekrets und verschlechtert demzufolge die Transportgeschwindigkeit (Ceesay et al. 1983, Goodman et al. 1978).

\subsubsection{Immunologischer Ablauf der Atemwegsinfektion}

Das Flimmerepithel reagiert auf Bakterien oder deren Bestandteile mit der Bildung von proinflammatorischen Mediatoren, wie IL-6, IL-8 und TNF- $\alpha$ (Khair et al. 1996, Cromwell et al. 1992). Diese Mediatoren, produziert unter anderem von Monozyten und Alveolarmakrophagen, beeinflussen direkt oder indirekt die Aktivität der neutrophilen Granulozyten und lösen deren zahlreiche Einwanderung aus (Khair et al. 1996, Dentener et al. 1993). Trotz der terminalen Differenzierung der neutrophilen Granulozyten sind sie auch in der Lage, eine bestimmte Anzahl von Zytokinen bzw. Mediatoren zu synthetisieren (Dubravec et al. 1990, Tiku et al. 1986, Lord et al. 1991, Cicco et al. 1990, Strieter et al. 1992, Lindemann et al. 1989, Shirafuji et al. 1990). Durch Anlockung, Aktivierung und 
Proliferation weiterer neutrophiler Granulozyten und Lymphozyten am Entzündungsort spielen somit die neutrophilen Granulozyten eine zentrale Rolle im immunologischen Ablauf der Atemwegsinfektion

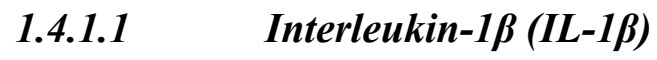

Ein wichtiges zur Entzündung beitragendes Zytokin ist Interleukin-1 $\beta$. Zusammen mit TNF- $\alpha$ gehört IL-1 $\beta$ zu den Hauptfaktoren der systemischen Immunantwort und des septischen Schocks (Hehlgans und Pfeffer 2005). Es wird hauptsächlich von aktivierten Makrophagen und neutrophilen Granulozyten produziert, aber auch von Endothelien, Keratinozyten und etc. Seine Synthese wird durch eine Reihe anderer Zytokine, Endotoxine, Viren, Mitogene und Antigene stimuliert (Rosenwasser 1998).

Die während der Immunantwort aktivierte IL-1-Produktion löst ein breites Spektrum entzündungsassoziierter Veränderungen aus, wie Fieberanstieg und gesteigerte Bildung der Akute-Phase-Proteinen. Zusätzlich fördert das IL-1 die Expression der interzellulären Adhäsionsmoleküle und erleichtert damit den Leukozyten deren Adhäsion an Endothelzellen. Ebenfalls eine der wichtigsten biologischen Aktivitäten des IL-1 ist seine Funktion als Lymphozyten-aktivierender Faktor. Zusätzlich führt IL-1 zur Synthese weiterer Zytokine, wie TNF, IL-6 und GM-CSF. Im positiven Rückkopplungskreis steigert es seine eigene Synthese (Rosenwasser 1998).

\subsubsection{Interleukin-6 (IL-6)}

Das IL-6 wird von verschiedenen Zellarten produziert, wie B- und T-Lymphozyten, Monozyten, Fibroblasten, Keratinozyten, Endothelzellen, Mesangiumzellen und einigen Tumorzellen. Seine Synthese wird durch eine Reihe von Faktoren reguliert, u.a. von IL-1, LPS, Viren, IFN- $\beta$, PDGF und TNF- $\alpha$ (Content et al. 1985, Le und Vilcek 1989, Defilippi et al. 1987). Neutrophile Granulozyten sind ebenfalls in der Lage, nach der Stimulation mit GMCSF und TNF- $\alpha$, IL-6 zu produzieren (Cicco et al. 1990). Zu seinen mannigfaltigen biologischen Aufgaben und Einflussgebieten gehört die Stimulation der humoralen und zellulären Immunantwort, daher setzt seine Produktion gleich zu Beginn der Immunantwort ein (Kishimoto 1989). IL-6 aktiviert die Bildung der Akute-Phase-Proteine in der Leber und supprimiert gleichzeitig die Albuminsynthese (Nishimoto und Kishimoto 2006). Neben den proinflammatorischen Eigenschaften besitzt das IL-6 auch anti-inflammatorische Eigenschaften, indem es die TNF- $\alpha$-Synthese inhibiert und die ACTH-Freisetzung aus der 
Adenohypophyse mit anschließendem Cortisolanstieg erhöht (Aderka et al. 1989, Woloski et al. 1985).

\subsubsection{Interleukin-8 (IL-8)}

Das IL-8 ist ein Syntheseprodukt von Monozyten, das u. a. von Flimmerepithel, Alveolarepithelien, Alveolarmakrophagen, Hepatozyten, Endothelien, Fibroblasten nach einer Stimulation mit IL-1 $\alpha$, IL-1 $\beta$ und TNF- $\alpha$ exprimiert wird (Peveri et al. 1988, Standiford et al. 1990, Strieter et al. 1989, Thornton et al. 1990, Cromwell et al. 1992). Seine Synthese wird durch eine ganze Reihe von Faktoren, v.a. aber durch TNF- $\alpha$ und IL-1, stimuliert (Copewithcytokines 2008a). Es induziert die gesamte Reaktionsbreite in einem chemotaktisch aktivierten neutrophilen Granulozyt beginnend mit Aktivierung von Zytoskelett und Migrationsrichtung über Expression der Adhäsionsmoleküle bis hin zur Freisetzung von Enzymen und reaktiven Metaboliten (Baggiolini et al. 1989). Zusammenfassend initiiert und unterstützt das IL-8 die Interaktion zwischen Interstitium mit Gefäßbett und neutrophilen Granulozyten.

Die neutrophilen Granulozyten sind ebenfalls zur IL-8-Synthese befähigt. Diese Fähigkeit der neutrophilen Granulozyten führt $\mathrm{zu}$ Anlockung und Aktivierung weiterer neutrophiler Granulozyten und bewirkt einen sich selbst unterhaltenden Entzündungsprozess (Khair et al. 1996, Strieter et al. 1992). Mit der IL-8-Produktion reagieren die neutrophilen Granulozyten auf Phagozytose, LPS, TNF- $\alpha$ und IL-1 $\beta$. Außerdem werden die neutrophilen Granulozyten den chemotaktischen Faktoren wie LTB4 und C5a in der Anwesenheit von LPS ausgesetzt; dabei steigt die IL-8-Synthesemenge synergistisch mehr an als bei der Einwirkung eines einzelnen Agonisten (Strieter et al.1992).

\subsubsection{Interleukin-10 (IL-10)}

Das IL-10 ist ein immunsupprimierendes Zytokin. Es entstammt den aktivierten TLymphozyten und Monozyten, sowie den Mastzellen (Copewithcytokines 2008b). Neben dem hemmenden Einfluss des IL-4 auf die IL-10-Synthese, reguliert das IL-10 seine eigene Synthese mittels negativen Rückkopplungsmechanismus. Seine immunsupprimierende Wirkung äußert sich in der Synthesehemmung von IL-1 $\alpha$, IL-1 $\beta$, IL-6, IL-8, TNF-a, GM-CSF, G-CSF und der Reduktion der MHC-2- Expression in Monozyten / Makrophagen. Auf diese Weise hemmt es die Antigen-spezifische T-Zellproliferation (de Waal Malefyt et al.1991). Zusätzlich zu seiner inhibitorischen Wirkung auf proinflammatorische Zytokine hat es einen 
fördernden Effekt auf die IL-1-Rezeptorantagonist-Produktion aus Monozyten (Jenkins et al. 1994).

\subsubsection{Lipopolysaccharidbindendes Protein (LBP)}

Das Lipopolysaccharidbindende Protein ist ein von der Leber, Alveolarepithelien und Enterozyten synthetisiertes Akute-Phase-Protein (Schröder et al. 2004, Dentener et al. 2000, Vreugdenhil et al. 1999). Es spielt eine Schlüsselrolle in der Früherkennung des Pathogens (Schröder et al. 2004). LBP beschleunigt die Bindung von Lipopolysaccharid-Monomeren an CD14-Rezeptoren, in dem es sie von den LPS-Mizellen Richtung CD14 transferiert (Hailman et al. 1994, Tobias et al. 1995). Damit wird die Affinität des CD14-Rezeptors zu LPS mittels LPS-LBP-Komplex um das 10-Fache erhöht (Tobias et al. 1995). Anderseits erfolgt die spontane Diffusion der LPS-Monomeren von den im wässrigen Milieu entstehenden LPSMizellen zu der CD14-Bindungstelle sehr langsam (Hailman et al. 1994). Das LBP wird ebenfalls in der Erkennung des Pathogens über Peptidoglykane, Lipoproteine und Lipoteichonsäure benötigt. Lipoproteine und Lipopeptide sind bei großer Anzahl von Mikroorganismen nachweisbar. In Anwesenheit von LBP kommt es zu einer erheblichen Zytokininduktion durch Lipopeptide in Monozyten (Schröder et al. 2004). Seine Konzentration kann innerhalb kürzerer Zeit nach der LPS-Inhalation deutlich ansteigen (Dubin et al. 1996, Brass et al. 2004). Ebenso führen IL-1 $\beta$, IL-6 und Dexamethason zur gesteigerten Produktion von LBP in Alveolarepithelien (Dentener et al. 2000).

\subsubsection{Granulozyten-Makrophagen-Kolonienstimulierender Faktor (GM-CFS)}

Der GM-CSF wird von T-Lymphozyten, Makrophagen im Gewebe, Endothelien und Fibroblasten produziert und ist ein wichtiger Mediator der Entzündungsreaktion. Seine Synthese in Endothelien, Fibroblasten und anderen Zellen wird von TNF- $\alpha$, TNF- $\beta$, IL-1, IL2 und IFN induziert. Neben der Stimulation des Wachstums und der Entwicklung von Makrophagen- bzw. Granulozytenvorläuferzellen und neben der Initiation von deren irreversibler Differenzierung besitzt GM-CSF außerdem starke chemotaktische Eigenschaften auf die neutrophilen Granulozyten und erhöht die Expression von Adhäsionsmolekülen, wie CD11a und CD11b an deren Oberfläche. Ferner verbessert er die Zytotoxität und verstärkt die mikrobizide Aktivität, oxidativen Metabolismus und phagozytotische Tätigkeit von neutrophilen Granulozyten und Makrophagen (Copewithcytokines 2008 c). 


\subsection{Andere Faktoren mit Einfluss auf die Clearance}

Zusätzlich zu ablaufenden Entzündungsprozessen beeinflusst eine Reihe von physiologischen Faktoren die mukoziliäre Clearance. Flache Körperlagerung, Schlaf / Sedierung, Rauchen beeinträchtigen sie ebenfalls. Bezüglich des Einflusses von Alter und Geschlecht auf die mukoziliäre Clearance sind die Auffassungen in der Literatur uneinheitlich (Svartengren et al. 2005, Goodman et al. 1978, Konrad et al. 1998, Konrad et al. 1993, Patrick und Stirling 1977, Ledowski et al. 2006, Wong et al. 1977, Mortensen et al. 1994, Hasani et al. 1994, Svartengren et al. 1986, Yager et al. 1978, Roth et al. 1991).

Neben dem Entzündungsprozess und den erwähnten pathophysiologisch relevanten Faktoren üben diverse applizierte Medikamente einen negativen Effekt auf die mukoziliäre Clearance aus. Houtmeyers et al. (1999a) machen Anticholinergika, Aspirin, Anästhetika, Benzodiazepine für die Verschlechterung der mukoziliären Clearance verantwortlich. Antibiotika dagegen beeinflussen die mukoziliäre Clearance nicht.

Die Gesamtheit der aufgeführten negativen Einflussfaktoren kann also zu einer schwerwiegenden Beeinträchtigung der Clearance bei den intensivpflichtigen Patienten führen. Durch die entzündlichen Prozesse und den durch beatmungs- bzw. therapieassozierte Faktoren gestörten Transport nimmt die Sekretmenge zu, was die Bildung von Dys/Atelektasen begünstigt.

\subsection{Warum spielt die Vermeidung von Atelektasen eine bedeutende Rolle?}

Liegen Atelektasen bzw. Mikroatelektasen vor, so stellen diese durch Verschlechterung der pulmonalen antibakteriellen Schutzmechanismen einen Risikofaktor für die Entwicklung einer Pneumonie bzw. eines Atelektotraumas dar (Frederick und Pesanti 1987, Tsuchida et al. 2006). Durch die Hypoxie im atelektatischen Lungenabschnitt ist die Funktion der Alveolarmakrophagen verschlechtert. In ihrer Funktion beeinträchtigte Alveolarmakrophagen können nicht mehr die bakterielle alveoläre Clearance gewährleisten. Gehen die Makrophagen unter Hypoxie zugrunde, wandern die polymorphkernigen Leukozyten ein, von denen angenommen wird, dass sie proteolytisch das pulmonale Endothel schädigen (Shennib et al. 1984, Kawano et al. 1987).

Aufgrund der Luftumverteilung in Richtung nicht kollabierter Lungenabschnitte mit nachfolgender Überblähung tritt eine ausgeprägte alveoläre Schädigung durch Atelektotrauma in diesen Lungenabschnitten ein (Tsuchida et al. 2006). Beachtenswert ist auch die mit den 
Atelektasen und nach deren Auflösung zu beobachtende Veränderung des Surfactants. Sie äußert sich in Verminderung und abweichender Zusammensetzung der Surfactantphospholipide. Infolgedessen prädisponieren die betroffenen Lungenabschnitte zu weiteren Mikroatelektasen und somit entwickelt sich ein Circulus vitiosus (Nakos et al. 2003).

Dies hat nun eine Beeinträchtigung der Lungenfunktion mit damit verbundener Infektneigung zur Folge. Das Pneumonierisiko steigt konsekutiv an (Konrad et al. 1994, Konrad et al. 1995). Um das Pneumonierisiko zu reduzieren, müssen Maßnahmen zur Reduktion der Dys/Atelektasen durch Verbesserung der mukoziliären Clearance ergriffen werden.

1.7

RhDNase - Dornase alfa

\subsubsection{Klinische Erfahrungen}

$\mathrm{Zu}$ den Medikamenten mit dem positiven Effekt auf die mukoziliäre Clearance gehört die DNase (Houtmeyers et al. 1999a, Goodman et al. 1978). Unter Inhalation mit DNase werden mehr als $90 \%$ der extrazellulär vorkommenden DNA-Moleküle hydrolytisch in kleinere Polynukleotide mit einer niedrigen Viskosität gespalten (Cliffton und Grossi 1960, Shah et al. 1996a). Auf diese Weise wird die Viskoelastizität des Trachealsekrets vermindert und eine bessere Bronchialtoilette bei den beatmeten Patienten ermöglicht. Dies wirkt der Ausbildung von Atelektasen entgegen. Die Minderung der Atelektasen schwächt das Bakterienwachstum in den Alveolen ab und erniedrigt die Wahrscheinlichkeit der bakteriellen Translokation aus der Lunge in die Blutbahn und die damit verbundene Bakteriämie bzw. Sepsis (van Kaam et al. 2004).

Rekombinante humane DNase (rhDNase) wurde zum ersten Mal 1990 ausführlich sequenziert und hergestellt. Seitdem wurde sie in klinischen Studien bei Patienten mit Mukoviszidose (zystische Fibrose, CF) untersucht (Shak et al. 1990). Seit 1994 ist rhDNase für die inhalative mukolytische Therapie bei Mukoviszidose-Patienten zugelassen. Mehrere klinische Studien (Shah et al. 1996a, Zahm et al. 1998, Harms et al. 1998) haben einen positiven Effekt von rhDNase auf die rheologischen Eigenschaften der Sputen von CF-Patienten mit der Folge einer Verbesserung der Lungenfunktionsparameter belegt. Des Weiteren wurde auch eine Reduktion der Infekthäufigkeit beobachtet (Shah et al. 2001, Fuchs et al. 1994). In den letzten Jahren wurde das Medikament bei anderen Erkrankungen des respiratorischen Traktes angewendet. Es konnte eine Verbesserung des Krankheitsverlaufs bei den Patienten mit 
ARDS (Reiter et al. 2000), Asthma (Gershan et al. 1994, Patel et al. 2000), Atelektasen (Riethmueller et al. 2006 Küpeli et al. 2003; El Hassan et al. 2001) bzw. bei Patienten mit Rückenmarkstraumata (Voelker et al. 1996), RSV-Bronchiolitis (Nasr et al. 2001), Kartagener-Syndrom (Desai et al. 1995), Thoraxempyem (Simpson et al. 2003), plastischer Bronchitis bei Sichelzell-Anämie (Manna et al. 2003) und bronchopulmonaler Dysplasie (Reiter et al. 2000) gezeigt werden. In den Berichten über die klinische Anwendung der rhDNase wurden schwerwiegende Nebenwirkungen mit lebensbedrohlichen Komplikationen bisher nicht beschrieben. Im Rahmen einer Studie bei Lupusnephritis wurde die Substanz sogar intravenös appliziert, ohne dass es zu anaphylaktischen oder toxischen Reaktionen kam (Davis et al. 1999).

Bemerkenswerterweise wurden schon 1960 die ersten Patienten mit Atelektasen oder anderen gravierenden pulmonalen Komplikationen nach chirurgischen Eingriffen mit einem aus Rinder-Pankreas gewonnen Desoxyribonuklease-Aerosol therapiert: 91\% der insgesamt 120 in die Studie eingeschlossenen Patienten zeigten eine Besserung der Symptome. Die Wirkung trat nach wenigen Stunden und eine komplette Besserung der Beschwerden nach max. drei Tagen in Erscheinung. Unerwünschte Nebenwirkungen oder toxische bzw. allergische Reaktionen wurden nicht beobachtet (Cliffton und Grossi 1960). Hendriks et al. (2005) untersuchten beatmete und spontan atmende pädiatrische Patienten mit unteren Atemwegsinfektionen und mindestens einer Lappenatelektase. Sie konnten eine Effizienz der rhDNase-Applikation mit Hilfe von rasch erscheinenden Zeichen der klinischen und radiologischen Verbesserung bei zwei Drittel der Patienten feststellen. Die prospektive randomisierte placebokontrollierte Doppelblindstudie an postoperativ beatmeten pädiatrischen Patienten bestätigte die positive Wirkung der rhDNase im Sinne der niedrigeren Inzidenz von Atelektasen, Verkürzung der Intubationszeit um 26\% und kürzerer Behandlungsdauer auf Intensivstation um 25\% (Riethmueller et al. 2006).

\subsubsection{Produktion und chemische Charakteristika}

Das Enzym wird von der genetisch veränderten CHO (Chinese Hamster Ovary)-Zelllinie (gekennzeichnet CHO-DP7) produziert. Diese rhDNase produzierende Zellreihe wurde durch Co-Transfection von zwei für rhDNase kodierenden Plasmiden plus Dihydrofolatreduktase (DHFR) erzeugt. Die Co-Transfection mit diesen Vektoren führte zur stabilen Integration der rhDNase und DHFR in das CHO-Zellgenom und zur Expression von zwei Proteinen. 
RhDNase ist ein Glykoprotein und enthält 260 Aminosäuren mit einem Molekulargewicht von etwa 33000-38000 Dalton.

Die Anwesenheit bivalenter Kationen ist für die optimale enzymatische Aktivität unerlässlich. Die hydrolytische Aktivität der radioaktiven rhDNase ist in Gegenwart von $4 \mathrm{mM} \mathrm{Ca}^{2^{+}}$und $\mathrm{Mg}^{2}+>10$ fach erhöht, verglichen mit Lösungen, denen eines der Ionen fehlt. RhDNase besitzt ein $\mathrm{pH}$-Optimum bei 5,5-7,5 und wird bei $100{ }^{\circ} \mathrm{C}$ innerhalb von $10 \mathrm{~min}$. inaktiviert. Spezifisch ist sie durch Aktin im Verhältnis 1:1 hemmbar.

Im Rahmen der Enzymproduktion werden die Asparaginreste des Enzyms desamidiert. 100\% desamidierte rhDNase ist $50 \%$ potenter in ihrer Wirkung als die nicht desamidierte Form. Deshalb ist die anwendungsgeeignete Dornase alfa zu $65 \pm 17 \%$ desamidiert (Pulmozyme ${ }^{\circledR}$ 2002a).

\subsubsection{Zu erwartende Wirkung des Medikaments}

Die zu erwartende Wirkung besteht primär in der hydrolytischen Spaltung der sich extrazellulär anhäufenden hochmolekularen DNA aus den nekrotisch zerfallenen neutrophilen Granulozyten. Unter Inhalation mit DNase werden die extrazellulär vorkommenden DNAMoleküle hydrolytisch in kleinere Polynukleotide gespalten, die in mehr als 90\% zur Gruppe der "rod-like chains" mit der niedrigen Viskosität gehören (Brandt et al. 1995). Damit wird die Viskoelastizität des Trachealsekrets vermindert und die Ausbildung der Atelektasen reduziert (Shah et al. 1996a, Cliffton und Grossi 1960). Ferner wurden andere Angriffspunkte der DNase in verschiedenen Studien festgestellt:

- Zum Ersten beeinflusst die DNase die viskoelastischen Eigenschaften des Trachealsekrets über die Ausbildung der Aktin-DNase-Komplexe. Aktin wird während des Zellunterganges aus den neutrophilen Granulozyten freigesetzt und bildet Polymere aus, die sich durch eine hohe Viskoelastizität auszeichnen. Desoxyribonuklease bewirkt die Depolymerisation des filamentären Muskel-Aktins. Auf diesem Wege entstehen stabile 1:1- Komplexe von monomerem Aktin und Desoxyribonuklease, was allerdings die hydrolytische Aktivität des Enzyms einschränkt. Dennoch könnten die ausgebildeten Komplexe zu erniedrigter Viskoelastizität führen (Shah et al. 1996a).

- Zum Zweiten resultiert die Behandlung mit rhDNase in der Freisetzung von kationischen Proteasen, die vorher durch die elektrostatischen Kräfte von den anionischen DNA-Polymeren angezogen wurden. Die von den Proteasen erzeugte 
Proteolyse könnte ebenfalls zu erniedrigter Viskoelastizität beitragen (Shah et al. 1996a).

- Zum Dritten setzt rhDNase oberflächenaktive Phospholipide frei, die eine wichtige Rolle bei den Gleiteigenschaften der Sekretsoberfläche spielen und auf diese Weise den Trachealsekrettransport durch Husten oder Zilienschlag erleichtern. Phosphatidylglycerol trägt von den im Trachealsekret vorhandenen Phospholipiden am meisten zu den veränderten adhäsiven Eigenschaften der Sekretoberfläche bei. Freie DNA bildet zusammen mit den Trachealsekret-Glykoproteinen und Phospholipiden Sequester in der Gel-Schicht des Trachealsekrets aus. Die mit Hilfe von rhDNase entstandenen DNA-Polynukleotide breiten sich in allen Sekretschichten, aus der Gel-Schicht in die Sol-Schicht, gleichmäßig aus und ziehen vermehrte Flüssigkeitsmengen nach sich. Damit wird die Menge an freiem Wasser im gesamten Trachealsekret erhöht, speziell desgleichen in der Sol-Schicht. Den gleichen Weg nehmen auch die freigesetzten Phospholipide. Ihr erhöhter Anteil in der Sol-Schicht bewirkt die Erniedrigung der Oberflächenspannung und zusammen mit der erhöhten Wassermenge bedingen sie gemeinsam verbesserte Transporteigenschaften des Trachealsekrets (Zahm et al. 1998).

Die zu erwartende Wirkung bleibt aus, wenn im Trachealsekret keine Leukozyten und keine aus Leukozyten stammende DNA vorhanden sind. Sanders et al. (2006) berichteten, dass in in-vitro-Untersuchungen das Trachealsekret $\mathrm{Mg}^{2+}$-Kationen in einer minimalen Konzentration von $1,7 \mathrm{mM}$ enthalten soll, dies damit die rhDNase ihre enzymatische Aktivität entfalten kann. Die zu erwartende Wirkung des Prüfpräparats tritt bei $\mathrm{Mg}^{2+}$-Mangel nicht bzw. schwach ein. Außerdem könnte die Wirkung beeinträchtigt sein, wenn aus anderer medizinischer Indikation applizierte Substanzen eine noch nicht bekannte Interaktion mit dem Prüfpräparat eingehen.

\subsubsection{Nebenwirkungen}

Weder im Rahmen der zugelassenen Anwendung als inhalative Therapie bei zystischer Fibrose noch im Rahmen anderer ex-juvantibus-Behandlungsformen, nicht einmal nach i.v. Anwendungen wurden ernsthafte und lebensbedrohliche Komplikationen registriert (El Hassan et al. 2001, Küpeli et al. 2003, Reiter et al. 2000, Gershan et al. 1994, Voelker et al. 1996, Simpson et al. 2003, Manna et al. 2003, Davis et al. 1999). Während der inhalativen Therapie traten reversible Schleimhautreizungen, wie Pharyngitis, Laryngitis, Rhinitis oder 
Konjunktivitis auf. Überdies berichteten die Patienten über thorakale Schmerzen, Dyspepsie, Dyspnoe und Fieber. Allergische Reaktionen äußerten sich in Hautausschlag, Urtikaria sowie Auftreten von Antikörpern gegen Dornase alfa, allerdings nicht der Immunglobulinklasse E (RoteListe ${ }^{\circledR}$ 2008a). Als direkte Folge der endotrachealen rhDNase-Applikation wurde in einem Abstand von einigen Stunden eine massive Zunahme der Sekret- und Schleimabsonderung mit nachfolgender Atemwegsobstruktion und Ausbildung von neuen Atelektasen, sowie ein Ventilations-Perfusions-Ungleichgewicht beobachtet (Küpeli et al. 2003, Hendriks et al. 2005).

\subsection{5 Überdosierung}

Die durchgeführten Studien an Ratten und Affen mit einmaliger inhalativer, über 180-mal höherer Dosis als sie üblicherweise angewendet wird, wurden gut toleriert (Gene 2008). Isolierte orale Gabe von Dornase alfa mit einer Dosis von über $200 \mathrm{mg} / \mathrm{kg}$ oder ein in einer Konzentration von 30-70 $\mu \mathrm{g} / 1$ und 40-107 $\mu \mathrm{g} / 1$ appliziertes Aerosol wurde ebenfalls von Ratten gut toleriert ohne pulmonale Komplikationen oder Einflüsse auf Körper und Gewicht. Die intravenöse Applikation des Präparates bei Ratten und Affen in einer über 1000-mal höheren Dosis, als sie in klinischen Studien verwendet wurde, bestätigte die gute Verträglichkeit (Pulmozyme $\left.{ }^{\circledR} 2002 b\right)$.

\subsection{Besonderheit der neurologischen Patienten}

In einem Zeitraum von Januar 2006 bis Juni 2006 wurden in die Studie 22 Patienten der neurologischen Intensivstation der Universitätsmedizin Göttingen (UMG) eingeschlossen. Die Studienpatienten sind für das Patientenkollektiv der Intensivstation repräsentativ.

Der Qualitätsbericht über die neurologische Intensivstation (UMG) aus dem Jahre 2002, erstellt von der interdisziplinären Arbeitsgruppe (IAG) Qualitätssicherung der deutschen interdisziplinären Vereinigung der Intensiv- und Notfallmediziner (DIVI), führt den Krankheitsschweregrad der Patienten und die damit verbundenen Besonderheiten vor Augen. Der Bericht entstand aus dem Vergleich der an der Qualitätssicherung innerhalb eines Jahres (2001) beteiligten 28 Abteilungen aus verschiedenen Regionen Deutschlands mit über 19000 Patienten.

Aus dem Bericht wird ersichtlich, dass die Patienten der neurologischen Intensivstation (UMG) im Vergleich zu nicht-neurologischen Patienten längerer mittlerer Beatmungsdauer (11,8 Tagen vs. 4,1 Tagen) und Liegedauer (12 Tagen vs. 3,5 Tagen) bedürfen, 5-mal 
häufiger tracheotomiert werden und mehr Zugänge benötigen. Die beatmeten neurologischen Intensivpatienten werden 3,4-mal länger beatmet und verbringen 3-mal mehr Zeit auf Intensivstation als andere beatmete nicht neurologische Patienten. Zur Vervollständigung des Bildes trägt noch der größere Anteil von Patienten mit Multi-Organversagen gemessen in der SOFA-Score bei $(72,3 \%$ vs. 43,3\%). Übereinstimmend mit den oben genannten Besonderheiten haben die Patienten ein hohes kumulatives Risiko, an einer schweren nosokomialen Pneumonie zu erkranken. Eine Anlage des Tracheostomas bei Patienten wird am 10. Tag nach Beatmungsbeginn angestrebt.

Diese Veränderung des Beatmungsweges ist mit dem erhöhten Risiko bakterieller Kolonisation der unteren Atemwege vergesellschaftet. Nach der Anlage des Tracheostomas ändert sich das Bakterienspektrum zu Gunsten der nosokomialen Flora (25\% auf 50\%) (Morar et al. 2002). Mit der Tracheotomie werden die Patienten im verstärkten Maße gefährdet, eine nosokomiale Pneumonie zu entwickeln, die aufgrund der herrschenden antibiotischen Resistenzen im Krankenhaus mit Behandlungsschwierigkeiten verbunden ist.

Die Komplexität des Krankheitsbildes eines neurologischen Patienten wird in der erhöhten Sterblichkeit sichtbar. Die im Qualitätsbericht für neurologische Patienten ausgerechnete Standardisierte Mortalitätsrate ist mit 1,33 versus 1 bei nicht neurologischen intensivpflichtigen Patienten deutlich erhöht. Für die Ermittelung der Standardisierten Mortalitätsrate wurde die beobachtete Sterblichkeit durch die Prognose dividiert, die mit der auf dem SAPS II basierten Prognoseformel erstellt wurde (Lefering 2002). 


\section{2. $\quad$ Fragestellung}

Die oben beschriebenen Mechanismen führten zu dem Wunsch, im Rahmen einer Studie zu analysieren, ob sich die bisherigen positiven Ergebnisse bei der Anwendung von rhDNase auch bei beatmeten Erwachsenen einer neurologischen Klinik bestätigen lassen. Bis jetzt wurde die Wirkung von rhDNase an beatmeten erwachsenen Patienten in einer prospektiven placebokontrollierten Studie noch nicht untersucht. Zu diesem Zweck wurde die Lufit-Studie* von der Arbeitsgruppe um Dr. med. Riethmüller aus der Universität Tübingen konzipiert. Die Teilnahme der neurologischen Intensivstation der Universitätsmedizin Göttingen (UMG) an der Lufit-Studie war insofern von Bedeutung, weil Patienten mit lebensbedrohlichen neurologischen Erkrankungen im Durchschnitt längere Beatmungs- und Liegedauer, höhere Morbiditäts- und Mortalitätsrate, verglichen mit den anderen intensivpflichtigen Patienten, aufweisen.

\section{Grundlegende Hypothesen der Lufit-Studie:}

1. Durch 2-mal tägliche intratracheale Verabreichung von rhDNase in einer Dosierung von je 2,5 ml während der gesamten künstlichen Beatmung lässt sich die Beatmungsdauer verkürzen.

2. Die rhDNase führt durch Spaltung der DNA aus dem Zelldetritus zugrunde gegangener neutrophiler Granulozyten und Bronchialepithelien zu einer Verbesserung der Rheologie des Bronchial- und Trachelasekretes, welches effektiver während Absaugung mobilisiert werden kann. Dadurch werden die Atelektasenbildung, erhöhte Infektneigung und damit verbundene Bakteriämie bzw. Sepsis verhindert. Zusätzlich wird die periziliäre Flüssigkeitsschicht neu gebildet, die das erforderliche Milieu für die effektive Wirkung von respiratorischen antimikrobiellen Peptiden und Defensinen darstellt. Hierdurch kommt es zu einer Verbesserung der Lungenfunktion und in der Folge zu einer Reduktion der Beatmungsdauer.

Das primäre Ziel dieser Arbeit war die rhDNase- Wirkung auf die Gesamtbeatmungsdauer der langzeitbeatmeten ( $>3$ Tagen) erwachsenen neurologischen Patienten im Vergleich zur

\footnotetext{
*Lufit-Studie: Beatmungsdauer und Lungenfunktion bei beatmeten Patienten unter Therapie mit Dornase alfa
} 
„Placebo“-Gruppe in einer prospektiven randomisierten placebokontrollierten doppelt-blinden Studie zu prüfen.

Gesondert wurden die Charakteristika der Patienten der neurologischen Intensivstation der Universitätsmedizin Göttingen (Zentrum 27) gegenüber den restlichen Patienten der Gruppe 3 der Lufit-Studie (genannt modifizierte Gruppe 3) verglichen.

Außerdem wurden die Folgen der erleichterten Mobilisierung des Bronchial- und Trachealsekretes als sekundäre Ziele gesetzt:

1. Verbesserung der Lungenfunktionsparameter;

2. Verringerung des DNA- Gehaltes, Verkürzung der DNA- Kettenlängen und Senkung der Zytokinkonzentration im Trachealsekret;

3. Verkürzung des Aufenthaltes auf der Intensivstation;

4. Verkürzung der Krankenhausverweildauer.

Für die statistische Zuverlässigkeit der Ergebnisse wurde der Einschluss von mind. 80 Patienten geplant. Allerdings wurde aufgrund der hervorragenden Resultate der Zwischenauswertung (Gruppe 3 der Lufit-Studie) die Lufit-Studie vorzeitig als beendet erklärt, daher konnten nur 22 neurologische Patienten an der Lufit-Studie teilnehmen (Siehe auch Material und Methoden S. 19-29). 


\section{Material und Methoden}

\section{1}

Patienten

Alle kurz zuvor intubierten und maschinell beatmeten Patienten der neurologischen Intensivstation der Universitätsmedizin Göttingen (Leitung: Dr. Hilmar Prange) wurden vom Prüfarzt nach Beatmungsbeginn auf ihre Eignung bezüglich der Einschluss- und Ausschlusskriterien für die Lufit-Studie evaluiert. Die neurologische Intensivstation der Universitätsmedizin Göttingen erhielt die Bezeichnung des Studienzentrums 27.

\section{Einschlusskriterien:}

Für die Aufnahme in die Lufit-Studie musste der Patient / die Patientin folgende Kriterien erfüllt haben. Er / sie musste:

1. maschinell beatmet sein;

2. mindestens 18 Jahre alt sein;

3. der Therapie im vollen Umfang und ohne Einschränkungen zugänglich sein;

4. mit Wahrscheinlichkeit mindestens 3 Tage beatmet werden (die Beendigung der maschinellen Beatmung sollte innerhalb von 21 Tagen ab Studienbeginn wahrscheinlich sein);

5. die Bestätigung von den Angehörigen haben, dass der mutmaßliche Wille, an der Studie teilzunehmen, besteht.

\section{Ausschlusskriterien:}

Aus der Lufit-Studie ausgeschlossen wurde der Patient / die Patientin beim Vorliegen folgender Kriterien. Er / sie sollte nicht:

1. mehr als $48 \mathrm{Std}$. beatmet sein;

2. weder im Rahmen einer Operation / eines Traumas noch aufgrund einer pulmonalen Dekompensation beatmet sein;

3. nach begründeter ärztlicher Einschätzung, trotz der maximalen möglichen Therapie, die nächsten 21 Tagen überleben;

4. an einer aktuellen pneumonologischen Begleiterkrankung (z.B. zentrales, stenosierendes, inoperables Bronchialkarzinom, Sarkoidose, Tuberkulose, Lungenfibrose, schweres Thoraxtrauma) leiden;

5. endotracheale oder bronchiale Blutungszeichen zeigen;

6. an einem Pneumothorax, der nicht entlastet ist, leiden; 
7. an einer weiteren klinischen Studie teilnehmen;

8. schwanger sein;

9. stillen.

Der Patient / die Patientin, der / die alle Einschlusskriterien erfüllte, und keine Ausschlusskriterien vorwies, wurde in die Lufit-Studie aufgenommen. Die Lufit-Studie bestand aus drei Diagnosegruppen, die folgendermaßen vor dem Studienbeginn definiert waren:

- Diagnosegruppe 1: Alle Patienten, die aufgrund einer Operation oder eines Traumas maschinell beatmet werden und gleichzeitig die Diagnose COPD nicht erfüllen.

- Diagnosegruppe 2: Alle Patienten, die aufgrund einer Operation oder eines Traumas maschinell beatmet werden und gleichzeitig die Diagnose COPD erfüllen.

- Diagnosegruppe 3: Alle Patienten, die nicht aufgrund einer Operation oder eines Traumas maschinell beatmet werden, sondern aufgrund einer kardiopulmonalen Dekompensation.

\section{2}

\section{Allokation}

Waren die Einschlusskriterien gegeben und der mutmaßliche Patientenwillen festgestellt, erfolgte die Zuweisung zu einer der drei Diagnosegruppen. Am Folgetag (Studientag 1) wurde mit der Behandlung begonnen.

\subsection{Studiendesign}

Bei der Lufit-Studie handelt sich um eine prospektive randomisierte placebokontrollierte doppelt-blinde multizentrische deutschlandweite Studie bei erwachsenen maschinell beatmeten Patienten, wobei die neurologische Intensivstation der Universitätsmedizin Göttingen die einzige teilnehmende neurologische Einrichtung darstellte. Die Gesamtpatientenzahl lag bei 262 .

RhDNase wurde als Verum gegenüber $\mathrm{NaCl} \quad 0,9 \%$ als Placebo verglichen. Randomisierungslisten mit Blockrandomisierung und variable Blocklänge wurden vom Institut für Medizinische Biometrie der Universität Tübingen (Direktor: Prof. Dr. K. Dietz) erstellt und nur den zur Herstellung der Medikation beteiligten Apothekeneinrichtungen übermittelt. Die Randomisierungslisten wurden nach Diagnosegruppen unterteilt. Das Verhältnis Verum zu Placebo betrug 1:1. 
Die Unterteilung der Patienten erfolgte entsprechend der Diagnosen in 3 Gruppen (s. Abb. 3.3/1).

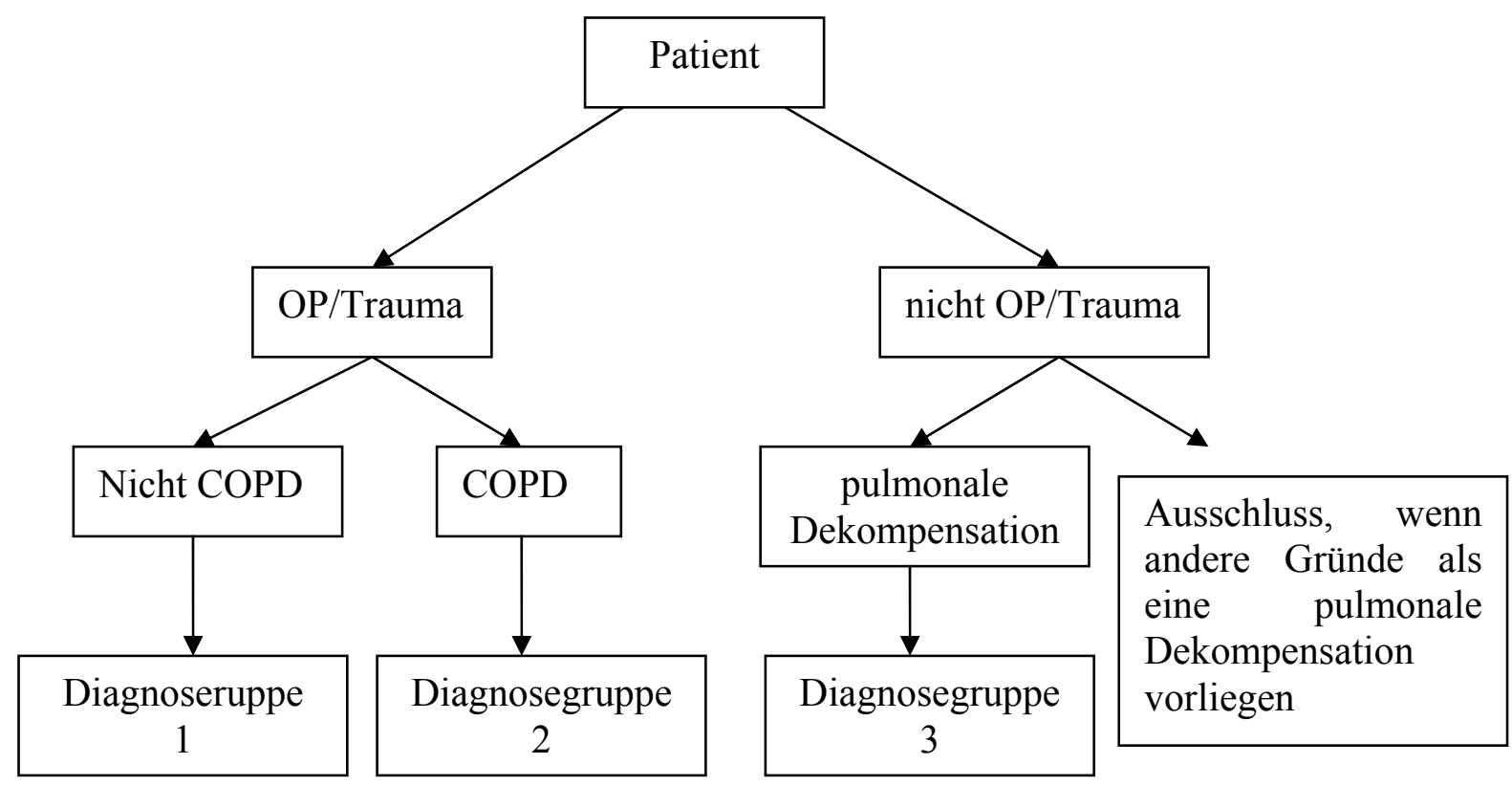

\section{Abbildung 3.3/1.:}

Baumdiagramm der Gruppenzuweisung

Die individuelle Studiendauer für einen Studienpatienten betrug maximal 21 Tage. Die Beendigung der maschinellen Beatmung vor dem 21. Studientag und die mögliche Spontanatmung über die 24 Std. nach der Extubation oder das Eintreten eines der Abbruchkriterien galten für einen Patienten als das individuelle Studienende.

Zur Beendigung der maschinellen Beatmung sollten folgende Kriterien erfüllt sein:

1. Erfolgreicher Spontanatmungsversuch über die Dauer von 30 min. (T-Stück oder Druckunterstützung $\left.<7 \mathrm{~cm} \mathrm{H}_{2} \mathrm{O}\right)$;

2. F/VT Verhältnis < 105 (Atemfrequenz / Tidalvolumen Verhältnis);

3. Atemfrequenz $<35 / \mathrm{min}$;

4. Sauerstoffsättigung $>90 \%$ bei $\mathrm{FiO}_{2}<0,4$;

5. Maximaler Inspirationsdruck $<20$ mbar;

6. Herzfrequenz $<140 /$ min und keine persistierende Abweichung über 20\% des Ausgangwertes vor dem Beginn des Spontanatmungsversuches;

7. Systolischer Blutdruck $<180 \mathrm{mmHg}$ oder $>90 \mathrm{mmHg}$ und keine persistierende Abweichung über 20\% des Ausgangwertes; 
8. Psychische Verfassung ohne Unruhe, Angst oder Agitation.

Im Weiteren wurde das individuelle Studienende je nach Beatmungsweg (Tubus, Tracheostoma) von verschiedenen Kriterien beeinflusst:

- Tubus: Mit der Extubation war die Beatmung beendet. Eine Unterbrechung der maschinellen Beatmung bzw. akzidentelle Extubation mit nachfolgender Reintubation für weniger als 24 Std. durfte erfolgen, sofern nicht mehr als eine Prüfpräparatapplikation ausgelassen wurde, und galt nicht als Abbruchkriterium.

- Tracheostoma: Die Beatmung über Tracheostoma galt als beendet, wenn über 24 Std. keine maschinelle Beatmung erfolgte. Patienten erhielten im wachen, spontanatmenden Zustand keine intratrachealen Gaben. Kam es zur Wiederaufnahme der Tracheostomabeatmung und dauerte die Unterbrechung der maschinellen Beatmung weniger als 24 Std., so durfte die Studie weitergeführt werden, sofern nicht mehr als eine Prüfpräparatapplikation ausgelassen wurde.

Die Lufit-Studie wurde bei einem Patienten abgebrochen, wenn eines der folgenden Kriterien eintrat:

- Unterbrechung der Prüfpräparatapplikation / Verletzung des Studienprotokolls (ein einmaliges Auslassen der Prüfpräparatapplikation galt nicht als Unterbrechung);

- nicht tolerierbare Nebenwirkungen;

- Diagnosegruppe 3: jede Operation nach Studienbeginn;

- jeder neu aufgetretener Pneumothorax;

- jede neu aufgetretene endotracheale oder bronchiale Blutung;

- andere Umstände, die die Gesundheit des Patienten gefährden würden, wenn er weiterhin an der Studie teilnimmt.

Entwöhnungs- und "Beobachtungsbeginn":

Jede / $\mathrm{r}$ in die Lufit-Studie eingeschlossene Patient / in wurde täglich auf die Wahrscheinlichkeit der Beendigung der maschinellen Beatmung evaluiert. In der Diagnosegruppe 3 wurde der Beobachtungsbeginn gleich dem Beatmungsbeginn gesetzt. Aufgrund des Studiendesigns wurde dem Patienten / der Patientin der Diagnosegruppe 1 und 2 vom behandelten Arzt ein Zeitpunkt zugeordnet, ab dem die Behandlung des Grundleidens weitgehend abgeschlossen war und die pulmonale Pathologie den maßgeblichen Beatmungsgrund darstellte. Der Beobachtungsbeginn entsprach dem Zeitpunkt, ab dem die erste Spontanatmungsaktivität unter maschineller Beatmung $\mathrm{zu}$ beobachten war. Dieser 
Zeitpunkt diente dazu, den Zeitraum zu erfassen, ab dem die Beendigung der maschinellen Beatmung von Seiten des Atemantriebes her theoretisch möglich war. Die Entwöhnung sollte mit Hilfe von Druckunterstützung / CPAP-Modus in der Beatmung des Patienten erfolgen.

Folgende Anhaltspunkte galten als richtungweisend für die Festlegung des Zeitpunktes des "Weaning-Beginn":

- Wegfall oder weitestgehende Besserung des Grundleidens, welches den ursprünglichen Beatmungsgrund darstellte;

- $\mathrm{PaO}_{2} / \mathrm{FiO}_{2}$ Verhältnis > 150;

- $\mathrm{FiO}_{2}<0,6$;

- $\quad \mathrm{PEEP}<10 \mathrm{~cm} \mathrm{H}_{2} \mathrm{O}$;

- Noradrenalin oder Adrenalin bis zu 0,05 $\mu \mathrm{g} / \mathrm{kg} / \mathrm{min}$, Dobutamin oder Dopamin bis zu $5 \mu \mathrm{g} / \mathrm{kg} / \mathrm{min}$;

- Patient ist kontaktfähig.

Nachbeobachtung:

Vom Zeitpunkt des individuellen Studienendes und bis zum Ende des stationären Aufenthaltes erfolgte für alle Patienten eine Nachbeobachtung anhand der Patientenakte. Die Nachbeobachtung schloss folgende Parameter ein:

- Extubation (bei Patienten, die über den 21. Tag hinaus beatmet waren);

- Reintubation;

- Tag der Entlassung von der Intensivstation;

- Tag der Entlassung aus dem Krankenhaus.

\section{$3.4 \quad$ Prüfpräparat}

Medikamentzusammensetzung:

Dornase alfa ist eine sterile, farblose, hoch gereinigte Lösung der rekombinanten menschlichen Desoxyribonuklease 1 (rhDNase 1). Die Lösung besteht aus $1 \mathrm{mg} / \mathrm{ml}$ Dornase alfa, $0,15 \mathrm{mg} / \mathrm{ml} \mathrm{Kalziumchlorid-Dihydrat} \mathrm{und} 8,77 \mathrm{mg} / \mathrm{ml} \mathrm{NaCl}$ mit einer Osmolalität von $277 \mathrm{mOsm} / \mathrm{kg}$. Die Präparation enthält keine Konservierungsstoffe. Der pH-Wert liegt bei 6,3 (Pulmozyme® 2002 c).

Die Herstellung und der Versand der Prüfsubstanz an die Apotheken des Universitätsklinikums Tübingen und der Universität Ulm erfolgte durch die Firma Hoffmann- 
LaRoche, Grenzach. Die Umverpackung, Beschriftung, Verblindung und Lagerung der Medikation erfolgte nach $\S 10$ AMG in den beiden Apotheken nach einer nur dort bekannten Randomisierungsliste.

\subsection{Placebo}

Das Präparat enthält 2,5 $\mathrm{ml} \mathrm{0,9 \%} \mathrm{NaCl-Lösung.}$

\subsection{Trachealsekretentnahme}

Das Trachealsekret wurde nur bei über Tubus oder Tracheostoma beatmeten Patienten abgenommen. Die Entnahme erfolgte unter sterilen Bedingungen immer vor der Prüfpräparatapplikation. Es wurden etwa $\geq 2,5 \mathrm{ml}$ Trachealsekret, zur DNA-Quantifizierung und -Qualifizierung sowie zur Zytokin- und Zytologie-Bestimmung, täglich bis Studientag 7, dann 2-tägig abgenommen. Das Trachealsekret-Röhrchen wurde täglich mittels mitgelieferter Etiketten und Versandtaschen an die zuständigen Zytokin- und Zytologielabore in der Abteilung I der Universitäts-Kinderklinik Tübingen verschickt. Die am Wochenende gewonnenen Proben wurden bis zum nächsten Werktag bei mindestens $-10{ }^{\circ} \mathrm{C}$ eingefroren. Der Versand erfolgte ungekühlt.

\subsection{Erfassung des klinischen Patientenzustandes}

Aus der Vielzahl der während der medizinisch indizierten Untersuchungen, erhobenen Daten wurden folgende Parameter zur Erfassung des klinischen Zustandes vom Patienten im Datenerhebungsbogen erfasst:

- Beatmung (Beatmungsweg, Beatmungsart, Spitzendruck, Pmean, PEEP, AF, AMV, $\left.\mathrm{FiO}_{2}\right)$;

- $\quad$ Blutgasanalyse (pH, art. $\mathrm{pO}_{2}$, ven. $\mathrm{pO}_{2}, \mathrm{pCO}_{2}, \mathrm{BE}, \mathrm{HCO}_{3}{ }^{-}, \mathrm{SaO}_{2}$ );

- Blutbild (Hämoglobin, Leukozyten, Thrombozyten);

- Klinische Chemie (CRP, Kreatinin, Harnstoff);

- Erregernachweis, Bronchoskopiebefund, Kathecholamin- und Antibiotikatherapie;

- Klinisches Score - Glasgow Coma Scale (GCS).

\section{8}

\section{Applikationsmodus}

Jede / $r$ neu in die Studie eingeschlossene / $r$ Patient / in erhielt vom Studientag 1 an, entweder bis zum individuellen Studienende, definiert durch Beendigung der maschinellen Beatmung 
oder Auftreten eines der Abbruchkriterien, oder bis zum Studientag 21, zwei mal täglich 2,5 $\mathrm{ml}$ des Prüfpräparates appliziert.

\subsubsection{Beschreibung der Verum-Behandlung}

Ab Studientag 1 wurde 2x täglich im Abstand von 12 Std. (09:00 +/-3 Std. und 21:00 +/- 3 Std.) Dornase alfa appliziert. Die applizierte Flüssigkeitsmenge beträgt 2,5 $\mathrm{ml} \pm 0,2 \mathrm{ml}$, dies entspricht 2,5 mg Dornase alfa oder 2500 U Dornase alfa. Die Applikation erfolgte bei intubierten oder tracheotomierten Patienten intratracheal durch Instillation mittels eines über das Tubusende hinaus vorgeschobenen Absaugkatheters. Für die sichere intratracheale Applikation des Präparates wurde nach Instillation der Flüssigkeit noch $10 \mathrm{ml}$ Luft durch den Absaugkatheter injiziert.

\subsubsection{Beschreibung der Placebo-Behandlung}

Ab Studientag 1 wurde 2x täglich im Abstand von 12 Std. (09:00 +/-3 Std. und 21:00 +/- 3 Std.) $0,9 \% \mathrm{NaCl}$ appliziert. Die applizierte Flüssigkeitsmenge betrug 2,5 $\mathrm{ml} \pm 0,2 \mathrm{ml}$. Die Applikation erfolgte bei intubierten oder tracheotomierten Patienten intratracheal durch Instillation mittels eines über das Tubusende hinaus vorgeschobenen Absaugkatheters. Um sicher zu stellen, dass das applizierte Prüfpräparat nach intratracheal gelangte, wurde nach Instillation der Flüssigkeit noch $10 \mathrm{ml}$ Luft durch den Absaugkatheter injiziert.

Aufgrund des Studiendesigns verwendeten wir keinen Ultaschallvernebler, um eine mögliche Hitzedenaturierung des Medikamentes zu vermeiden. Aus physiologischen Gründen wurde maskenbeatmeten Patienten kein Trachealsekret abgenommen.

\section{9}

\section{Methoden zur Erfassung der Wirksamkeit und Sicherheit}

\subsubsection{Erfassung der klinischen Wirksamkeit}

Die klinische Wirksamkeit des Prüfpräparates äußert sich in der Verkürzung der Beatmungsdauer. Die Inhalation von rhDNase löst eine Verflüssigung des Trachealsekrets aus, das aufgrund dessen leichter mobilisieren werden kann. Durch Beseitigung des Sekrets werden die dystelektatischen und atelektatischen Lungenbereiche in ihrer Anzahl reduziert und der Sauerstoffbedarf des Patienten verringert sich. Dies wurde anhand der folgenden Beatmungsparameter festgestellt: Beatmungsmodus (BIPAP versus CPAP), $\mathrm{P}_{\max }, \mathrm{FiO}_{2}, \mathrm{PEEP}$, Atemfrequenz, Atemminutenvolumen. 
Mit Eröffnung der atelektatischen Lungenbereiche verkleinert sich das Shuntvolumen des mit Sauerstoff mindergesättigten Blutes. Die Reduzierung des Shuntvolumens macht sich in den Werten der Blutgasanalyse (Sauerstoff, Sättigung) bemerkbar. Als Folge dieser verbesserten Lungenfunktion, sowie der antiinflammatorischen Begleiteffekten der rhDNase-Applikation sind eine frühere suffiziente Spontanatmung und ausreichende Sauerstoffversorgung des Körpers gewährleistet. Auf diese Weise kann die maschinelle Beatmung frühest möglich beendet und die Reintubationsrate gesenkt werden. Mit der Reduzierung der Beatmungsdauer verkleinert sich das Risiko beatmungsassoziierter Pneumonien. Für die Diagnose einer Pneumonie wurden klinische Kriterien wie Temperatur, laborchemische Parameter wie Leukozytose und CRP-Erhöhung, sowie Röntgen-Thorax und gegebenenfalls Erregernachweis aus dem bronchoalveolären Lavage festgelegt. Um eine systemische Ausbreitung des Erregers zu verifizieren wurden Blutkulturen angelegt.

Die frühe Spontanatmung ermöglicht die Mobilisierung des Patienten und Minimierung des intensivstationären Aufenthalts und der Krankenhausverweildauer. Demzufolge wurden nach dem Studienende bis zur endgültigen Entlassung des Patienten folgende Parameter anhand der Patientenakten dokumentiert:

- Extubation (bei Patienten, die über den 21. Studientag hinaus beatmet wurden);

- Reintubation;

- Tag der Entlassung von der Intensivstation;

- Tag der Entlassung aus dem Krankenhaus.

\subsubsection{Erfassung der Wirksamkeit in vitro}

Zur quantitativen und qualitativen DNA-Bestimmung wurde täglich einmalig eine Trachealsekretprobe gewonnen. Nach dem Eintreffen der Trachealsekretprobe im Labor der Universität Tübingen wurde sie elektophoretisch untersucht.

\subsubsection{Verringerung der DNA-Konzentration}

Aus der Trachealsekretprobe wurden zwei Aliquots gewogen. Ein Aliquot der Trachealsekretprobe wurde 30 min bei Raumtemperatur mit Dithiotreitol (DTT) inkubiert. Anschließend wurde mit einem Puffer für 90 min unter leichtem Schütteln inkubiert. Ebenso wurde mit dem zweiten Aliquot allerdings unter rhDNase-Zusatz verfahren. Die beiden Ansätze wurden jeweils über ein 1 \%iges Agarosegel aufgetrennt. Nach 30-minütigem Lauf 
des Gels bei 300 Volt (650 mA) wurde das Gel photographiert und densitometrisch analysiert. Als Referenzwert verwendete man T-Lymphozyten, sogenannte Jurkat-Zellen, mit schon photometrisch verifizierter Konzentration freier DNA von $0,155 \mathrm{mg} / \mathrm{ml}$. Ein Aliquot der TLymphozyten-DNA-Extraktion wurde mehrfach photometrisch gemessen und zum densitometrischen Vergleich aller Proben verwendet.

Durch densitometrische Analyse erfolgte die Berechnung der Konzentration an freier DNA in den Gelproben nach der Formel $\mathrm{x}=(\mathrm{b}-\mathrm{c}) / \mathrm{a}$ x 0,155 mg/ml. Dabei wurde DNA in intakten Zellen subtrahiert und nur freie DNA gemessen.

\subsubsection{Verkürzung der DNA-Kettenlänge}

Nach der densitometrischer Bestimmung der freien DNA-Konzentration in den Trachealsekretproben wurden die fotografierten Gele zur qualitativen Auswertung der DNA herangezogen. Dies erfolgte mit dem Gel-Analyse-Programm Analysis Doku ${ }$, SIS Leinfelden, mittels einer Kilobasen (kb)-Leiter an 8 definierten DNA-Längen: 12.000, 4000, 3000, 2000, 1600, 1000, 500, und $200 \mathrm{~kb}$. Durch die densitometrische Analyse der Graustufenwerte der im Labor mit rhDNase unbehandelten Proben konnte per Zuordnung zur kb-Leiter eine prozentuale Verteilung der DNA-Längen gewonnen werden. Die Jurkat-Zellen mit und ohne rhDNase versetzt dienten auch hier als Referenzen, um die rhDNase-Aktivität in den Patientenproben mit in-vitro-Proben zu vergleichen. Aus diesen Graustufenanteilen wurde die prozentuale Verteilung der DNA-Fragmente nach ihrer kb-Größe in DNAFragment-Kurven ermittelt. Diese verlaufen entsprechend einer positiven oder negativen Steigung.

Nach Logarithmierung mit dem natürlichen Logarithmus $\ln$ der $\mathrm{x}$-Achse, auf der die kbGrößen aufgetragen wurden, erhält man Ausgleichsgeraden. Anschließend erfolgte die Berechnung der Steigungen dieser Regressionsgeraden. Die Abnahme der Steigungen der Kurven an den Behandlungstagen unter Therapie mit Dornase alfa wurde als Behandlungswirkung interpretiert.

\subsubsection{Zytokinkonzentration im Trachealsekret}

Zur quantitativen Bestimmung der inflammatorisch und antiinflammatorisch wirkenden Zytokine wurde das eingesandte Trachealsekret untersucht. Die Trachealsekretproben wurden 
zur Zytokinbestimmung im Anschluss an die DNA-Quantifizierung und -Qualifizierung bei $20^{\circ} \mathrm{C}$ bis zur weiteren Verarbeitung tiefgefroren und gelagert.

Es wurden folgende Parameter im Trachealsekret gemessen:

- Interleukin 1 (IL-1);

- Interleukin 6 (IL-6);

- Interleukin 8 (IL-8);

- Interleukin 10 (IL-10);

- Lipopolysaccharidbindendes Protein (LBP);

- Granulozyten-Makrophagen-Kolonienstimulierender Faktor (GM-CSF).

Die quantitative Bestimmung der oben genannten Parameter erfolgte maschinell durch einen ELISA-(enzyme-linked-immunosorbent-assay)Test („Immulyte“®, Firma DPC Biermann $\mathrm{GmbH}$, Bad Nauheim). Dabei handelt es sich um den hochempfindlichen Nachweis von an einen unlöslichen Träger gebundenen Antigenen oder Antikörpern mittels eines durch ein Enzym markierten Antikörpers.

Sofern für die Messung erforderlich, wurden die Trachealsekrete vorab mit jeweils entsprechender Pufferlösung verdünnt. Die Messungen erfolgten vom 1. bis zum 7. Studientag täglich, dann bis zum 21. Studientag zweitägig.

\subsection{Statistik und Auswertung}

\subsubsection{Fallzahl}

Aus statistischen Überlegungen wurde die Aufnahme von 540 Patienten in die Studie geplant. Aufgrund der hervorragenden Ergebnisse der Zwischenauswertung im Juni 2006 wurde die Studie mit 262 Patienten, als vorzeitig abgeschlossen erklärt. Es wurde der Einschluss von mind. 80 Patienten im Zentrum 27 angestrebt und durch vorzeitigen Studienabschluss wurden nur 22 Patienten eingeschlossen.

\subsubsection{Datenauswertung}

Nach Eingang aller zur Auswertung bestimmten Parameter erfolgte die Datenauswertung. Als erstes wurde der Erfolg der Randomisierung dokumentiert. Dies geschah, indem die 
Behandlungsgruppen auf gleiche Zusammensetzung nach Alter, Geschlecht, Schweregrad der jeweiligen Krankheit geprüft wurden. Hierzu wurde eine Tabelle mit Lage- und Streuungsmaßen je nach Skalentyp aufgestellt. Die Daten liegen im Ergebnismaterial beim Studienleiter Dr. Riethmüller in Tübingen vor und werden derzeit für die Publikation der kompletten Lufit-Studie aufgearbeitet. Die Angaben erfolgten sowohl im Querschnitt (z. B. Wilcoxon), als auch longitudinal (ANOVA) durch Korrelation verschiedener Zielparameter.

Durch den Logrank-Test wurde der Vergleich zwischen den Gruppen im Bezug auf der Dauer der Beatmung, des Aufenthaltes auf der Intensivstation und im Krankenhaus angestellt. Mittels Kaplan-Meier-Kurven erfolgte die Darstellung der vorher im Logrank-Test ausgewerteten Daten. Der auf der Y-Achse aufgetragene P-Wert bezeichnet den prozentualen Anteil der Patienten, die am jeweiligen Tag noch beatmet sind. Beide Methoden stammen von Schumacher und Olschewski (2002).

Für die einzelnen Vergleiche (DNA-Konzentration, DNA-Fragmentierung, Leukozytenzahl, Interleukine) wurde jeweils eine nichtparametrische Varianzanalyse für longitudinale Daten durchgeführt, um zu testen, ob es einen Behandlungs- bzw. Gruppeneffekt gibt. Als Signifikanzniveau wurde $\alpha=5 \%$ festgelegt.

Aus statistischen Repräsentativitätsgründen wurden die Daten nach der Errechnung der mittleren Beatmungsdauer der Patienten in der jeweiligen Gruppe (13 Tage- rhDNaseGruppe; 13.5 Tage- NaCl-Gruppe) bis zum Studientag 15 betrachtet. In den Grafiken wurden jeweils Mittelwert, Minimum und Maximum der entsprechenden Gruppe zu den einzelnen Zeitpunkten dargestellt.

Die Varianzanalyse wurde mit SAS 9.1 (SAS Institute) durchgeführt.

Zur Berechnung des Logrank-Tests, der Kurven und Graphiken wurde die freie Software R (Version 2.6, www.r-project.org) verwendet.

Im Text aufgeführte Studienergebnisse sind als Mittelwert \pm Standardfehler angegeben. 


\section{Ergebnisse}

\section{1}

Patientenkollektiv

Nach den Ein- und Ausschlusskriterien wurden in dem Zeitraum von Januar 2006 bis Juni 2006 insgesamt 22 Patienten im Zentrum 27 in die Lufit-Studie eingeschlossen. 21 Patienten erfüllten die Kriterien der Diagnosegruppe 3 und ein Patient die der Diagnosegruppe 1. Nach der erfolgten Entblindung erhielten 11 Patienten der Diagnosegruppe 3 die rhDNase-Therapie und die anderen 10 Patienten die NaCl-Therapie. Der Patient aus der Diagnosegruppe 1 erhielt $\mathrm{NaCl}$ und wurde in die statistische Auswertung nicht einbezogen.

\subsubsection{Altersverteilung}

Der Altersmedian der Patienten im Zentrum 27 lag bei 67 Jahren [56; 74] (Median [25Q; 75Q]), wobei der jüngste Patient 19 Jahre und der Älteste 80 Jahre alt waren. Der Altersmedian der rhDNase-Gruppe lag bei 72 Jahren [55,50; 74,50] und in der NaCl-Gruppe bei 62,5 Jahren $[56,25 ; 67,75]$.

\subsubsection{Geschlechtsverteilung}

Das Verhältnis von Männern zu Frauen war in der rhDNase-Gruppe 6:5 und in der NaClGruppe 6:4.

\subsubsection{Neurologische Grunderkrankungen}

Mit 35\% überwog der Anteil der Patienten mit der Diagnose eines supratentoriellen Ischämieereignisses gegenüber 22\% mit generalisierten epileptischen Anfällen und jeweils 10\% mit Enzephalitiden, intrazerebralen Blutungen und Erkrankungen des peripheren Nervensystems unterschiedlicher Ätiologie (s. Abb. 4.1.3./1). Andere in der Abb. 4.1.3/1 aufgeführte neurologische Grunderkrankungen stellten einen Einzelfall dar. 


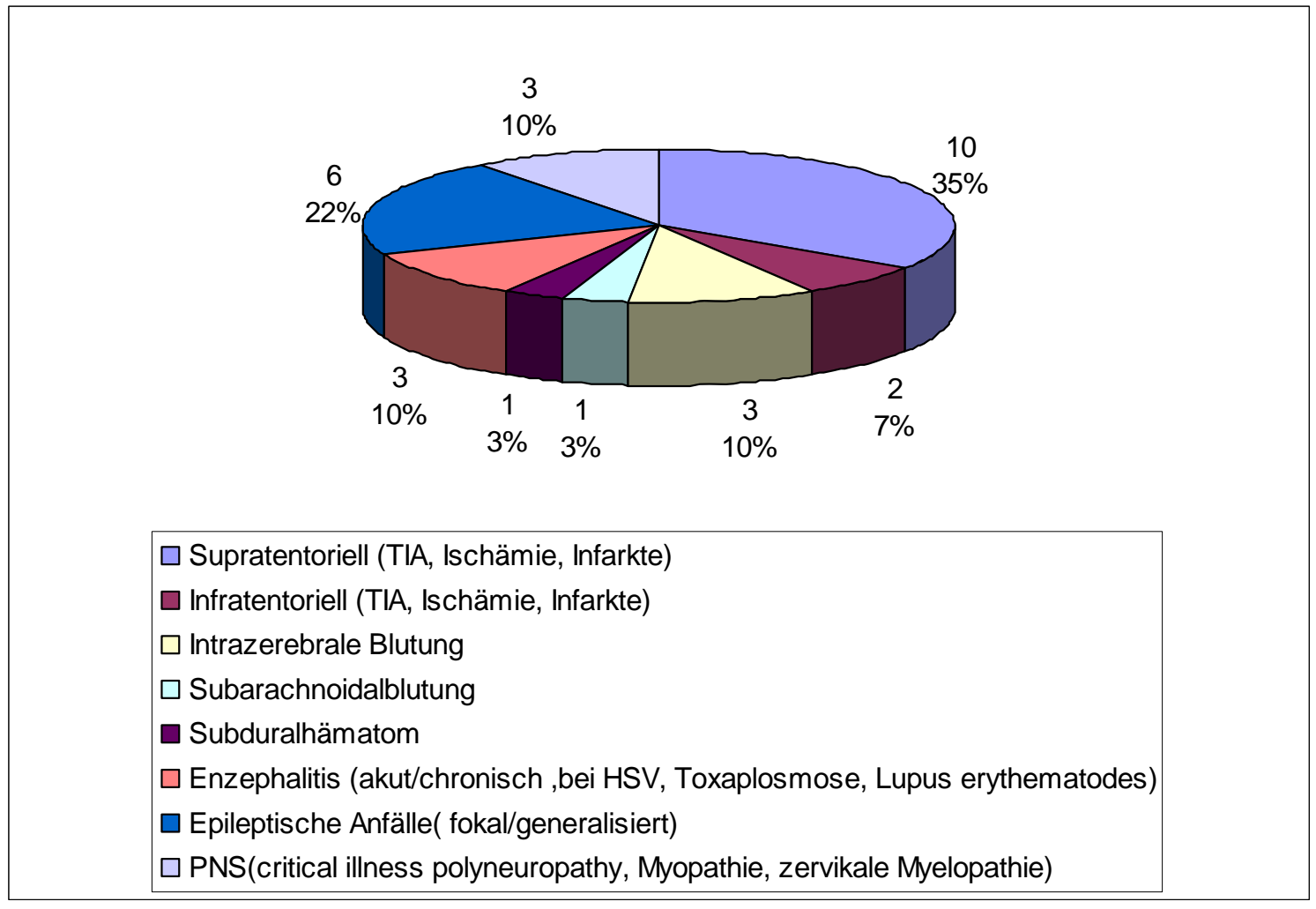

\section{Abbildung 4.1.3/1.}

Neurologisches Diagnosenspektrum der 21 Patienten der Diagnosegruppe 3 des Zentrums 27 (Daten in absoluten Zahlen bzw. in \%)

Die Aufteilung der neurologischen Diagnosen nach rhDNase- und NaCl-Gruppe ergab eine gleiche Verteilung der supratentoriellen und infratentoriellen ischämischen Ereignissen und epileptischen Anfällen in beiden Gruppen. In der rhDNase-Gruppe war jeweils ein Patient mehr mit der Diagnose der intrazerebralen Blutung, Enzephalitis bzw. Erkrankungen des PNS als in der NaCl-Gruppe. Andere Diagnosen stellten den Einzelfall dar (s. Tab. 4.1.3/1).

\section{Tabelle 4.1.3/1.}

Neurologische Diagnosen der 21 Patienten der Diagnosegruppe 3 des Zentrums 27 nach Gruppenzugehörigkeit

\begin{tabular}{|l|l|l|}
\hline & $\begin{array}{l}\text { rhDNase-Gruppe } \\
\text { absolute Zahlen }\end{array}$ & $\begin{array}{l}\text { NaCl-Gruppe } \\
\text { absolute Zahlen }\end{array}$ \\
\hline Supratentoriell (TIA*, Ischämie, Infarkte) & 5 & 5 \\
\hline Infratentoriell (TIA, Ischämie, Infarkte) & 1 & 1 \\
\hline Intrazerebrale Blutung & 2 & 1 \\
\hline Subarachnoidalblutung & 1 & 0 \\
\hline Subduralhämatom (akut/chronisch; bei HSV ${ }^{\dagger}$, & 0 & 1 \\
\hline $\begin{array}{l}\text { Enzephalitis } \\
\text { Toxoplasmose, Lupus erythematodes) }\end{array}$ & 1 \\
\hline Epileptische Anfälle (fokal/generalisiert) illness & 2 & 3 \\
\hline $\begin{array}{l}\text { Erkrankungen des PNS } \\
\text { polyneuropathy, Myopathie, zervikale Myelopathie) }\end{array}$ & 2 & 1 \\
\hline
\end{tabular}

"TIA: Transitorische ischämische Attacke; ${ }^{\dagger} \mathrm{HSV}$ : Herpes -simplex -Virus; ${ }^{\S}$ PNS: Peripheres Nervensystem 


\subsubsection{Pneumonologische Erkrankungen}

Zusätzlich zu neurologischen Erkrankungen litten die Patienten bei der Aufnahme unter Erkrankungen des respiratorischen Systems, die sowohl eine Indikation für Intubation darstellten als auch begleitend das Krankheitsbild erschwerten. Unter einer Pneumonie litten in der rhDNase-Gruppe 5 Patienten und 8 Patienten in der NaCl-Gruppe. COPD als Begleitdiagnose war bei 2 Patienten der rhDNase-Gruppe und einem Patienten der NaClGruppe vorhanden. Mit 2:1 überwog der Anteil der Patienten mit partieller oder globaler respiratorischer Insuffizienz verschiedener Genese in der $\mathrm{NaCl}$-Gruppe gegenüber der rhDNase-Gruppe (s. Tab. 4.1.4/1).

Tabelle 4.1.4/1.

Pneumonologische Diagnosen der 21 Patienten der Diagnosegruppe 3 des Zentrums 27 nach Gruppenzugehörigkeit

\begin{tabular}{|l|l|l|}
\hline & $\begin{array}{l}\text { rhDNase-Gruppe } \\
\text { absolute Zahlen }\end{array}$ & $\begin{array}{l}\text { NaCl-Gruppe } \\
\text { absolute Zahlen }\end{array}$ \\
\hline $\begin{array}{l}\text { Pneumonie } \\
\text { (Aspirations-/Broncho-/Retentionspneumonie) }\end{array}$ & 5 & 8 \\
\hline COPD & 2 & 1 \\
\hline Respiratorische Insuffizienz (partielle/globale) & 1 & 2 \\
\hline
\end{tabular}

"COPD: Chronisch-obstruktive pulmonale Erkrankung

Während der Beatmungspflichtigkeit entwickelten 3 Patienten in der rhDNase-Gruppe eine nosokomiale Pneumonie. In der NaCl-Gruppe wurde kein Fall der nosokomialen Pneumonie festgestellt.

\subsubsection{Systemisches Entzündungsstadium}

Bei mehr als 60\% (14) der Patienten wurde während des Aufenthalts auf Intensivstation die Diagnose Sepsis gestellt. Bei 14\% (3) der Patienten führte Sepsis zum Multiorganversagen und bei anderen 14\% (3) trat der Tod als Sepsisfolge ein (s. Abb. 4.1.5/1). 


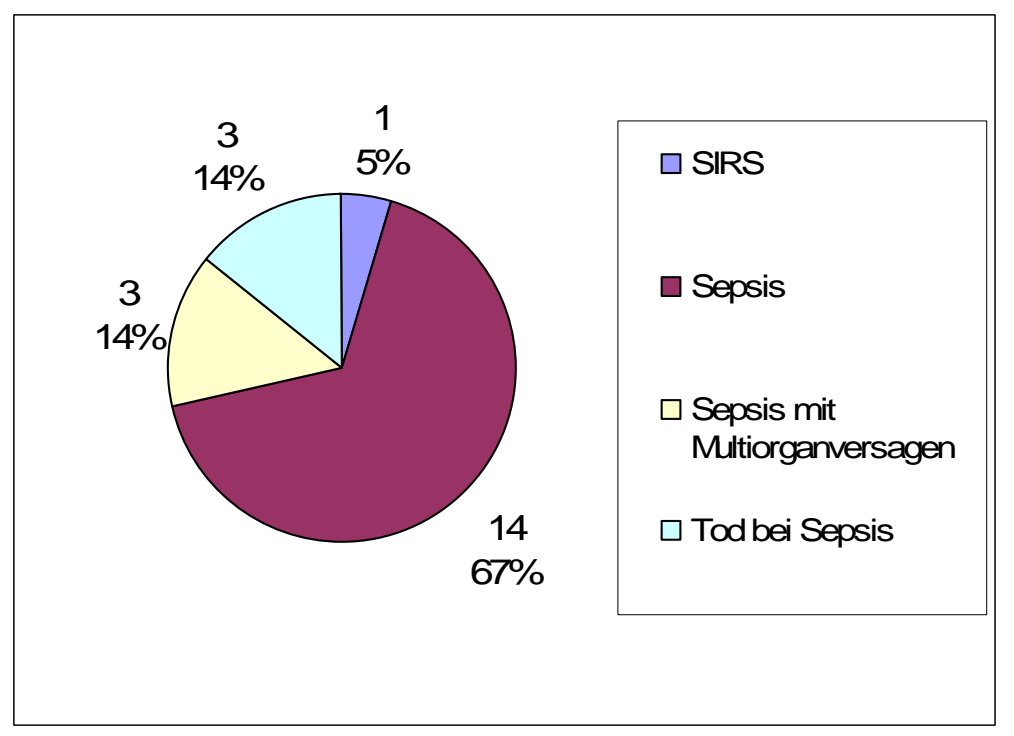

\section{Abbildung 4.1.5/1.}

Systemisches Entzündungsstadium der 21 Patienten der Diagnosegruppe 3 des Zentrums 27 (Daten in absoluten Zahlen bzw. in \%)

Das Verhältnis der Patienten mit Sepsis lag zwischen rhDNase- und NaCl-Gruppe bei 6:8. In der rhDNase-Gruppe verstarben 2 Patienten infolge einer Sepsis und in der NaCl-Gruppe 1 Patient. Ein Patient in der rhDNase-Gruppe mit SIRS verstarb an Folgen eines Hirnödems und Multiorganversagens und nicht infolge einer Sepsis (s. Tab. 4.1.5/1).

\section{Tabelle 4.1.5/1.}

Systemisches Entzündungsstadium der 21 Patienten der Diagnosegruppe 3 des Zentrums 27 nach Gruppenzugehörigkeit

\begin{tabular}{|c|c|c|}
\hline & $\begin{array}{l}\text { rhDNase } \\
\text { absolute Zahlen }\end{array}$ & $\begin{array}{l}\mathrm{NaCl} \\
\text { absolute Zahlen }\end{array}$ \\
\hline SIRS $^{*}$ & 1 & 0 \\
\hline Sepsis & 6 & 8 \\
\hline Sepsis mit Multiorganversagen & 2 & 1 \\
\hline Tod bei Sepsis & 2 & 1 \\
\hline
\end{tabular}

"SIRS: Systemisches inflammatorisches Response- Syndrom

\subsubsection{Tracheotomie}

Bei Vorhersehbarkeit der Notwendigkeit einer prolongierten Beatmung ( $>10$ Tagen) wurden 7 Patienten in der rhDNase-Gruppe und 6 Patienten in der NaCl-Gruppe tracheotomiert.

\subsubsection{Reintubation}

Sowohl in der rhDNase-Gruppe als auch in der NaCl-Gruppe wurden jeweils 2 Patienten innerhalb von 24 Std. nach Extubation reintubiert. 


\subsubsection{Beatmungsparameter}

Bis Studientag 13 waren in beiden Gruppen (rhDNase- und NaCl-Gruppe) mehr als 50\% der Patienten beatmet. Daher sind die Beatmungsparameter bis zu diesem Zeitpunkt am meisten aussagekräftig für jede Gruppe. In beiden Gruppen schwankte der PEEP-Wert zwischen 5,9 und 7,25 mbar. In der rhDNase-Gruppe stieg $\Delta \mathrm{P}$ von 13,3 auf 15 mbar im Verlauf an, während sich dieser Wert in der NaCl-Gruppe von 13,3 auf 10,7 mbar verminderte. Das Atemzugvolumen bewegte sich in beiden Gruppen zwischen 515 und $706 \mathrm{ml} / \mathrm{min}$.

\subsection{Erfassung der klinischen Wirksamkeit}

\subsubsection{Beatmungsdauer}

Aufgrund der definierten Studiendauer von 21 Tagen wurde bei allen Patienten, die tatsächlich länger als 21 Tage beatmet waren, eine Beatmungsdauer von 21 Tagen festgelegt. In der rhDNase-Gruppe lag die mediane Beatmungsdauer bei 13 Tagen, in der NaCl-Gruppe bei 13,5 Tagen. Statistisch war der Unterschied in der Beatmungsdauer nicht signifikant unterschiedlich (Behandlungseffekt: $p=0,69)(s$. Abb. 4.2.1/1).

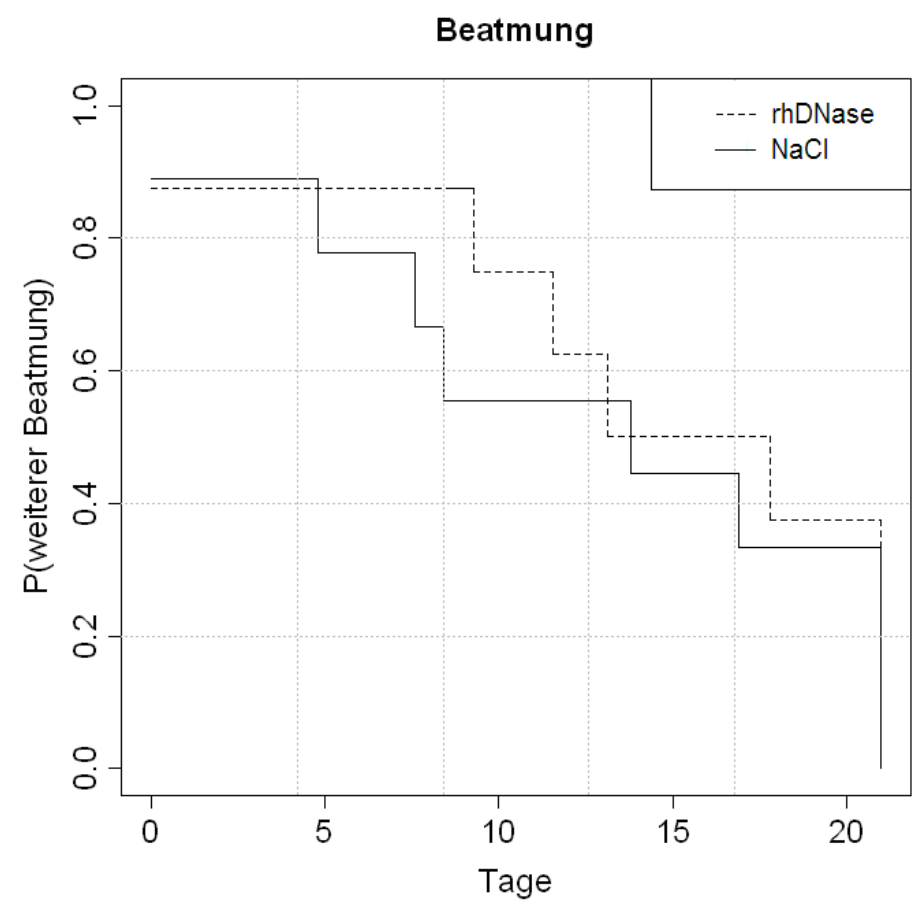

Abbildung 4.2.1/1.

Beatmungsdauer in Tagen der rhDNase- und NaCl-Gruppe der Diagnosegruppe 3 des Zentrums 27 


\subsubsection{Sauerstofffraktions $\left(\mathrm{FiO}_{2}\right)$-Bedarf}

Während der 21 Studientage benötigten die Patienten in der rhDNase-Gruppe im Durchschnitt 6\% mehr Sauerstoff in der eingeatmeten Sauerstofffraktion $\left(\mathrm{FiO}_{2}\right)$ als die Patienten in der NaCl-Gruppe. Dennoch erwies sich dieser Unterschied als nicht signifikant (Behandlungseffekt: $\mathrm{p}=0,26$ ). In beiden Gruppen veränderte sich der $\mathrm{FiO}_{2}$-Bedarf während des Studienzeitraumes, nämlich dessen leichte Zunahme bis zum 6. Studientag mit anschließender Abnahme auf den anfänglichen Wert in der rhDNase-Gruppe bzw. dessen kontinuierliche leichte Abnahme in der NaCl-Gruppe (s. Abb. 4.2.2.1/1).

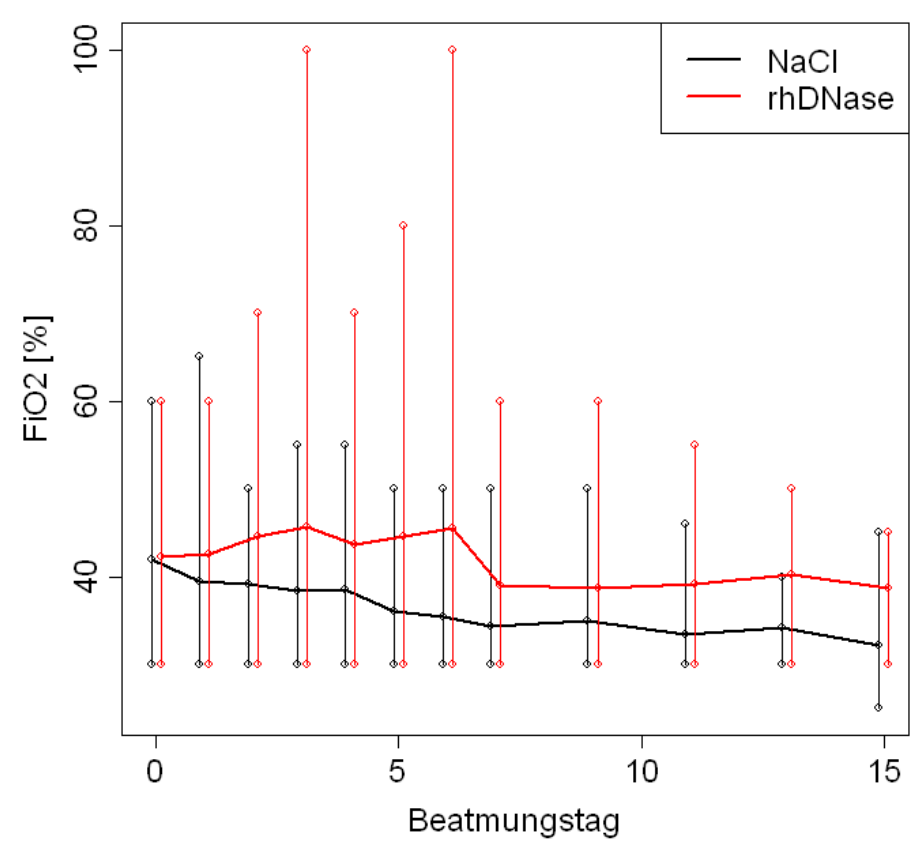

Abbildung 4.2.2.1/1.

Verlauf des täglichen $\mathrm{FiO}_{2}$-Bedarfs in der rhDNase- und NaCl-Gruppe der Diagnosegruppe 3 des Zentrums 27 


\subsubsection{Atemminutenvolumen (AMV)}

Im erforderlichen AMV unterschieden sich die beiden Gruppen nicht (Behandlungseffekt: $p=$ 0,95). Das AMV stieg sowohl in der rhDNase-Gruppe als auch in der NaCl-Gruppe im Studienverlauf an (s. Abb. 4.2.2.2/1.).

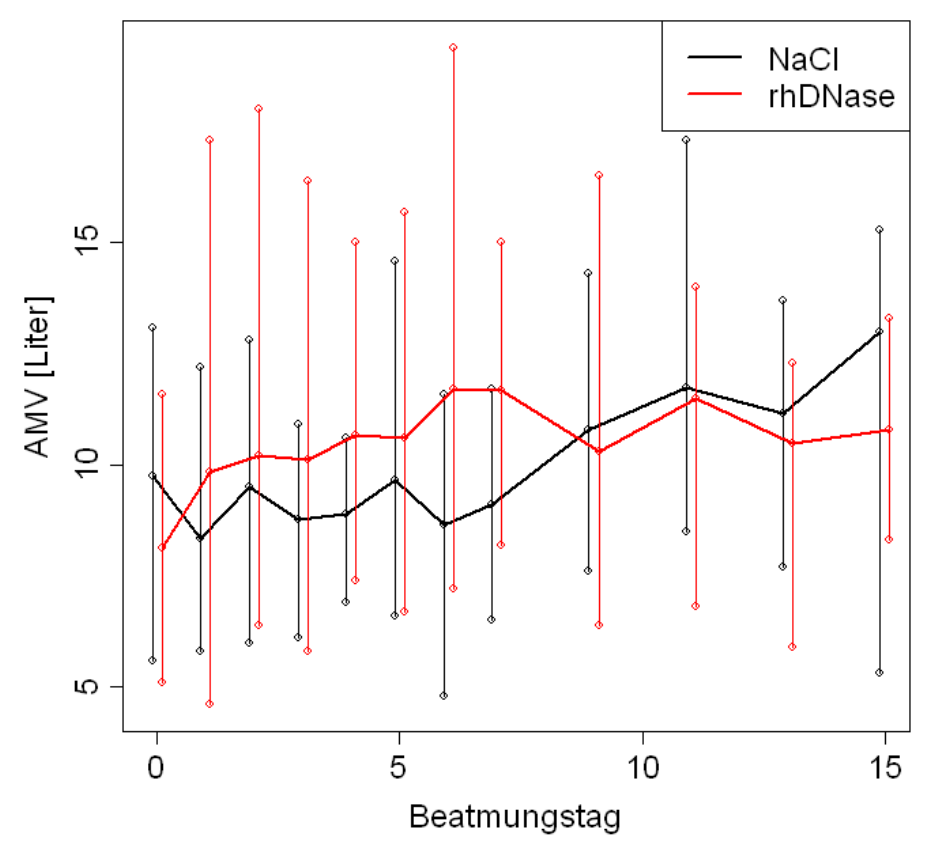

Abbildung 4.2.2.2/1.

Verlauf des täglichen AMV in der rhDNase- und NaCl-Gruppe der Diagnosegruppe 3 des Zentrums 27 


\subsubsection{Verkürzung des Aufenthaltes auf der Intensivstation}

Um die korrekte Liegedauer auf der Intensivstation $\mathrm{zu}$ ermitteln, wurde von der Gesamtpatientenzahl in jeweiliger Gruppe die Anzahl der verstorbenen Patienten während des intensivstationären Aufenthaltes abgezogen. Demnach konnte die Aufenthaltsdauer auf der Intensivstation von 8 Patienten in jeder Gruppe ausgewertet werden. Die Patienten der rhDNase-Gruppe verbrachten im Median 29,5 Tage auf der Intensivstation, die Patienten der NaCl-Gruppe nur 23 Tage. Dieser Unterschied erwies sich mit einem p-Wert von 0,83 als nicht signifikant (s. Abb. 4.2.3/1).

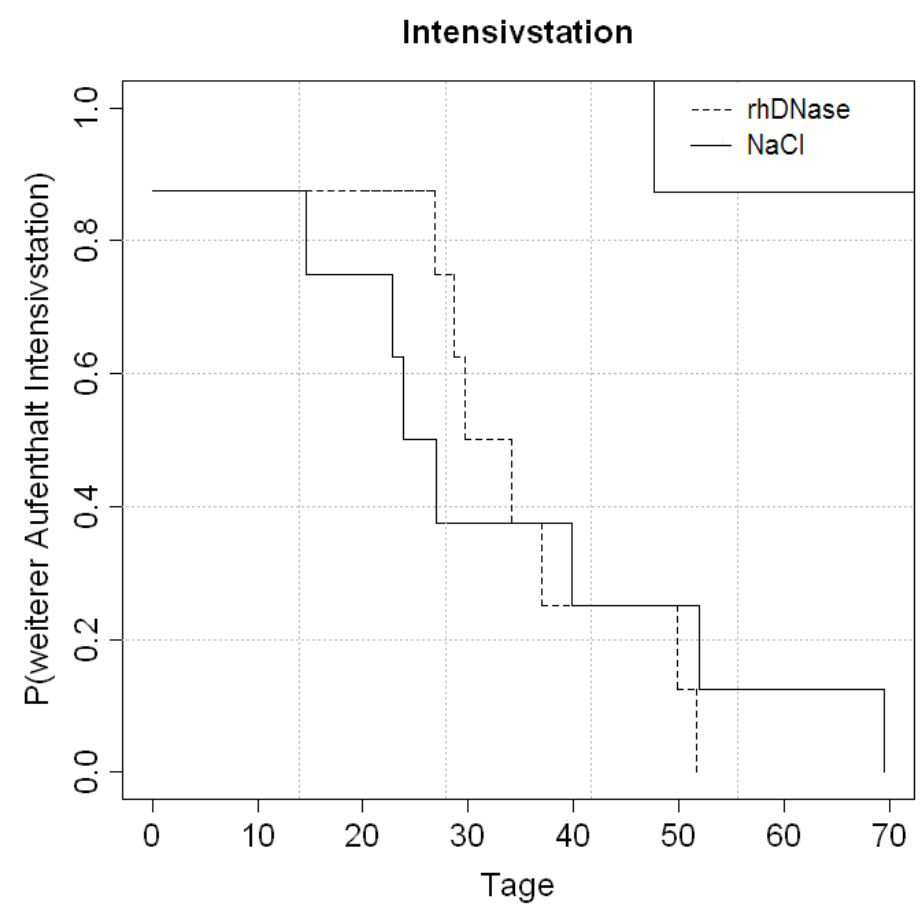

Abbildung 4.2.3/1.

Verweildauer auf Intensivstation in Tagen der rhDNase- und NaCl-Gruppe der Diagnosegruppe 3 des Zentrums 27 


\subsubsection{Verkürzung der Krankenhausaufenthaltsdauer}

Zum Zwecke der korrekten Berechnung der Aufenthaltsdauer im Krankenhaus wurde in jeder Gruppe die Patientenzahl auf die Krankenhausmaßnahmen überlebenden Patienten korrigiert. Somit befanden sich jeweils 8 Patienten in der rhDNase- und NaCl-Gruppe. Die Patienten der rhDNase-Gruppe hielten sich im Median 37 Tage im Krankenhaus auf. Der Krankenhausaufenthalt der Patienten der NaCl-Gruppe beschränkte sich im auf 26,5 Tage. Dieser Unterschied erwies sich mit einem p-Wert von 0,92 als nicht signifikant (s. Abb. 4.2.4/1).

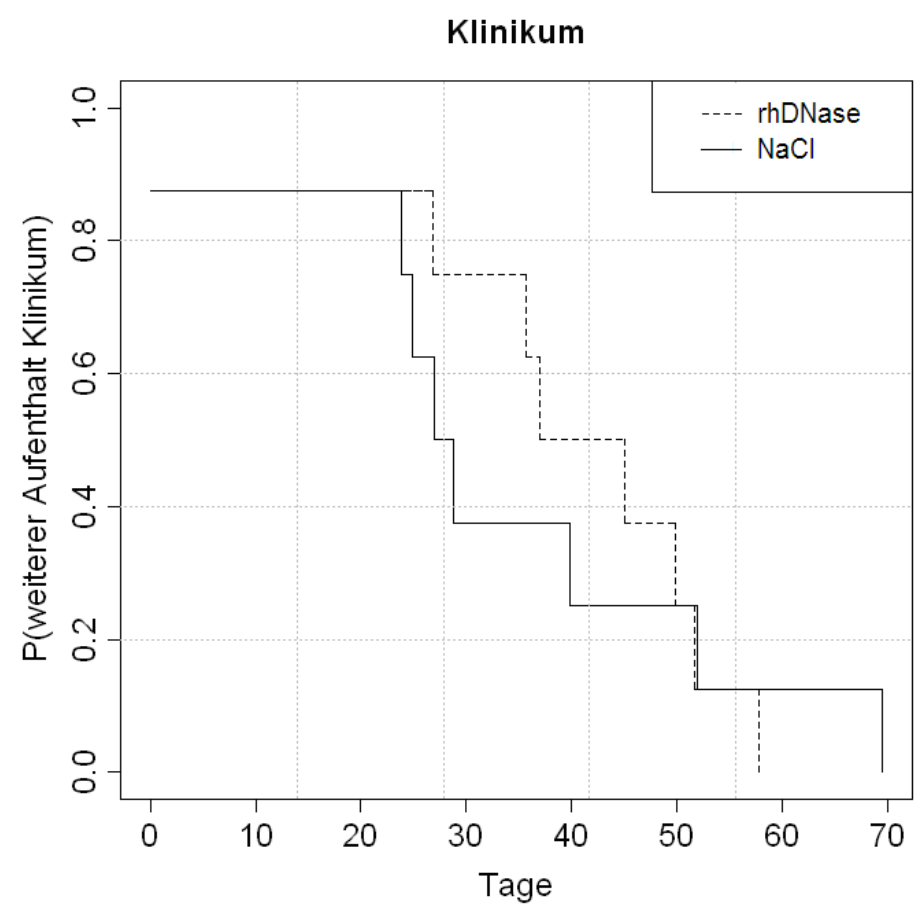

Abbildung 4.2.4/1.

Krankenhausaufenthaltsdauer in Tagen der rhDNase- und NaCl-Gruppe der Diagnosegruppe 3 des Zentrums 27 


\subsection{Erfassung der Wirksamkeit von rhDNase in vitro}

\subsubsection{Verringerung des DNA-Gehaltes und Verkürzung der DNA-Kettenlängen im Trachealsekret}

\subsubsection{DNA-Konzentration im Trachealsekret}

Die initiale DNA-Konzentration in der NaCl-Gruppe war höher als in der rhDNase-Gruppe $(0,80 \pm 0,29 \mathrm{mg} / \mathrm{ml}$ vs. 0,64 $\pm 0,42 \mathrm{mg} / \mathrm{ml})$. In beiden Gruppen zeichnete sich ein Abfall der DNA-Konzentration im Studienverlauf ab, wobei in der rhDNase-Gruppe unter der Therapie die DNA-Konzentration früher als in der NaCl-Gruppe abnahm (Behandlungseffekt: $p=0,02$ ) (s. Abb. 4.3.1.1/1).

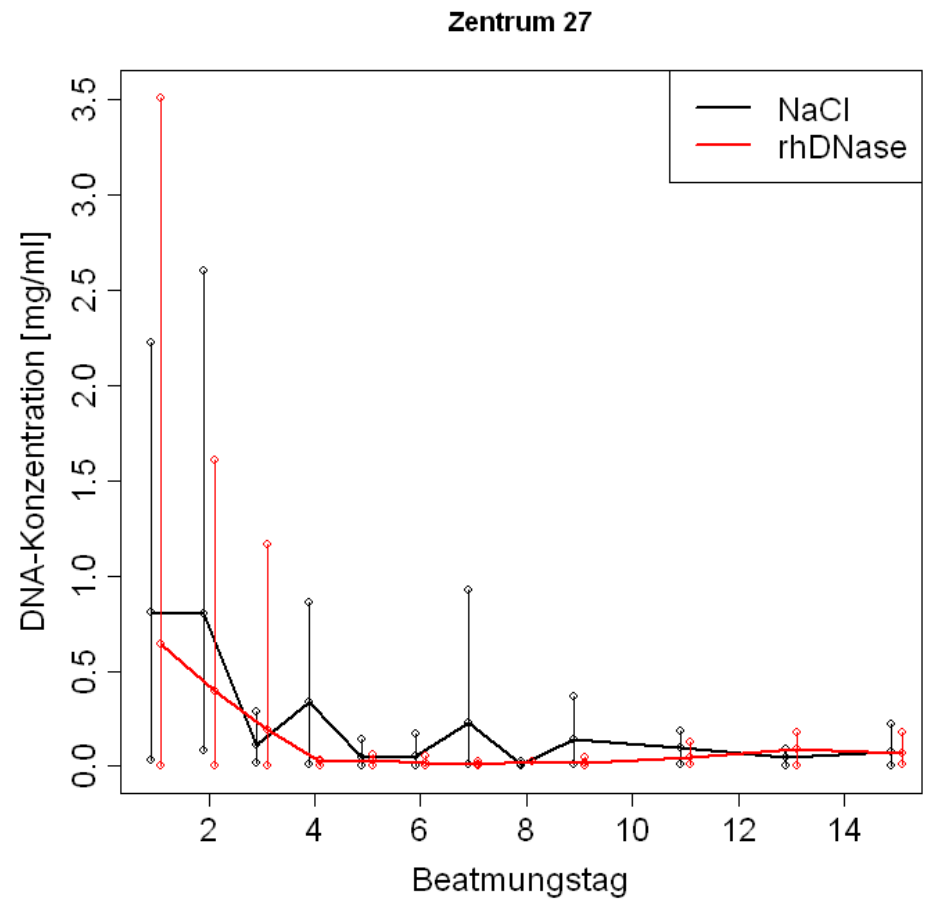

Abbildung 4.3.1.1/1.

DNA-Konzentration in $\mathrm{mg} / \mathrm{ml}$ im Trachealsekret der rhDNase- und NaCl-Gruppe der Diagnosegruppe 3 des Zentrums 27 


\subsubsection{DNA-Fragmente im Trachealsekret}

Die DNA-Fragmente wurden entsprechend ihrer kb-Größe und ihrer prozentualen Verteilung in DNA-Fragment-Kurven aufgetragen. Nach der Logarithmierung der kb-Größen auf der xAchse entstand eine Ausgleichsgerade, deren Steigung der Wirkung am Behandlungstag entsprach. Für jeden Studientag wurde ein Mittelwert der Steigungen der im Trachealsekret erhaltenen DNA-Fragmente der Gruppe nach errechnet. Am Studientag 1 enthielten die Patienten in der NaCl-Gruppe vermehrt längere DNA-Fragmente als die Patienten in der rhDNase-Gruppe $(0,16 \pm 0,04$ vs. $0,09 \pm 0,05)$, wenn auch in beiden Gruppen längere DNAFragmente überwogen. Mit der Zeit nahm in beiden Gruppen der Anteil der langkettigen DNA-Fragmente ab, dennoch enthielt das Trachealsekret der rhDNase-Patienten während des Studienzeitraumes mehr kürzere DNA-Fragmente als der Patienten in der NaCl-Gruppe (Behandlungseffekt: $\mathrm{p}<0,01$ ) (s. Abb. 4.3.1.2/1).

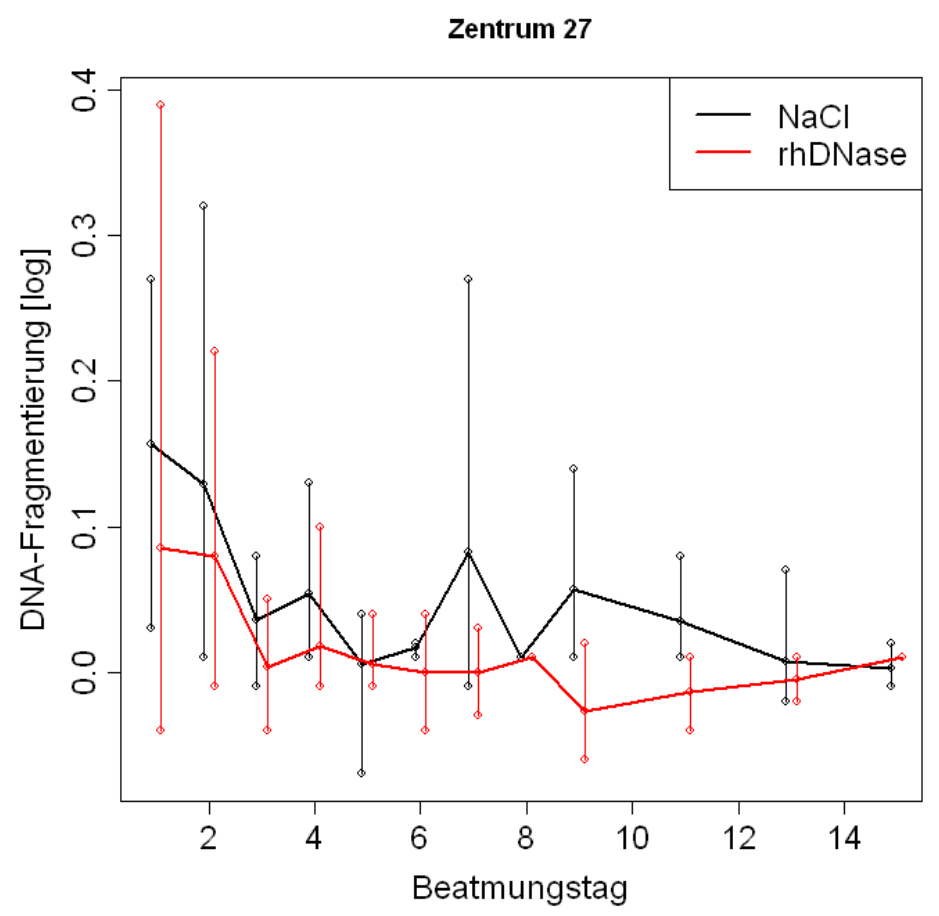

Abbildung 4.3.1.2/1.

DNA-Kettenlänge nach Logarithmierung im Trachealsekret der rhDNase- und NaCl-Gruppe der Diagnosegruppe 3 des Zentrums 27 


\subsubsection{Verminderung der Inflammation}

\subsubsection{Anzahl der Leukozyten im Trachealsekret}

Am Studienbeginn wiesen die Patienten in der NaCl-Gruppe eine größere Leukozytenzahl im Trachealsekret auf als die rhDNase-Patienten $\left(65 \pm 24,60 \times 10^{3} / \mu 1\right.$ vs. $\left.38 \pm 18,54 \times 10^{3} / \mu 1\right)$. Während des Studienzeitraumes fielen die Werte in beiden Gruppen mit der Zeit ab und erreichten bereits am Studientag 3 ähnlich hohe Leukozytenkonzentrationen. Eine Verringerung der Leukozytenzahl als Folge der rhDNase-Therapie ließ sich nicht nachweisen (Behandlungseffekt: $\mathrm{p}=0,99)$ (s. Abb. 4.3.2.1/1).

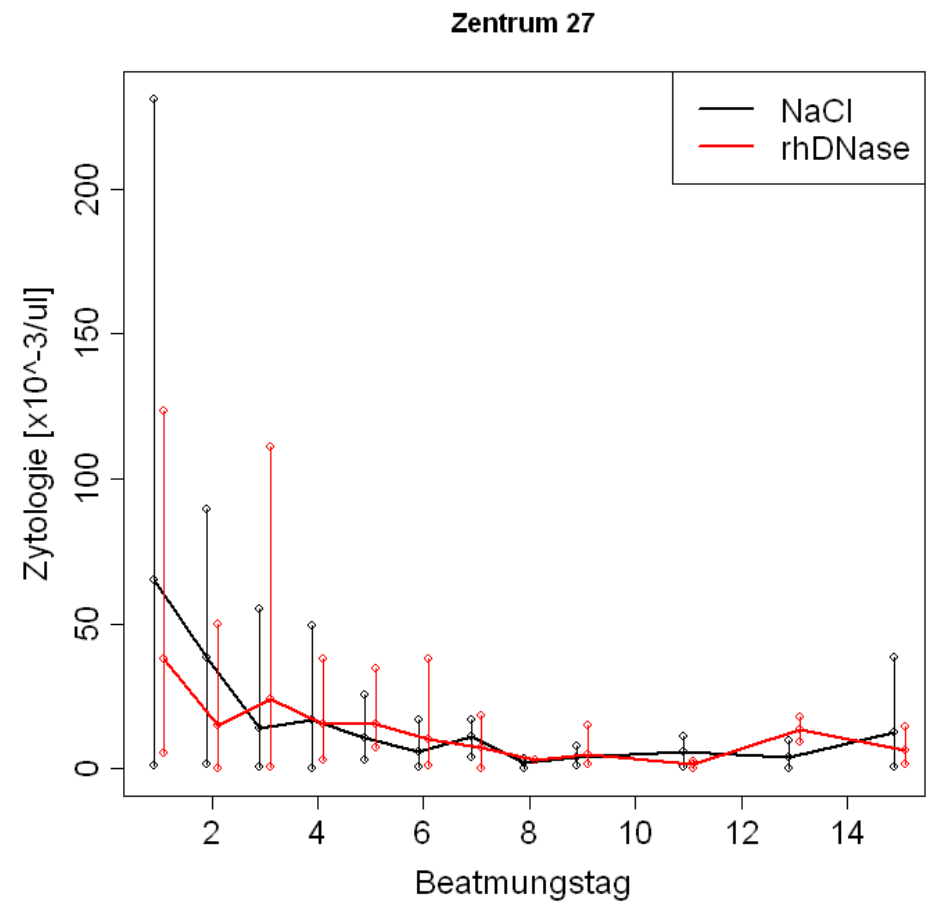

Abbildung 4.3.2.1/1.

Leukozytenzahl im Trachealsekret der rhDNase- und NaCl-Gruppe der Diagnosegruppe 3 des Zentrums 27 


\subsubsection{Senkung der Zytokinkonzentration im Trachealsekret}

\subsubsection{1}

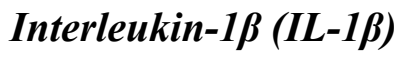

Der mittlere IL-1 $\beta$-Wert betrug am 1. Studientag bei den Patienten in der NaCl-Gruppe $40.440 \pm 25.153 \mathrm{pg} / \mathrm{ml}$ im Vergleich zu $30.984 \pm 21.721 \mathrm{pg} / \mathrm{ml}$ in der rhDNase-Gruppe. Die IL-1 $\beta$-Konzentration verringerte sich mit der Zeit in beiden Gruppen, jedoch nicht signifikant unterschiedlich in der rhDNase-Gruppe in Folge der Therapie (Behandlungseffekt: $p=0,71$ ). Am 5. Studientag wiesen beide Gruppen dem Gesamttrend abweichende Werte auf (s. Abb. 4.3.2.2.1/1).

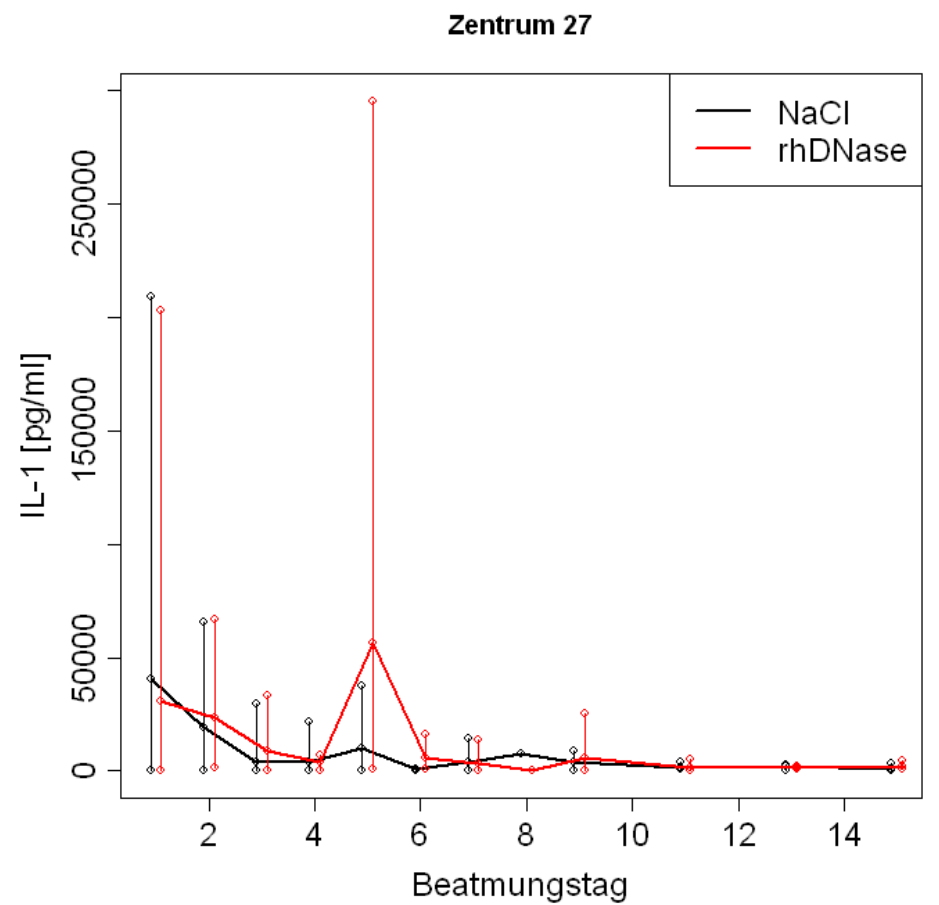

Abbildung 4.3.2.2.1/1.

IL-1 $\beta$-Konzentration im Trachealsekret der rhDNase- und NaCl-Gruppe der Diagnosegruppe 3 des Zentrums 27 


\subsection{Interleukin-6 (IL-6)}

Am Studienbeginn wiesen die rhDNase-Gruppe eine mittlere IL-6-Konzentration von 1.315 $\pm 910,33 \mathrm{pg} / \mathrm{ml}$ bzw. die NaCl-Gruppe von $469 \pm 259,04 \mathrm{pg} / \mathrm{ml}$ auf. In der NaCl-Gruppe nahm die IL-6-Menge im Trachealsekret schwankend vom Beginn an zu. Die IL-6- Konzentration in der rhDNase-Gruppe blieb trotz periodischen Schwankungen nahezu unverändert. Jedoch ließ sich kein Therapieeffekt beobachten (Behandlungseffekt: $p=0,59)(s$. Abb. 4.3.2.2.2/1).

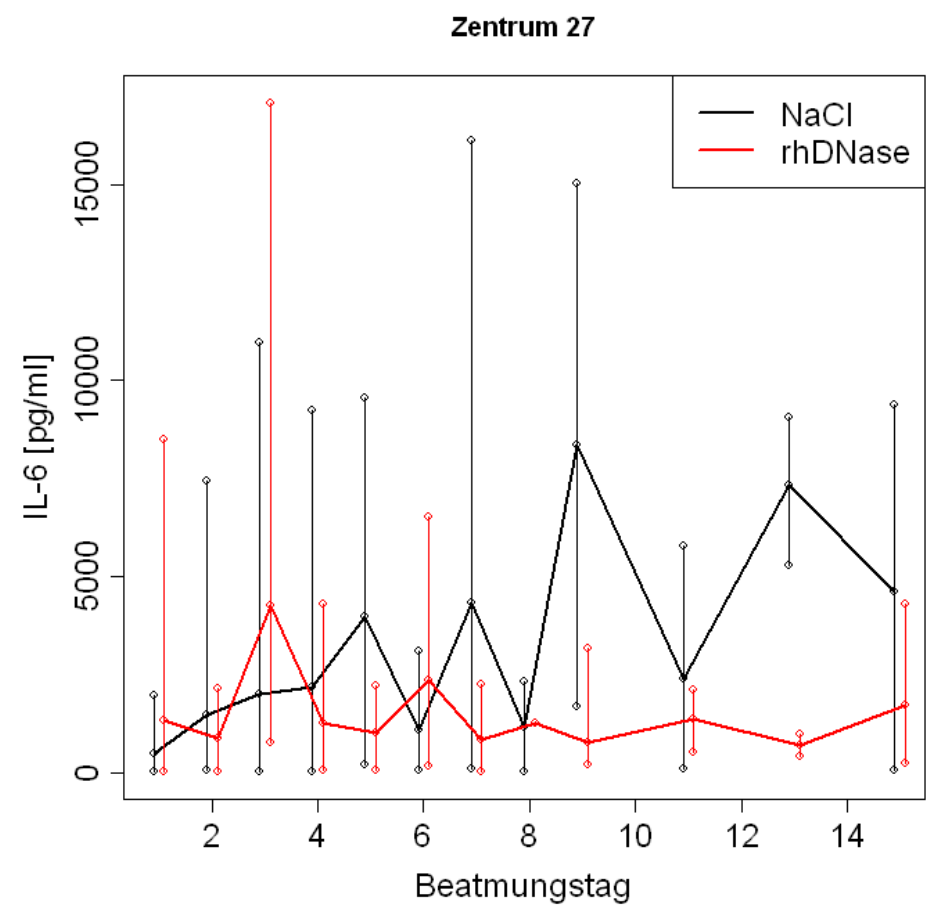

Abbildung 4.3.2.2.2/1.

IL-6-Konzentration im Trachealsekret der rhDNase- und NaCl-Gruppe der Diagnosegruppe 3 des Zentrums 27 


\subsection{Interleukin-8 $(I L-8)$}

In der rhDNase-Gruppe wies das Trachealsekret sehr voneinander abweichende IL-8Konzentration im Laufe der Studie auf, so dass keinen Trend festzustellen war. Hingegen zeigte das Trachealsekret der NaCl-Gruppe ab dem 2. Studientag eine Tendenz der Konzentrationsreduktion. Ab dem 11. Studientag begann die IL-8-Konzentration anzusteigen. Dessen ungeachtet wurde keine Auswirkung der rhDNase-Verabfolgung auf die IL-8Konzentration festgestellt (Behandlungseffekt: $\mathrm{p}=0,63$ ) (s. Abb. 4.3.2.2.3/1).

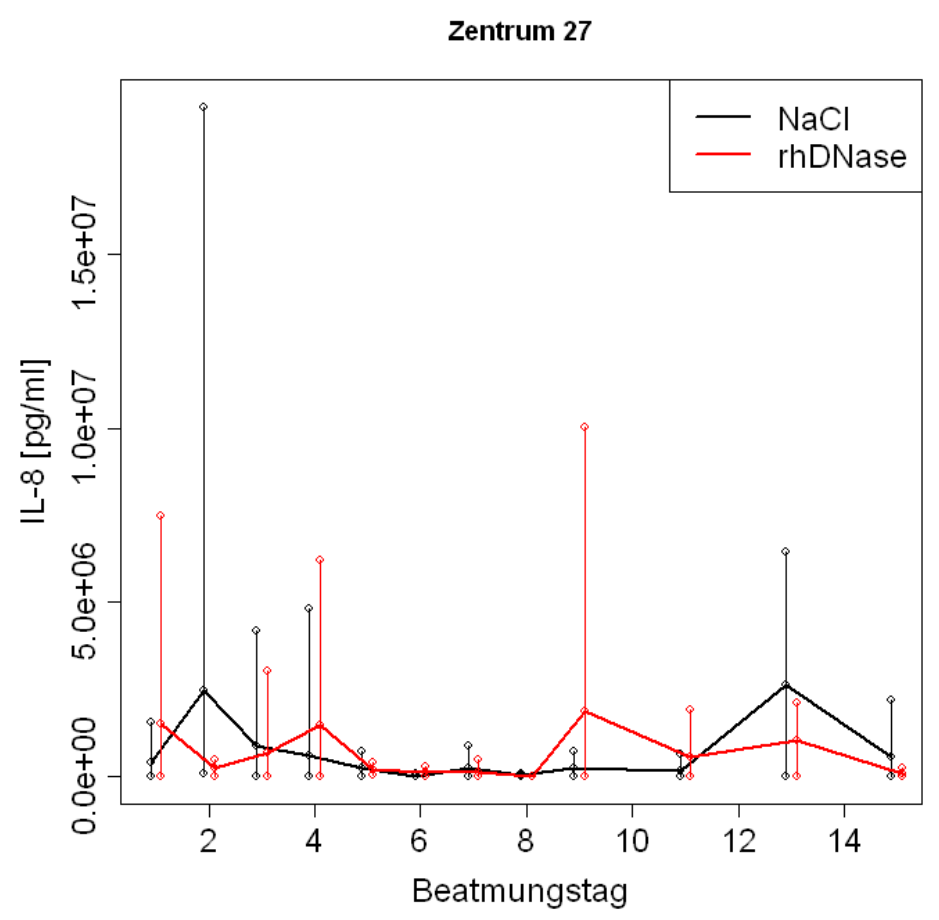

Abbildung 4.3.2.2.3/1.

IL-8-Konzentration im Trachealsekret der rhDNase- und NaCl-Gruppe der Diagnosegruppe 3 des Zentrums 27 


\subsection{Interleukin-10 (IL-10)}

In beiden Gruppen schwankte die IL-10-Konzentration im Laufe der Studie. Die rhDNaseGruppe wies an den meisten Studientagen höheren IL-10-Spiegel als die NaCl-Gruppe auf, dennoch war dieser Unterschied nicht signifikant (Behandlungseffekt: $p=0,55$ ) (s. Abb. 4.3.2.2.4/1).

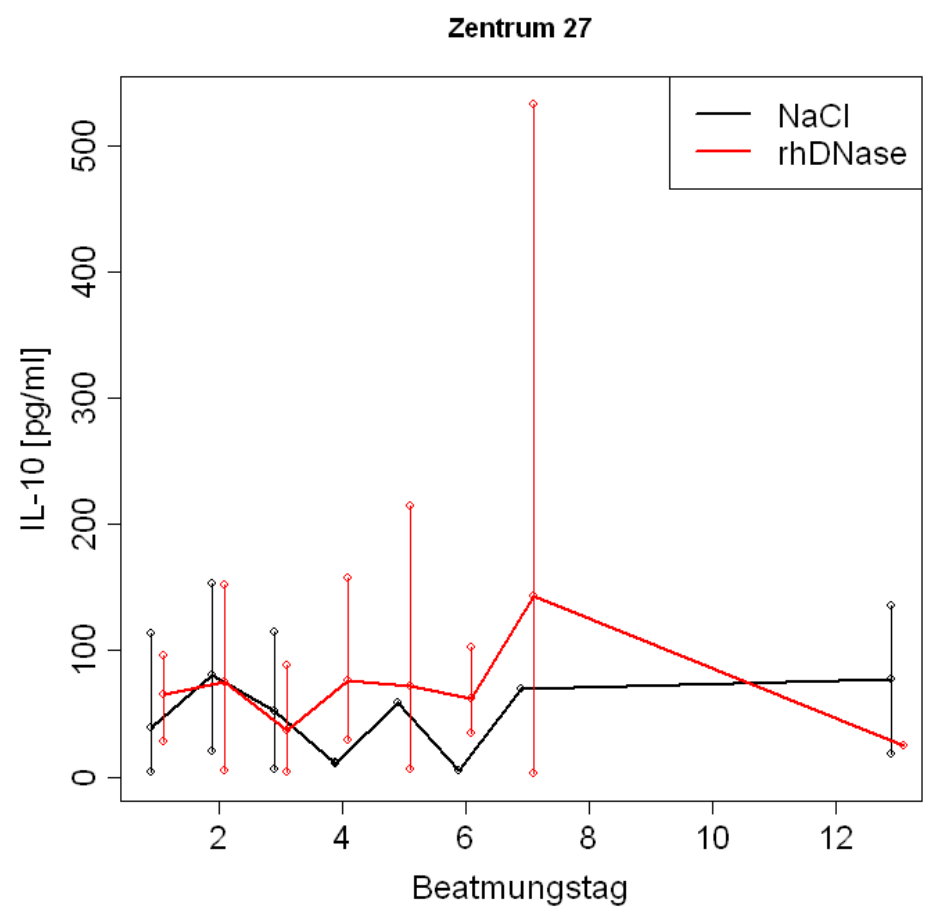

Abbildung 4.3.2.2.4/1.

IL-10-Konzentration im Trachealsekret der rhDNase- und NaCl-Gruppe der Diagnosegruppe 3 des Zentrums 27 


\subsubsection{5}

Lipopolysaccharidbindendes Protein (LBP)

Am ersten Studientag wies das Trachealsekret der rhDNase-Gruppe eine mittlere LBPKonzentration von $563 \pm 470,84 \mathrm{ng} / \mathrm{ml}$ auf, bei einer mittleren LBP-Konzentration von $40 \pm$ 20,4 $\mathrm{ng} / \mathrm{ml}$ in der NaCl-Gruppe. Der LBP-Spiegel in der rhDNase-Gruppe zeigte eine Tendenz zur Reduktion, wogegen in der NaCl-Gruppe die LBP-Konzentration den gegenläufigen Verlauf verzeichnete, sie nahm zu. Trotzdem unterschieden sich die Gruppen nicht (Behandlungseffekt: $\mathrm{p}=0,50)$ (s. Abb. 4.3.2.2.5/1).

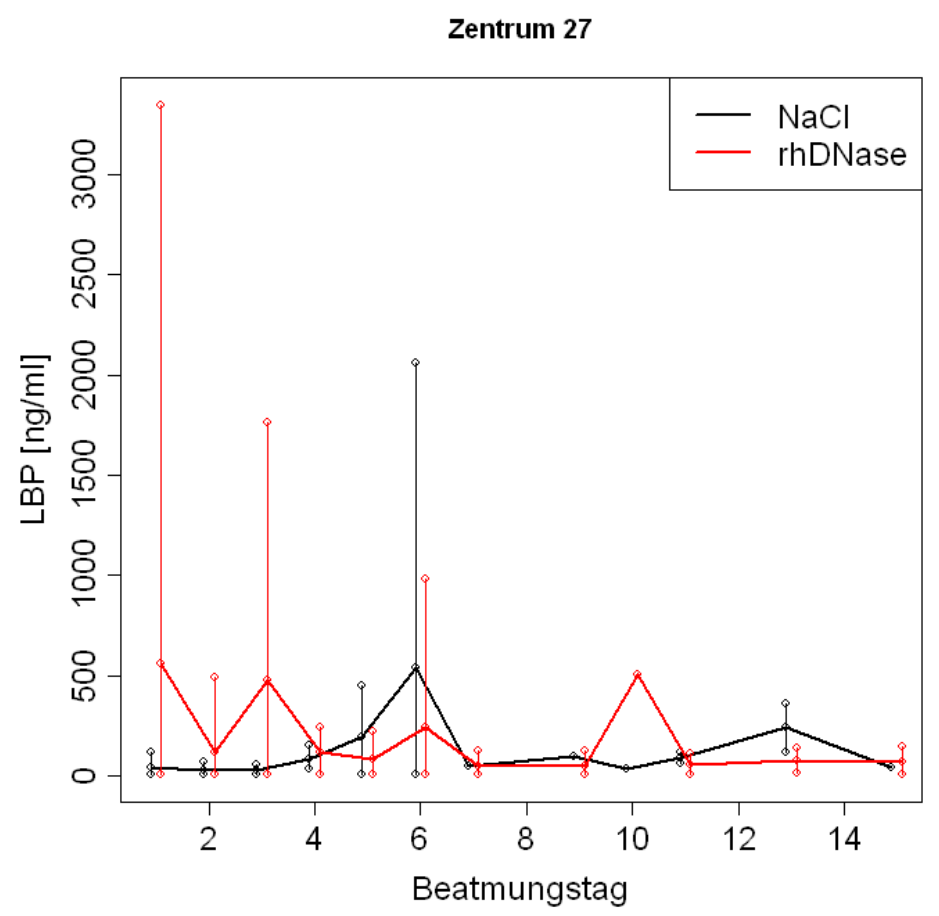

\section{Abbildung 4.3.2.2.5/1.}

LBP-Konzentration im Trachealsekret der rhDNase- und NaCl-Gruppe der Diagnosegruppe 3 des Zentrums 27 
4.3.2.2.6

Granulozyten-Makrophagen-Kolonienstimulierender Faktor

(GM-CSF)

Die gemessene Konzentration vom GM-CSF im Trachealsekret war initial und im gesamten Verlauf in der rhDNase-Gruppe höher als in der NaCl-Gruppe (s. Abb. 4.3.2.2.6/1). In beiden Gruppen zeigte die GM-CSF-Konzentration eine Tendenz zur Reduktion. Dennoch ließ sich die Veränderung nicht auf die Therapie mit rhDNase zurückzuführen (Behandlungseffekt: $\mathrm{p}=0,32$ ).

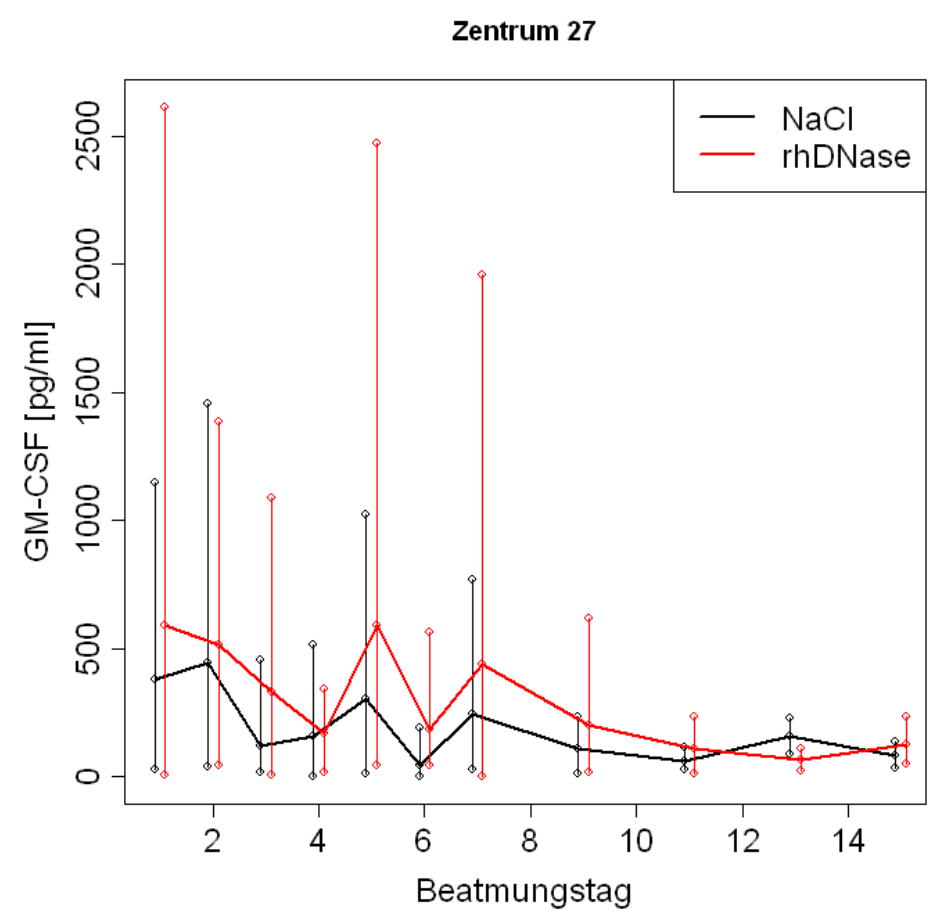

Abbildung 4.3.2.2.6/1.

GM-CSF-Konzentration im Trachealsekret der rhDNase- und NaCl-Gruppe der Diagnosegruppe 3 des Zentrums 27 


\subsection{Erfassung der klinischen Wirksamkeit von rhDNase im Vergleich zur modifizierten Gruppe 3 der Lufit-Studie}

In der modifizierten Gruppe 3 (Gruppe 3 ohne Göttinger Arm) standen 125 Patienten zur Auswertung. Der rhDNase-Gruppe waren 60 Patienten und der NaCl-Gruppe 65 Patienten zuzuordnen.

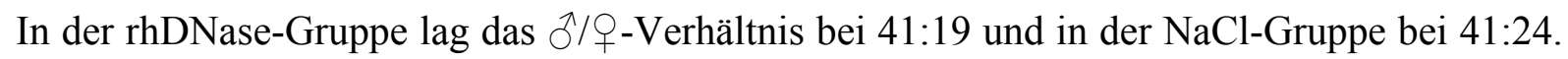
Das mediane Alter in der rhDNase-Gruppe lag bei 64,8 Jahren [48,9; 70] und in der NaClGruppe bei 69 Jahren [58,8; 75,8] (Median; 25Q; 75Q).

Unter den Patienten der rhDNase-Gruppe der modifizierten Gruppe 3 (mod. Gruppe 3) litten 19 Patienten an einer Pneumonie, 13 Patienten an Erkrankungen der inneren Organe, 13 Patienten an Erkrankungen des Nervensystems, 10 Patienten an Erkrankungen der HerzThorax-Gefäße bzw. 5 Patienten an einer Sepsis. Mit 31,7 \% überwog der Anteil der Patienten mit Pneumonie.

In der NaCl-Gruppe bestand die Beatmungsnotwendigkeit aufgrund der Pneumonie bei 21 Patienten. Es folgten Erkrankungen der inneren Organe bei 10 Patienten, Erkrankungen der Herz-Thorax-Gefäße bei 11 Patienten, Erkrankungen des Nervensystems bei 16 Patienten, Sepsis und chirurgische Eingriffe bei 2 Patienten. Der Anteil der Patienten mit Pneumonie lag bei $32,3 \%$.

Mit 24,6\% war der Anteil der neurologischen Patienten in der NaCl-Gruppe größer als 21,7\% in der rhDNase-Gruppe.

18 Patienten der rhDNase-Gruppe und 20 Patienten der NaCl-Gruppe litten begleitend zur ihren Grunderkrankung an COPD.

Sowohl in der rhDNase-Gruppe als auch in der NaCl-Gruppe verstarben 10 Patienten.

In der rhDNase-Gruppe wurden 13 Patienten und in der NaCl-Gruppe 26 Patienten tracheotomiert. 


\subsubsection{Beatmungsdauer}

In Folge der externen Verlegung, Operation während der Studie oder Tod wurden in der rhDNase-Gruppe nur 46 Patienten und in der NaCl-Gruppe 51 Patienten der mod. Gruppe 3 ausgewertet. Bei allen Patienten, die tatsächlich länger als 21 Tage beatmet waren, wurde aufgrund der definierten Studiendauer von 21 Tagen, eine Beatmungsdauer von 21 Tagen festgelegt.

RhDNase-Gruppenvergleich wie auch NaCl-Gruppenvergleich ergaben eine längere Beatmungsdauer der Patienten des Zentrums 27 als in der mod. Gruppe 3 (s. Abb. 4.4.1/1 und 4.4.1/2). Die mediane Beatmungsdauer in der mod. Gruppe 3 lag bei 6,5 Tagen in der rhDNase-Gruppe und bei 11 Tagen in der NaCl-Gruppe. Zwischen den rhDNase-Gruppen [mod. Gruppe 3 vs. Zentrum 27] erwies sich der Unterschied in der Beatmungsdauer im Gegensatz zu NaCl-Gruppen (Gruppeneffekt: $p=0,69$ ) als signifikant (Gruppeneffekt: $\mathrm{p}=0,02)$.

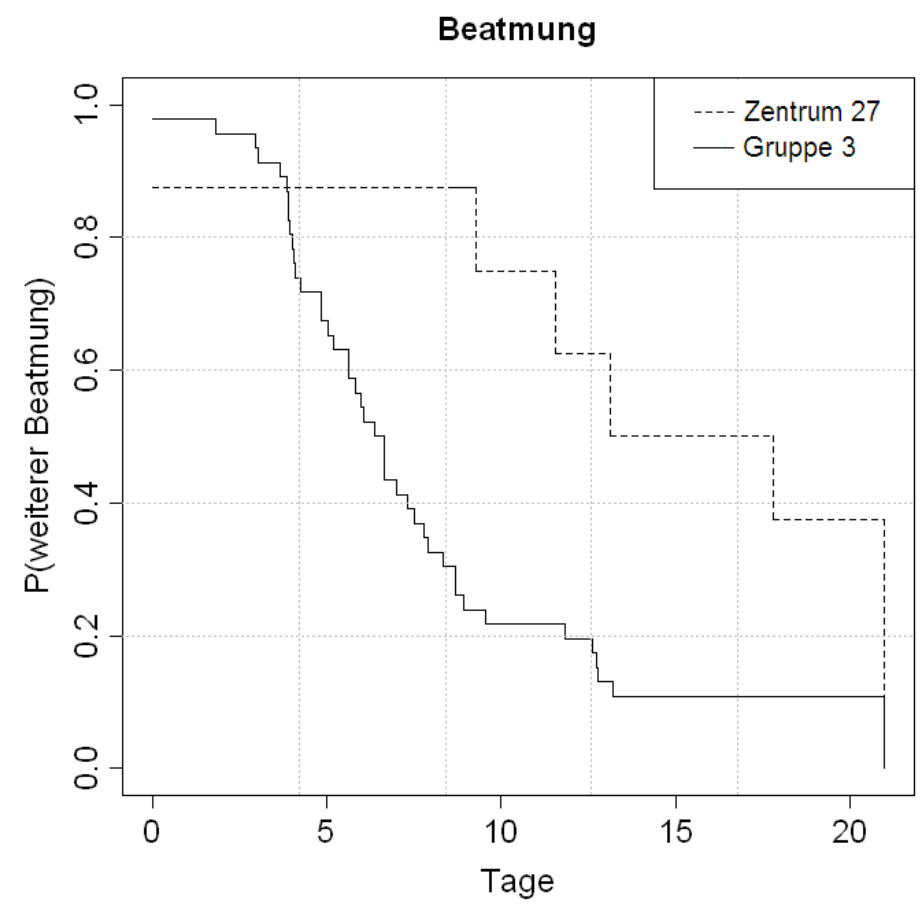

\section{Abbildung 4.4.1/1.}

Vergleich der Beatmungsdauer in Tagen zwischen den rhDNase-Gruppen des Zentrums 27 und der mod. Gruppe 3 


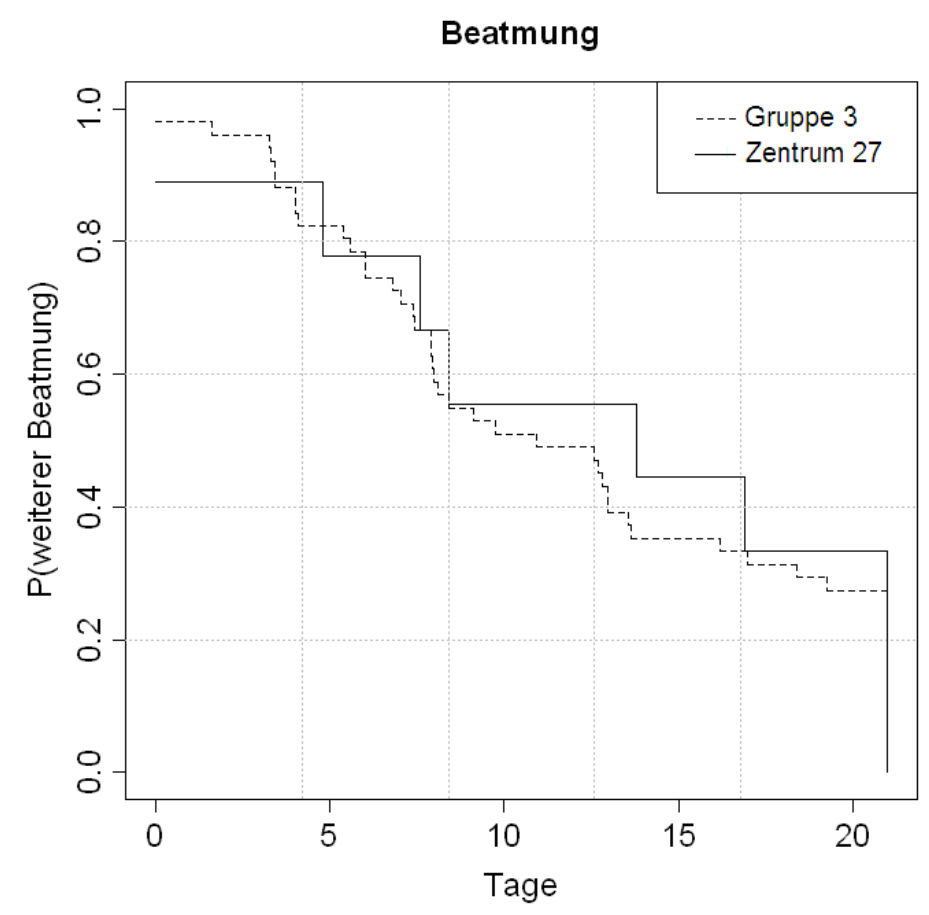

Abbildung 4.4.1/2.

Vergleich der Beatmungsdauer in Tagen zwischen den NaCl-Gruppen des Zentrums 27 und der mod. Gruppe 3 


\subsubsection{Verbesserung der Lungenfunktionsparameter}

\subsubsection{Sauerstofffraktions $\left(\mathrm{FiO}_{2}\right)$-Bedarf}

Beim Vergleich des Sauerstoffbedarfs in der Einatemluft zwischen den rhDNase-Gruppen des Zentrums 27 und der mod. Gruppe 3 wurde kein Unterschied festgestellt (Gruppeneffekt: $\mathrm{p}=$ 0,48). Trotz eines leichten Anstieges zu Beginn der Studie blieb der $\mathrm{FiO}_{2}-$ Bedarf im Zentrum 27 kaum verändert, während in der mod. Gruppe 3 der $\mathrm{FiO}_{2}-$ Bedarf leicht abnahm (s. Abb. 4.4.2.1/1).

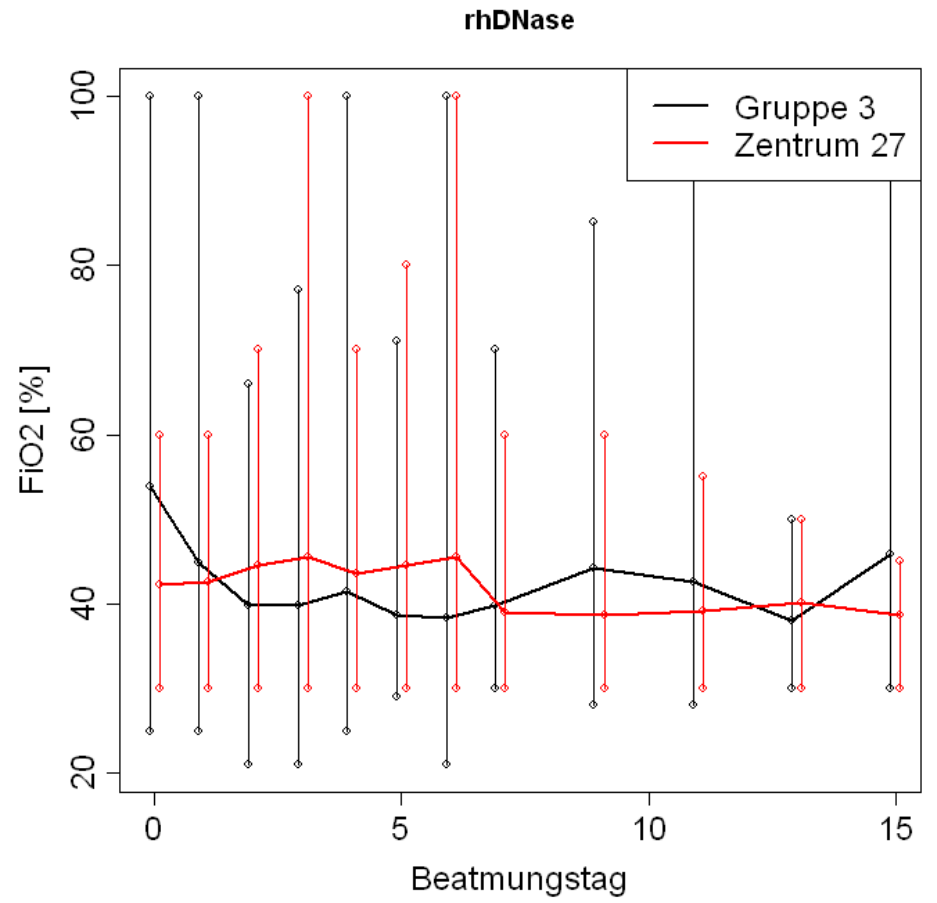

Abbildung 4.4.2.1/1.

Vergleich des täglichen $\mathrm{FiO}_{2}$-Bedarfs zwischen den rhDNase-Gruppen des Zentrums 27 und der mod. Gruppe 3 
Der Vergleich der $\mathrm{NaCl}$-Gruppen ergab, dass sich der $\mathrm{FiO}_{2}$-Bedarf in beiden Gruppen im Verlauf verringerte, wobei die NaCl-Gruppe des Zentrums 27 durchgehend einen niedrigeren $\mathrm{FiO}_{2}$-Bedarf aufwies. Der Unterschied zwischen den beiden Gruppen erwies sich als signifikant (Gruppeneffekt: $\mathrm{p}<0,01$ ) (s. Abb. 4.4.2.1/2.).

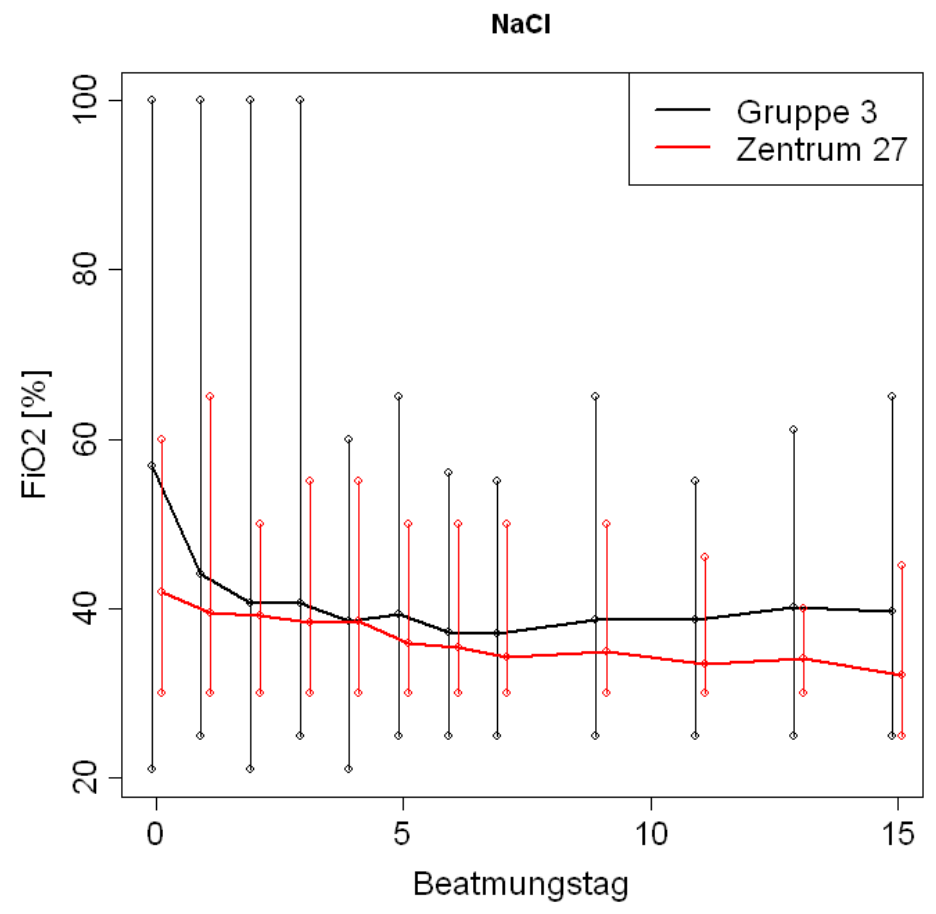

Abbildung 4.4.2.1/2.

Vergleich des täglichen $\mathrm{FiO}_{2}$-Bedarfs zwischen den NaCl-Gruppen des Zentrums 27 und der mod. Gruppe 3 


\subsubsection{Atemminutenvolumen (AMV)}

Am Studientag 0 bedurften die Patienten in der rhDNase-Gruppe der mod. Gruppe 3 ein höheres AMV als die Patienten in der rhDNase-Gruppe des Zentrums 27 (9,5 $\pm 0,361$ vs. 8,14 $\pm 0,70$ 1). Im Laufe der Studie blieb das AMV in der mod. Gruppe 3 fast unverändert, während das AMV im Zentrum 27 anstieg. Dennoch erreichte der Unterschied zwischen den „Verum“Gruppen kein Signifikanzniveau (Gruppeneffekt:p=0,96) (s. Abb. 4.4.2.2/1).

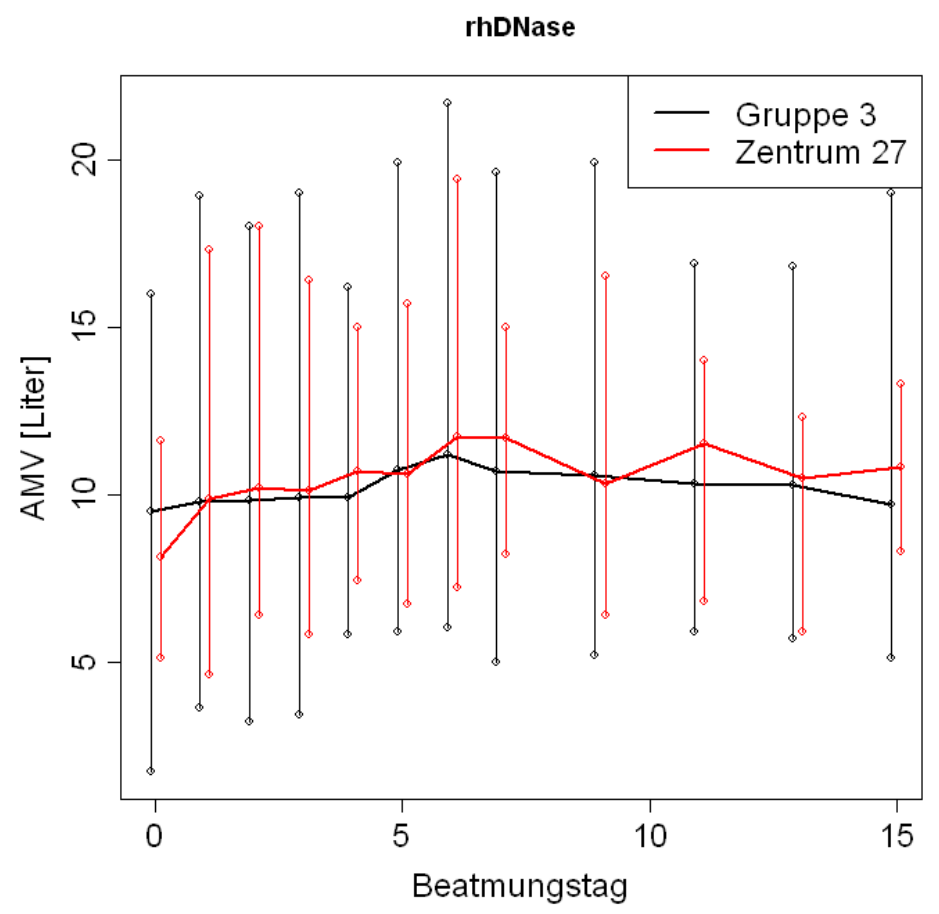

\section{Abbildung 4.4.2.2/1.}

Vergleich des täglichen AMV zwischen den rhDNase-Gruppen des Zentrums 27 und der mod. Gruppe 3 
Der Vergleich der beiden NaCl-Gruppen im Bezug auf AMV stellte keinen signifikanten Unterschied zwischen den Gruppen fest (Gruppeneffekt: $p=0,29$ ). Das AMV stieg in beiden Gruppen an, jedoch in der NaCl-Gruppe des Zentrums 27 erfolgte die Zunahme in höherem Maße als in der NaCl-Gruppe der mod. Gruppe 3 (s. Abb. 4.4.2.2/2).

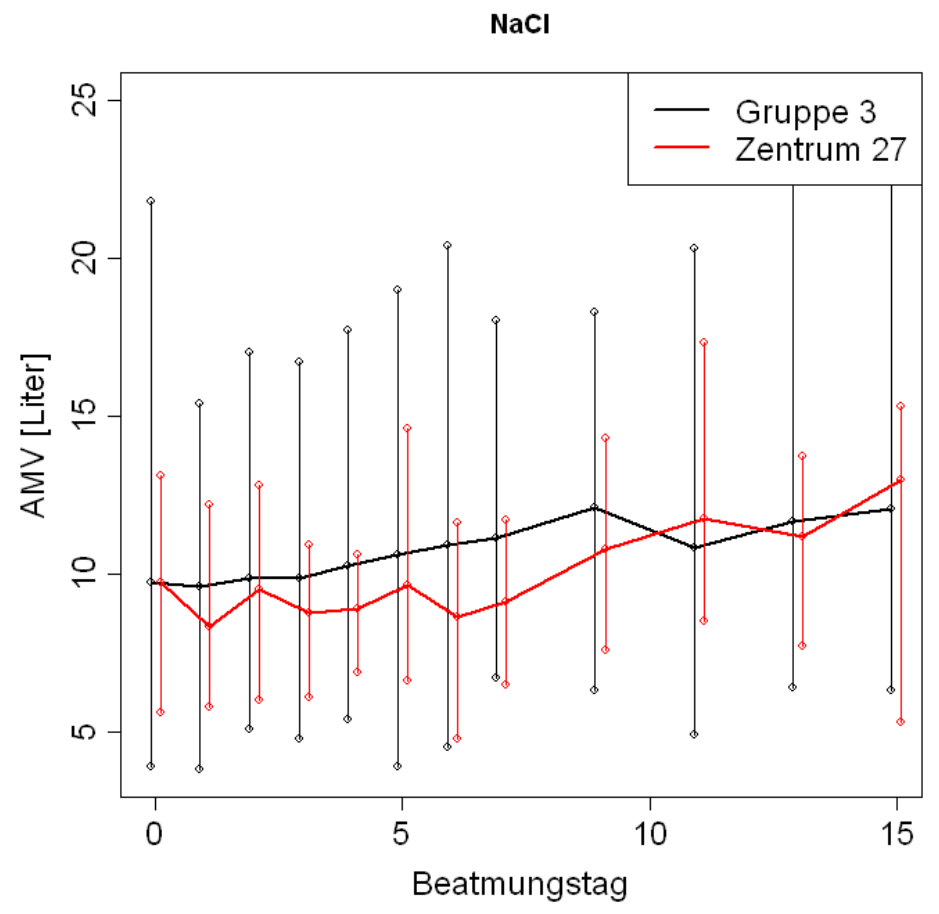

Abbildung 4.4.2.2/2.

Vergleich des täglichen AMV zwischen den NaCl-Gruppen des Zentrums 27 und der mod. Gruppe 3 


\subsubsection{Verkürzung des Aufenthaltes auf der Intensivstation}

Als Folge von externer Verlegung und Tod auf der Intensivstation nach Beendigung der Studie konnten die Daten von jeweils 40 Patienten in der rhDNase-Gruppe und in der NaClGruppe der mod. Gruppe 3 ausgewertet werden.

Die Patienten der rhDNase-Gruppe der mod. Gruppe 3 verbrachten im Median 11 Tage auf der Intensivstation, die Patienten der rhDNase-Gruppe des Zentrums 27 29,5 Tage. Dieser Unterschied zwischen den beiden rhDNase-Gruppen war signifikant (Gruppeneffekt: $\mathrm{p}<0,01)($ s. Abb. 4.4.3/1).

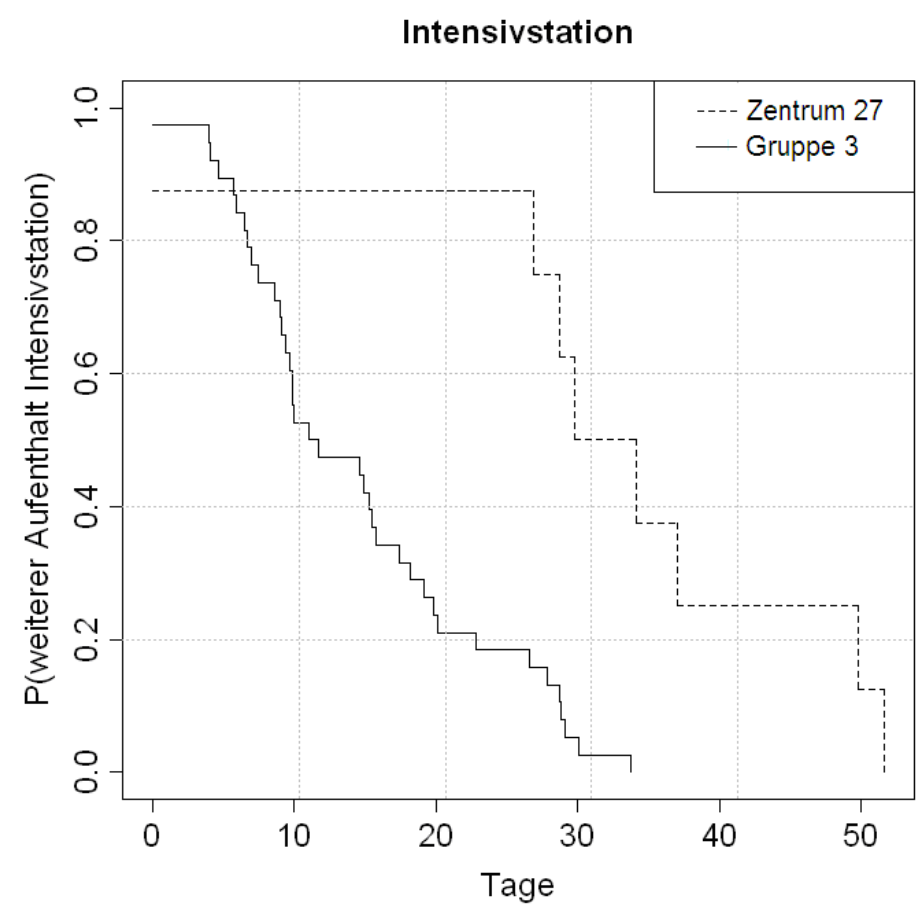

Abbildung 4.4.3/1.

Vergleich der intensivstationären Aufenthaltsdauer in Tagen zwischen den rhDNase-Gruppen des Zentrums 27 und der mod. Gruppe 3 
Die Patienten der NaCl-Gruppe der mod. Gruppe 3 verbrachten im Median 17,5 Tage auf der Intensivstation. Der Aufenthalt der Patienten der NaCl-Gruppe des Zentrums 27 war mit 23 Tagen ebenfalls deutlich länger. Dieser Unterschied verfehlte knapp das Signifikanzniveau, zeigte jedoch eine Tendenz in gleicher Richtung wie bei den rhDNase-Gruppen (Gruppeneffekt: $p=0,06$ ) (s. Abb. 4.4.3/2).

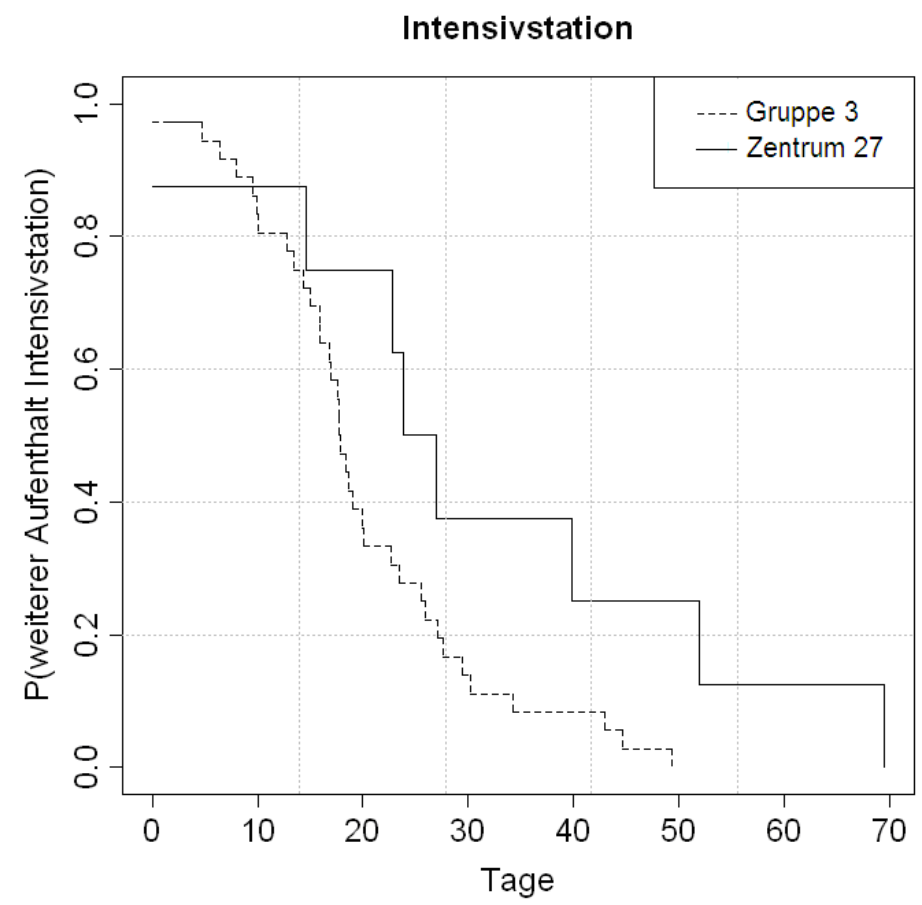

Abbildung 4.4.3/2.

Vergleich der intensivstationären Aufenthaltsdauer in Tagen zwischen den NaCl-Gruppen des Zentrums 27 und der mod. Gruppe 3 


\subsubsection{Verkürzung der Krankenhausaufenthaltsdauer}

Als Folge von externer Verlegung und Tod während des Krankenhausaufenthalts nach Beendigung der Studie konnten die Daten von 36 Patienten in der rhDNase-Gruppe und 39 Patienten in der NaCl-Gruppe der mod. Gruppe 3 ausgewertet werden.

Die Patienten der rhDNase-Gruppe der mod. Gruppe 3 hielten sich im Median 25 Tage im Krankenhaus auf. Der Krankenhausaufenthalt von Patienten der rhDNase-Gruppe des Zentrums 27 dauerte länger, nämlich 37 Tage. Dennoch erwies sich dieser Unterschied als nicht signifikant (Gruppeneffekt: $\mathrm{p}=0,14)$ (s. Abb. 4.4.4/1).

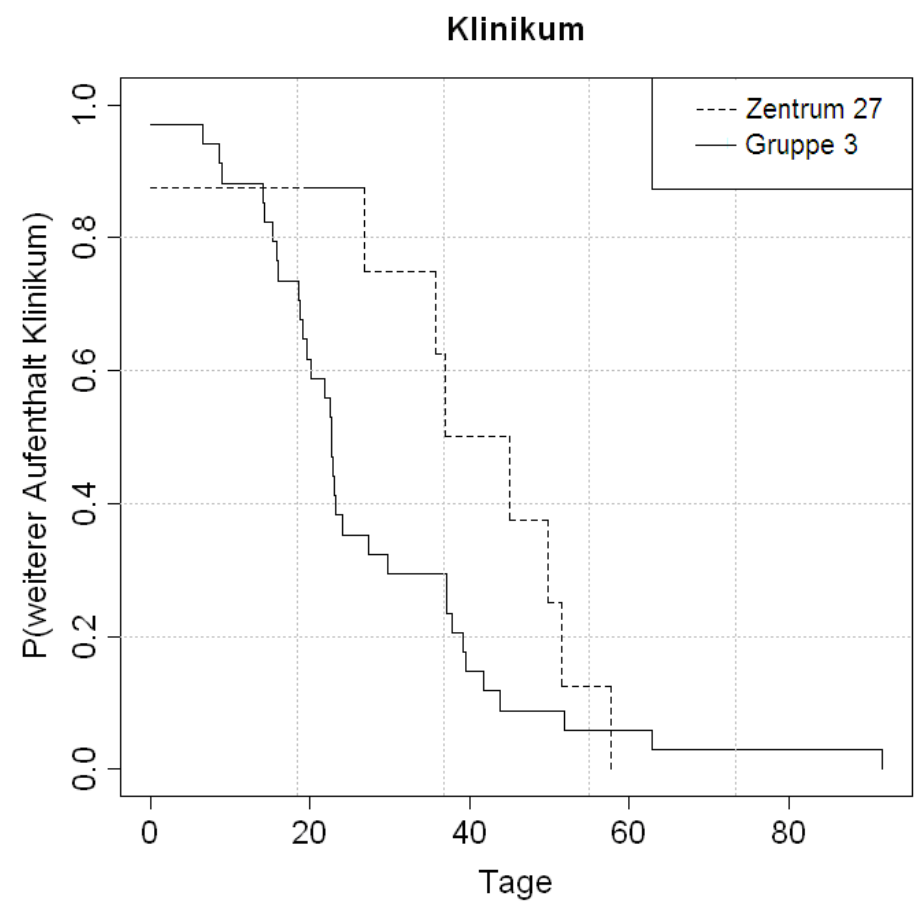

\section{Abbildung 4.4.4/1.}

Vergleich der Krankenhausaufenthaltsdauer in Tagen zwischen den rhDNase-Gruppen des Zentrums 27 und der mod. Gruppe 3 
Die mediane Krankenhausaufenthaltsdauer von Patienten der NaCl-Gruppen der mod. Gruppe 3 und des Zentrums 27 unterschied sich etwas voneinander (30 Tage vs. 26,6 Tage). Es wurde kein Signifikanzniveau erreicht (Gruppeneffekt: $p=0,62$ ) (s. Abb. 4.4.4/2).

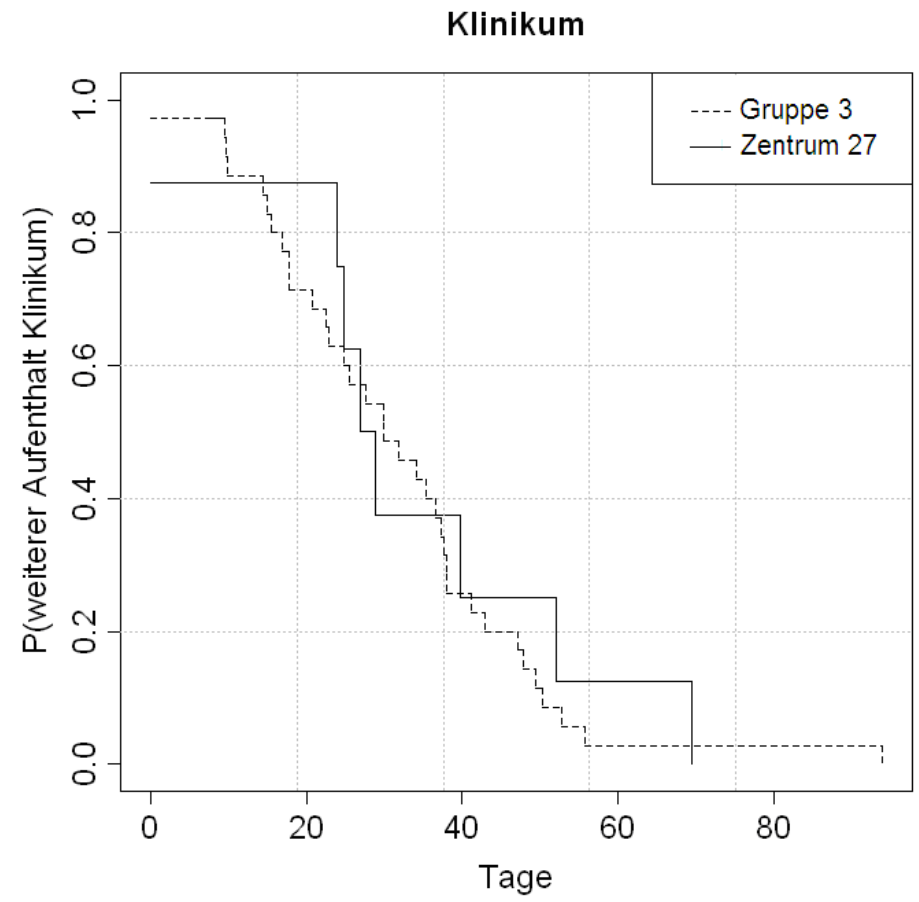

\section{Abbildung 4.4.4/2.}

Vergleich der Krankenhausaufenthaltsdauer in Tagen zwischen den NaCl-Gruppen des Zentrums 27 und der mod. Gruppe 3 
4.5 Erfassung der Wirksamkeit von rhDNase in vitro im Vergleich zur modifizierten Gruppe 3 der Lufit-Studie

\subsubsection{Verringerung des DNA-Gehaltes und Verkürzung der DNA-Kettenlängen im Trachealsekret im Vergleich}

\subsubsection{DNA-Konzentration im Trachealsekret}

Der Vergleich zwischen den rhDNase-Gruppen bezüglich der DNA-Konzentration ergab keinen Unterschied (Gruppeneffekt: $p=0,26$ ). Von anfänglich hohen Werten fiel die DNAKonzentration in beiden Gruppen im Studienverlauf ab. Am Studientag 3 unterschritt die DNA-Konzentration im Trachealsekret des Zentrums 27 die der mod. Gruppe 3 und wies anschließend kontinuierlich niedrigere Werte auf (s. Abb. 4.5.1.1/1).

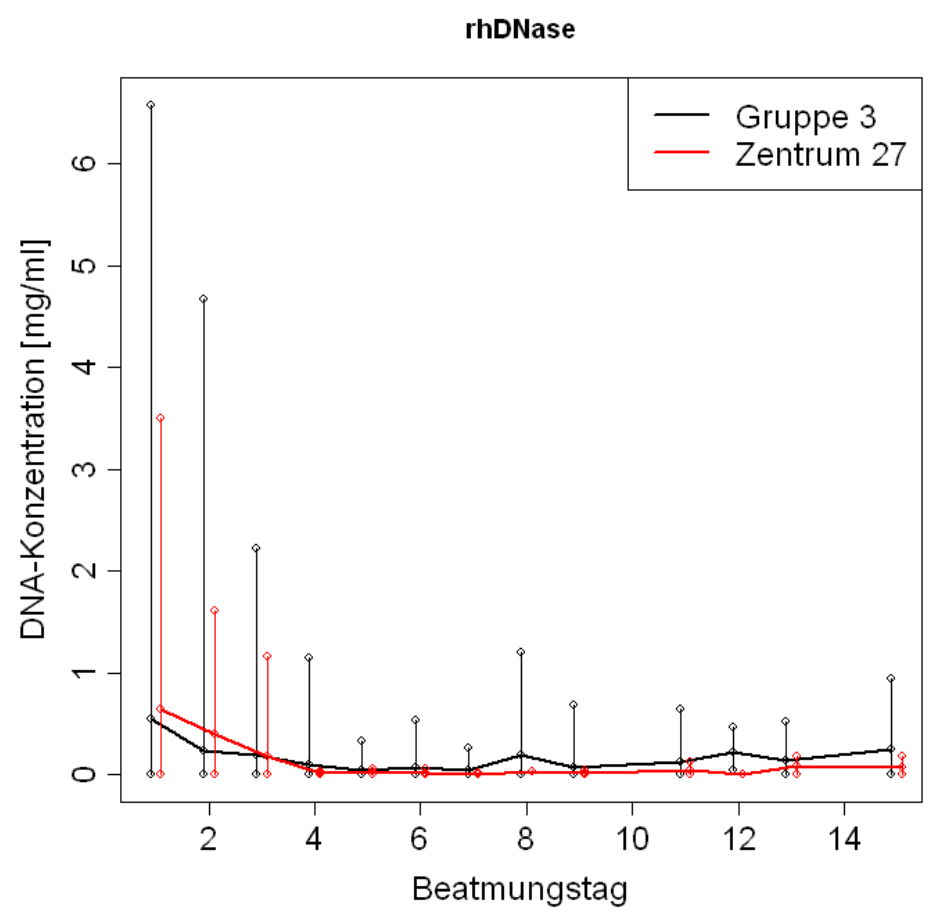

Abbildung 4.5.1.1/1.

Vergleich der DNA-Konzentration in $\mathrm{mg} / \mathrm{ml}$ im Trachealsekret zwischen den rhDNase-Gruppen des Zentrums 27 und der mod. Gruppe 3 
Im Studienverlauf zeigte die DNA-Konzentration in den NaCl-Gruppen neben einem Trend zur Verminderung der DNA-Konzentration starke Schwankungen. Trotz der anfänglich höheren DNA-Konzentration im Trachealsekret im Zentrum 27, verglichen mit der mod. Gruppe 3 blieb sie ab Studientag 3 unter dem DNA-Konzentrationsniveau der mod. Gruppe 3. Jedoch war der Unterschied nicht signifikant (Gruppeneffekt: $p=0,32$ ) (s. Abb. 4.5.1.1/2).

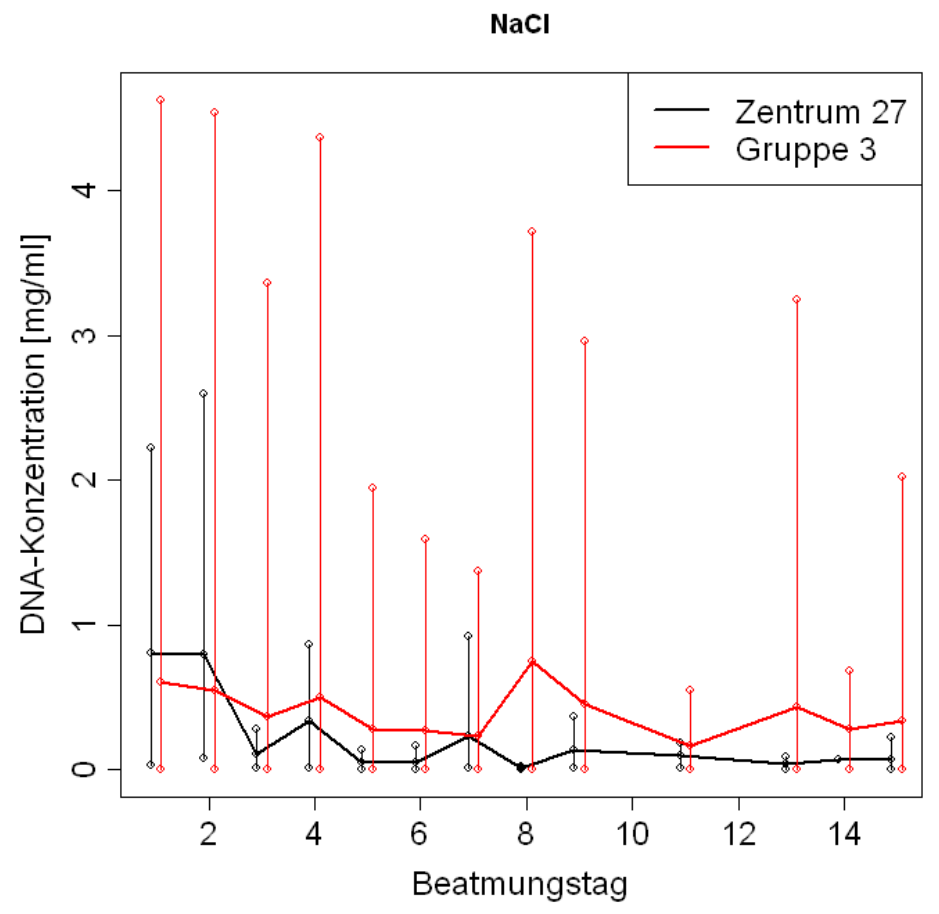

Abbildung 4.5.1.1/2.

Vergleich der DNA-Konzentration in $\mathrm{mg} / \mathrm{ml}$ im Trachealsekret zwischen den NaCl-Gruppen des Zentrums 27 und der mod. Gruppe 3 


\subsubsection{DNA-Fragmente im Trachealsekret}

Beim Vergleich der DNA-Kettenlängen in den rhDNase-Gruppen wiesen die beiden Gruppen den Trend zur Verkleinerung der DNA-Kettenlängen auf. Ab dem Studientag 3 enthielt das Trachealsekret des Zentrums 27 kontinuierlich mit wenigen Ausnahmen mehr kürzere DNAFragmente als im Trachealsekret der mod. Gruppe 3. Dennoch bestand kein Unterschied zwischen den Gruppen (Gruppeneffekt: $p=0,92)(\mathrm{s}$. Abb. 4.5.1.2/1).

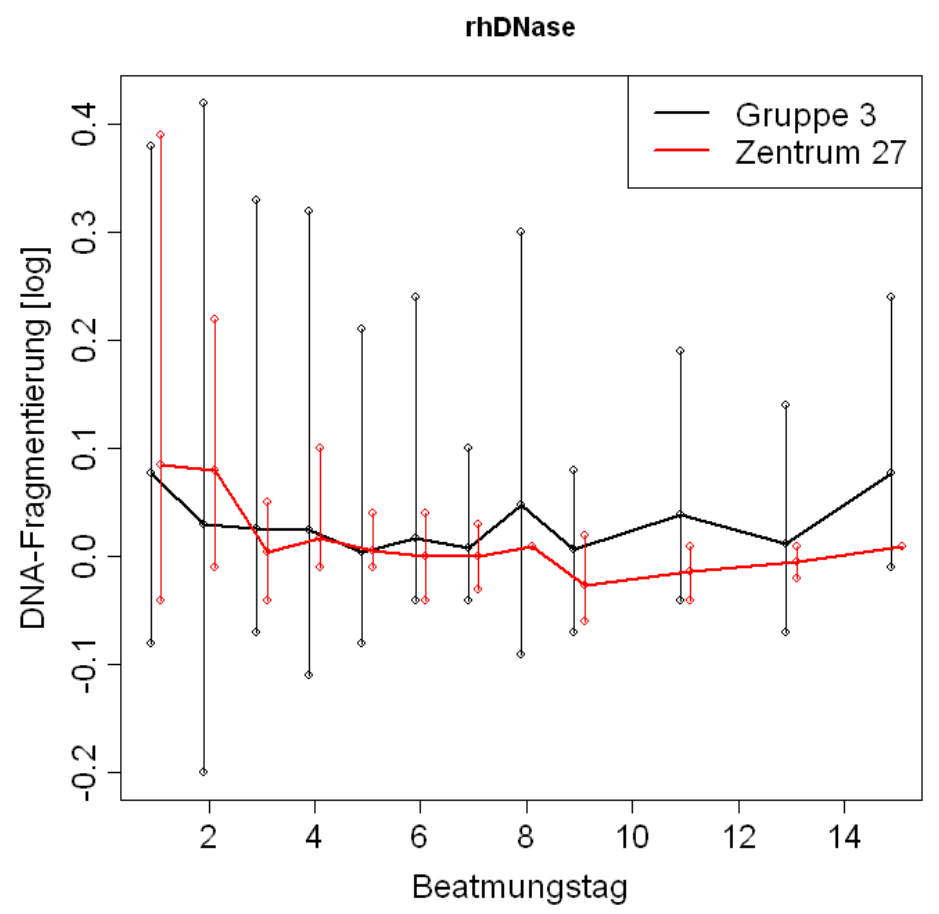

Abbildung 4.5.1.2/1.

Vergleich der DNA-Kettenlängen nach Logarithmierung im Trachealsekret zwischen den rhDNaseGruppen des Zentrums 27 und der mod. Gruppe 3 
Bei der Gegenüberstellung der DNA-Kettenlängen in den NaCl-Gruppen zeichnete sich ein signifikanter Unterschied zwischen den Gruppen ab (Gruppeneffekt: $p=0,03$ ). Trotz des anfänglich größeren Anteils von langen DNA-Fragmenten in der NaCl-Gruppe des Zentrums 27 enthielt das Trachealsekret ab dem Studientag 3 eine höhere Anzahl kürzeren DNAFragmente als in der mod. Gruppe 3. In der NaCl-Gruppe der mod. Gruppe 3 verkürzte sich die DNA-Kettenlänge trotz Schwankungen im Laufe der Studie minimal (s. Abb. 4.5.1.2/2).

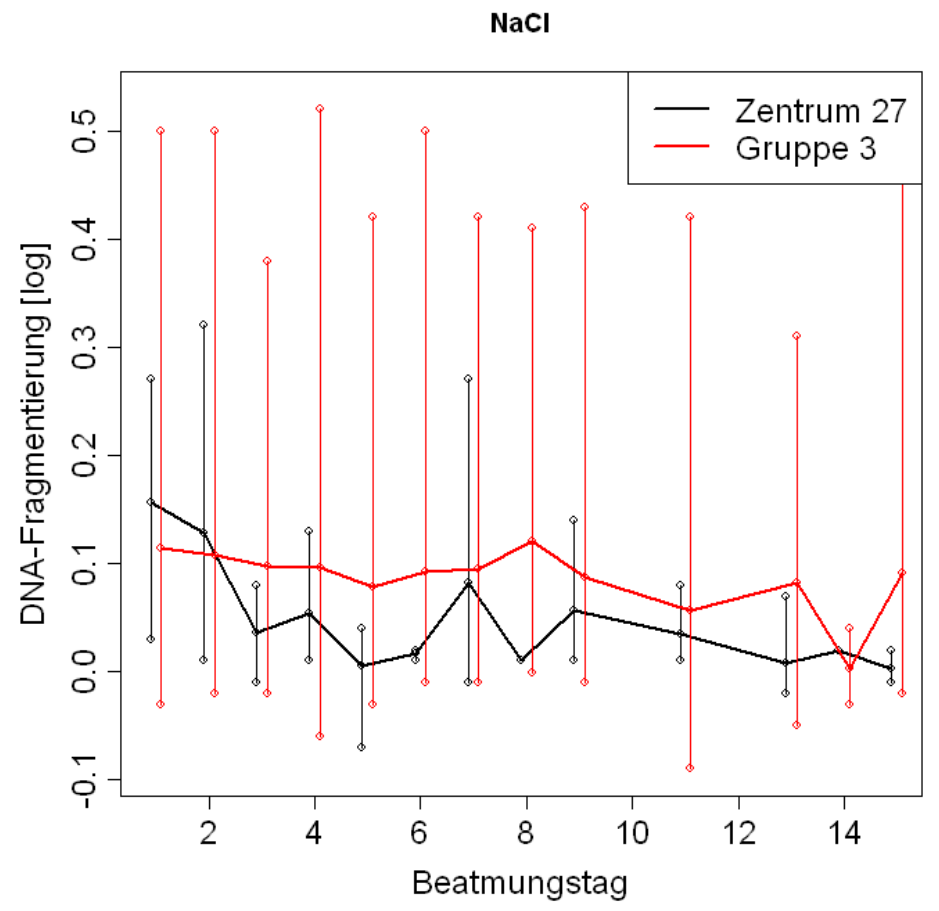

Abbildung 4.5.1.2/2.

Vergleich der DNA-Kettenlängen nach Logarithmierung im Trachealsekret zwischen den $\mathrm{NaCl}$ Gruppen des Zentrums 27 und der mod. Gruppe 3 


\subsubsection{Verminderung der Inflammation}

\subsubsection{Die Anzahl der Leukozyten im Trachealsekret}

Am ersten Studientag herrschte im Trachealsekret der beiden rhDNase-Gruppen eine identische Leukozytenzahl $\left(39 \pm 7,97 \times 10^{3} / \mu 1\right.$ vs. $38 \pm 18,54 \times 10^{3} / \mu 1$; [mod. Gruppe 3 vs. Zentrum 27]). In beiden Gruppen verringerte sich die Leukozytenzahl begleitet mit Schwankungen im Zeitgang der Studie. Die Verminderung der Leukozytenzahl wies in beiden Gruppen keine Differenz auf (Gruppeneffekt: $p=0,06)(\mathrm{s}$. Abb. 4.5.2.1/1).

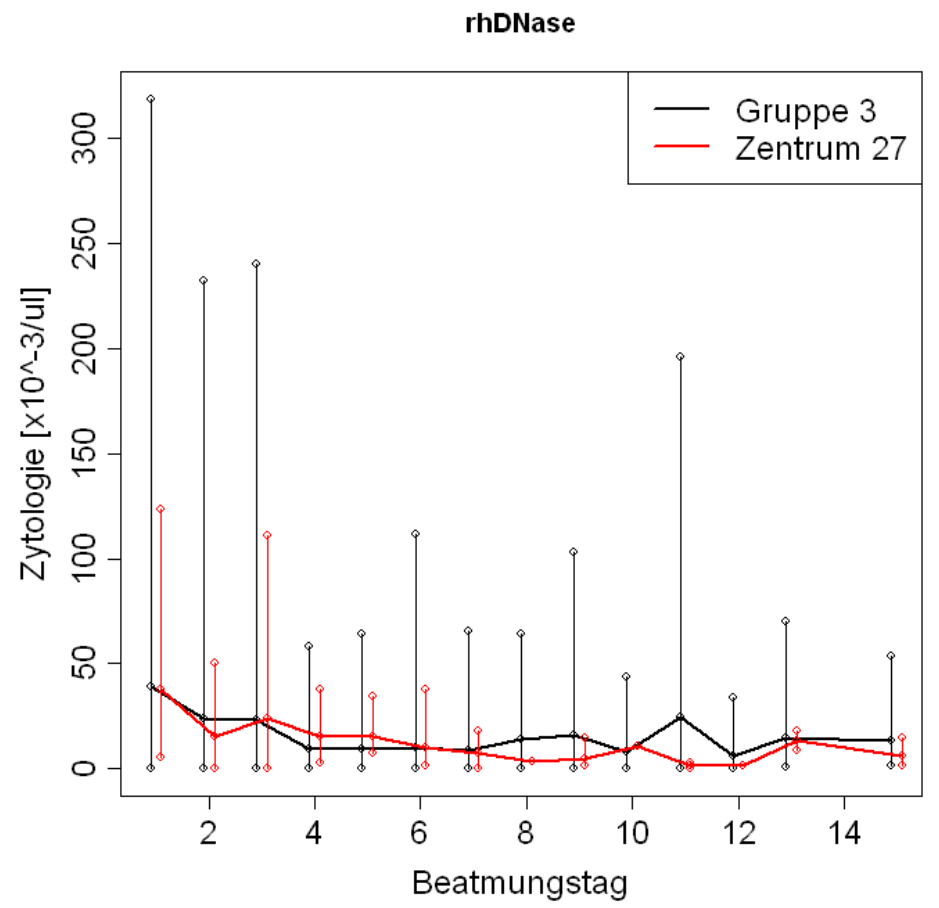

Abbildung 4.5.2.1/1.

Vergleich der Leukozytenzahl im Trachealsekret zwischen den rhDNase-Gruppen des Zentrums 27 und der mod. Gruppe 3 
Die NaCl-Gruppe des Zentrums 27 wies primär höhere Leukozytenzahl im Trachealsekret als die NaCl-Gruppe der mod. Gruppe 3 auf. Ab dem Studientag 3 wurden niedrigere Leukozytenzahl im Trachealsekret des Zentrums 27 im Vergleich zu der mod. Gruppe 3 gemessen, jedoch ohne signifikanten Unterschied (Gruppeneffekt: $p=0,11$ ) zwischen den Gruppen (s. Abb. 4.5.2.1/2).

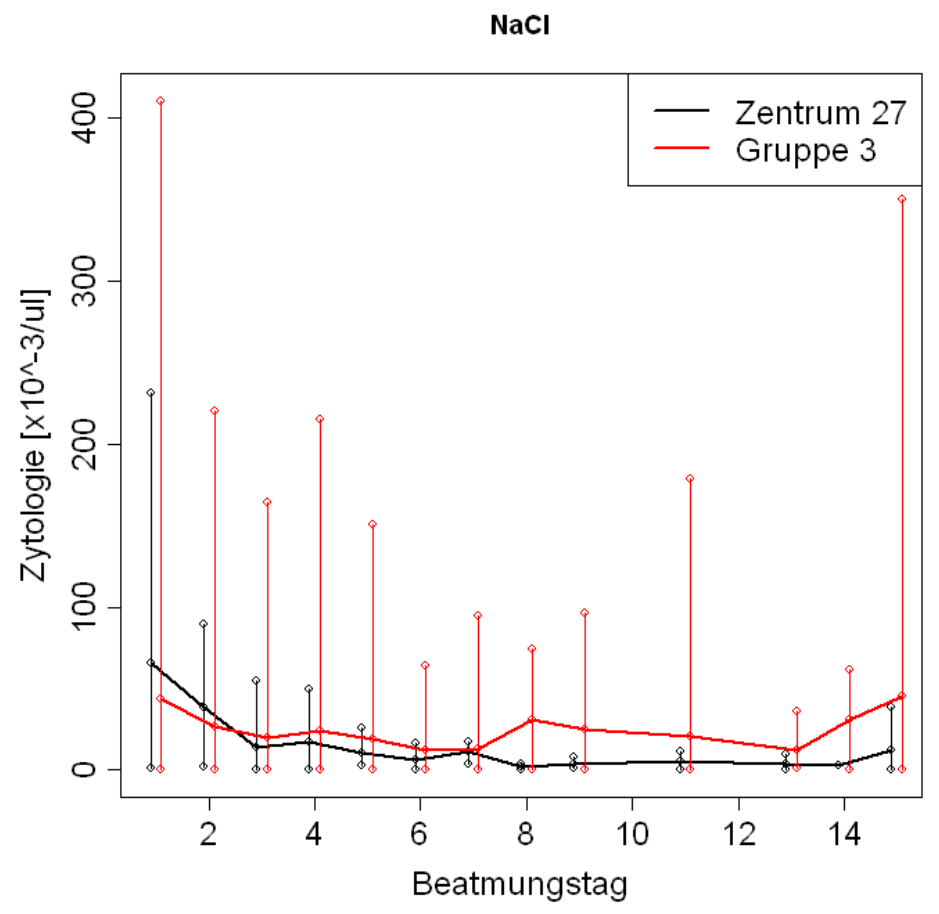

Abbildung 4.5.2.1/2.

Vergleich der Leukozytenzahl im Trachealsekret zwischen den NaCl-Gruppen des Zentrums 27 und der mod. Gruppe 3 


\subsubsection{Senkung der Zytokinkonzentration im Trachealsekret}

\subsubsection{1}

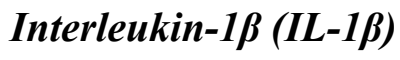

In beiden rhDNase-Gruppen nahm die IL-1 $\beta$-Konzentration im Studienverlauf ab, wobei in jeder Gruppe ein von der Gesamttendenz abweichender Wert am 3. bzw. 5. Studientag zu verzeichnen war. Obwohl im Trachealsekret des Zentrums 27 primär eine höhere IL-1 $\beta$ Konzentration gemessen wurde, enthielt das Trachealsekret im Verlauf ähnlich hohe IL-1 $\beta$ Konzentration wie im Trachealsekret der rhDNase-Gruppe der mod. Gruppe 3 (Gruppeneffekt: $\mathrm{p}=0,42$ ) (s. Abb. 4.5.2.2.1/1).

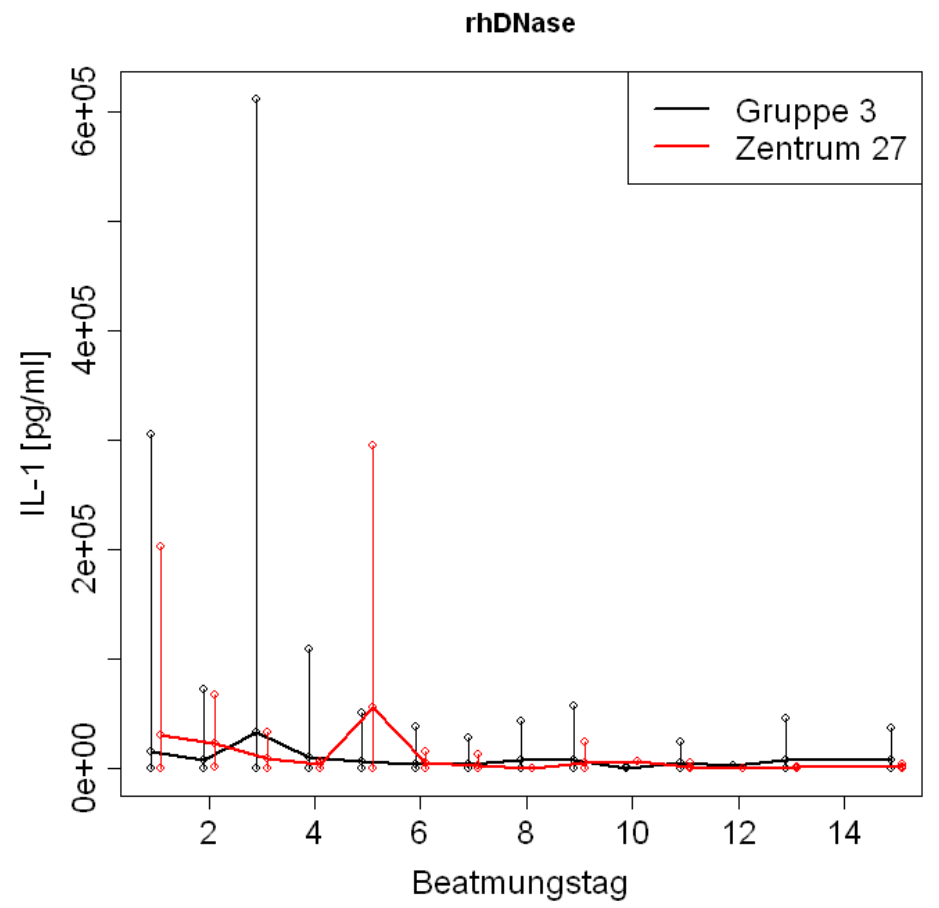

Abbildung 4.5.2.2.1/1.

Vergleich der IL-1 $\beta$-Konzentration im Trachealsekret zwischen den rhDNase-Gruppen des Zentrums 27 und der mod. Gruppe 3 
Bei der Gegenüberstellung der IL-1 $\beta$-Konzentration im Trachealsekret der NaCl-Gruppen zeichnete sich im Trachealsekret des Zentrums 27 der Trend zur Verringerung der IL-1 $\beta$ Konzentration ab, wogegen im Trachealsekret der mod. Gruppe 3 dieser Trend nicht festzustellen war. Die Veränderungen in beiden Gruppen waren signifikant unterschiedlich (Gruppeneffekt: $\mathrm{p}=0,04)$ (s. Abb. 4.5.2.2.1/2).

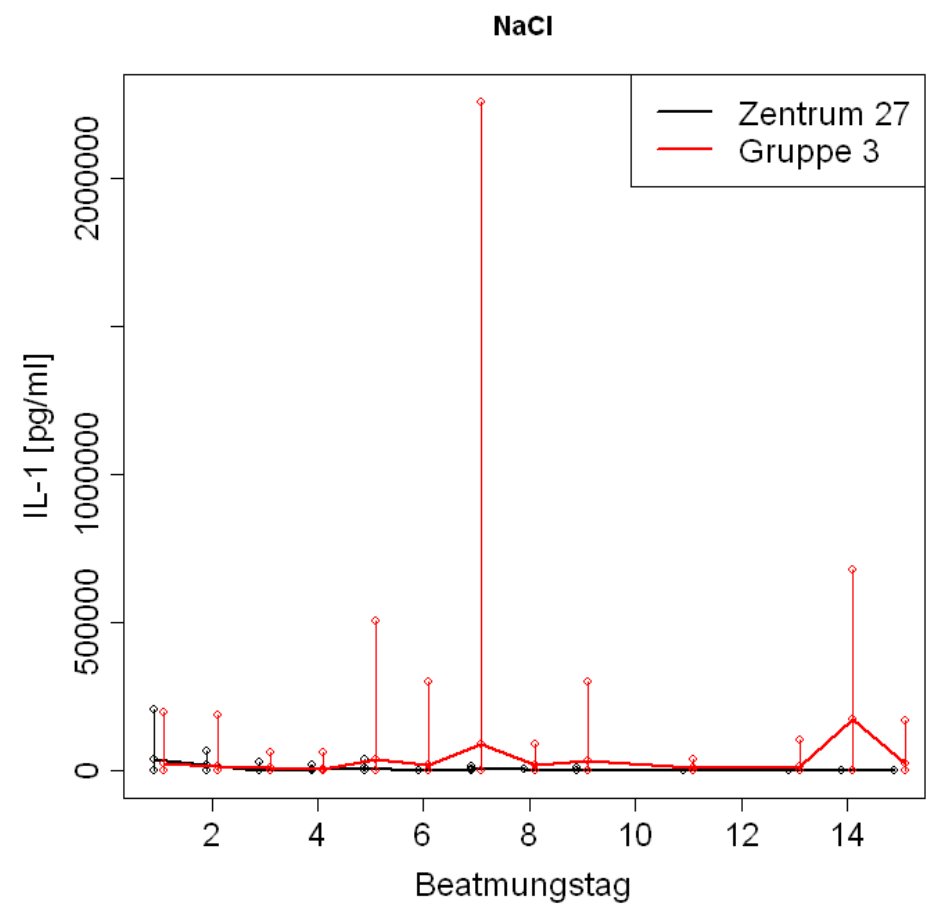

Abbildung 4.5.2.2.1/2.

Vergleich der IL-1 $\beta$-Konzentration im Trachealsekret zwischen den NaCl-Gruppen des Zentrums 27 und der mod. Gruppe 3 


\subsubsection{2}

Interleukin-6 (IL-6)

Die IL-6-Konzentration in der rhDNase-Gruppe des Zentrums 27 nahm im Verlauf zu, während die IL-6-Konzentration in der rhDNase-Gruppe der mod. Gruppe 3 sich verringerte. Dennoch ergab sich kein signifikanter Unterschied (Gruppeneffekt: $p=0,29$ ) zwischen den Gruppen (s. Abb. 4.5.2.2.2/1).

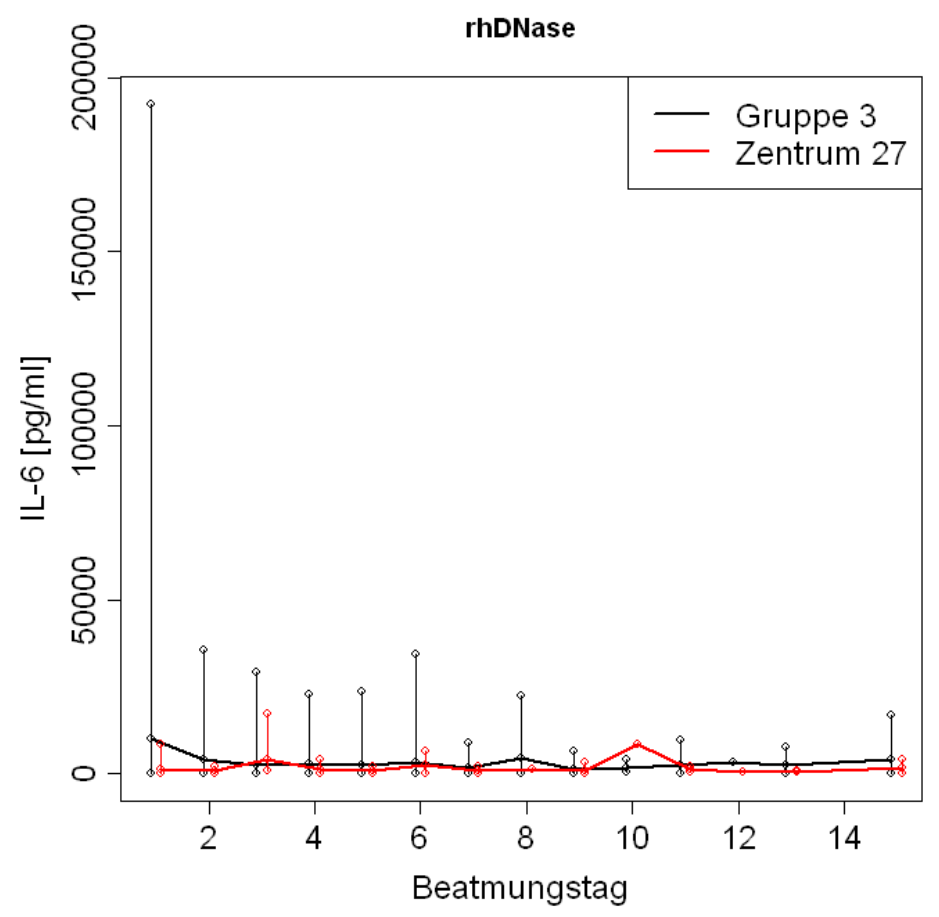

Abbildung 4.5.2.2.2/1.

Vergleich der IL-6-Konzentration im Trachealsekret zwischen den rhDNase-Gruppen des Zentrums 27 und der mod. Gruppe 3 
Der Vergleich der IL-6-Konzentration im Trachealsekret der NaCl-Gruppen ergab, dass sich die Trends der IL-6-Konzentration gegenläufig verhalten. Im Trachealsekret des Zentrums 27 nahm die IL-6-Konzentration im Verlauf zu. In der mod. Gruppe 3 zeichnete sich die Reduktion des IL-6-Spiegels im Trachealsekret im Studienverlauf, mit Ausnahme am 4. und 6. Studientag, ab. Dieser Unterschied erwies sich als signifikant (Gruppeneffekt: $p=0,03$ ) (s. Abb. 4.5.2.2.2/2).

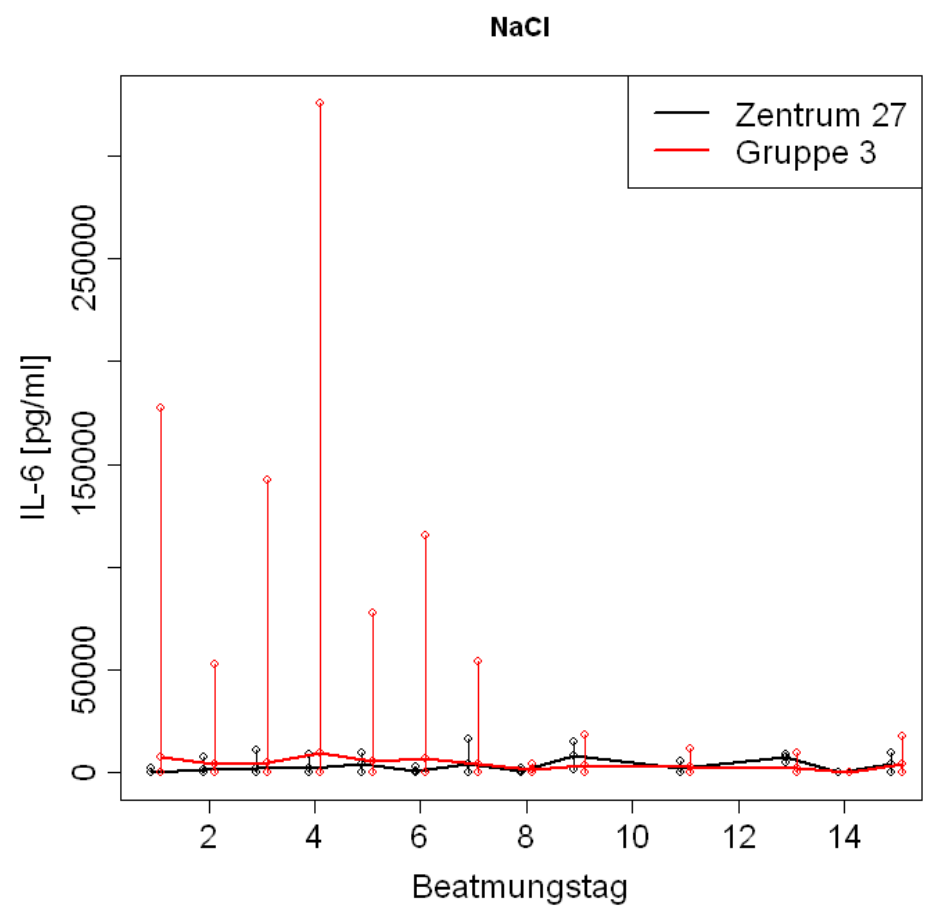

Abbildung 4.5.2.2.2/2.

Vergleich der IL-6-Konzentration im Trachealsekret zwischen den NaCl-Gruppen des Zentrums 27 und der mod. Gruppe 3 


\subsection{Interleukin-8 $(I L-8)$}

Die gemessenen IL-8-Konzentrationen im Trachealsekret der rhDNase-Gruppen erlauben keine Aussage über deren Trend. Im Laufe der Studie schwankte die IL-8-Konzentration in der jeweiligen Gruppe mehrmals, so dass keine Gruppendifferenz festzustellen war (Gruppeneffekt: $\mathrm{p}=0,97)($ Abb. 4.5.2.2.3/1).

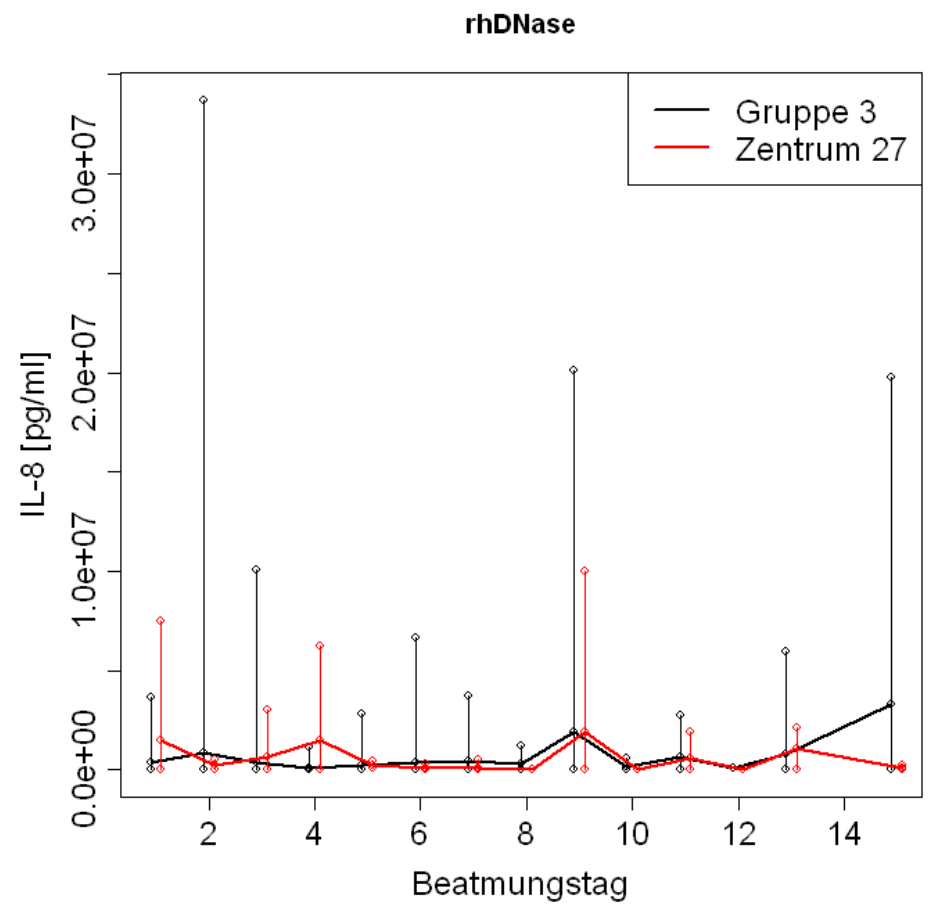

Abbildung 4.5.2.2.3/1.

Vergleich der IL-8-Konzentration im Trachealsekret zwischen den rhDNase-Gruppen des Zentrums 27 und der mod. Gruppe 3 
Die IL-8-Konzentration der NaCl-Gruppe der mod. Gruppe 3 zeigte einen alternierenden Verlauf. Ab dem Studientag 3 nahm die IL-8-Konzentration alle 2 Tage zu und alle 2 Tage versetzt um 1 Tag, nahm sie bis zum Studientag $11 \mathrm{ab}$. Danach veränderte sie sich kaum, so dass eine ähnlich hohe Konzentration wie am Studienbeginn vorlag. Die IL-8-Konzentration der NaCl-Gruppe des Zentrums 27 verzeichnete mit 2 Ausnahmen am 2. und 13. Studientag einen eher unveränderten Verlauf. Der Gruppenunterschied ließ sich nicht beobachten (Gruppeneffekt: $\mathrm{p}=0,39$ ) (s. Abb. 4.5.2.2.3/2).

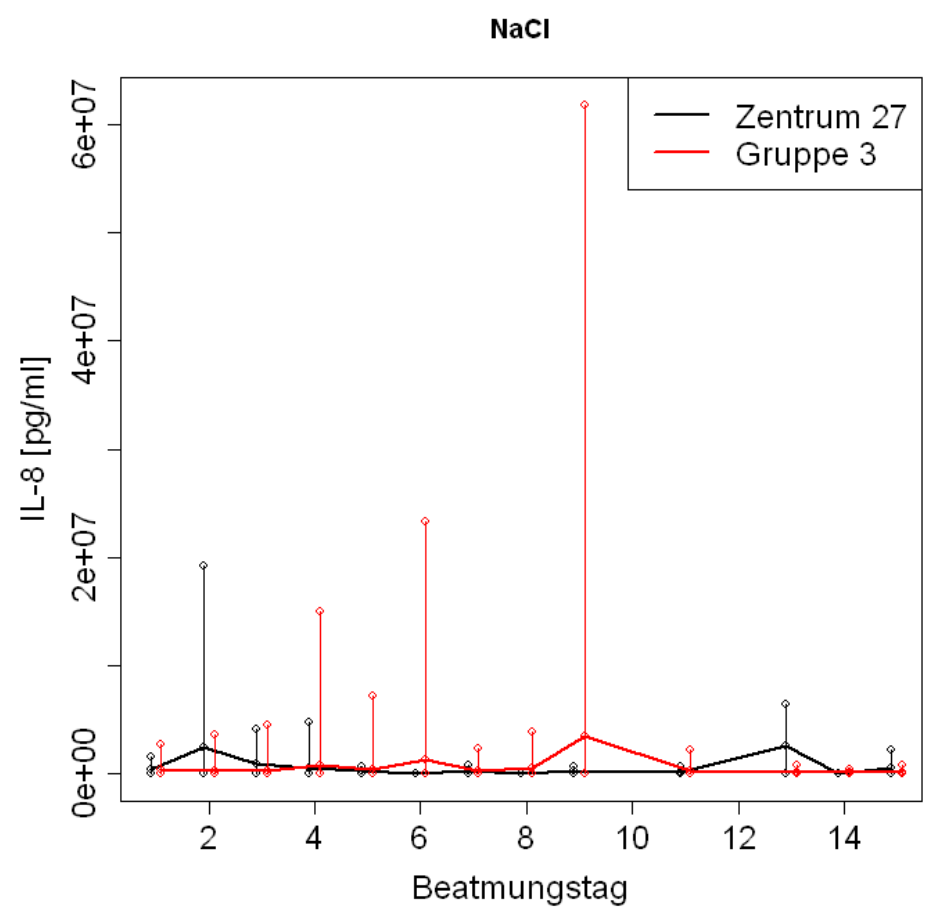

Abbildung 4.5.2.2.3/2.

Vergleich der IL-8-Konzentration im Trachealsekret zwischen den NaCl-Gruppen des Zentrums 27 und der mod. Gruppe 3 


\subsection{Interleukin-10 (IL-10)}

Bei dem Vergleich der IL-10-Konzentration zwischen den rhDNase-Gruppen des Zentrums 27 und der mod. Gruppe 3 stellte sich ein signifikanter Unterschied zwischen den Gruppen heraus (Gruppeneffekt: $\mathrm{p}<0,01$ ). Im Trachealsekret des Zentrums 27 stieg die IL-10Konzentration bis zum Studientag 10. deutlich an. Gleich danach nahm sie bis hin zum anfänglichen Wert wieder ab. Bei der mod. Gruppe 3 nahm die IL-10-Konzentration mit Schwankungen bis zum Studientag $10 \mathrm{ab}$. Im Anschluss begann die IL-10-Konzentration anzusteigen (s. Abb. 4.5.2.2.4/1).

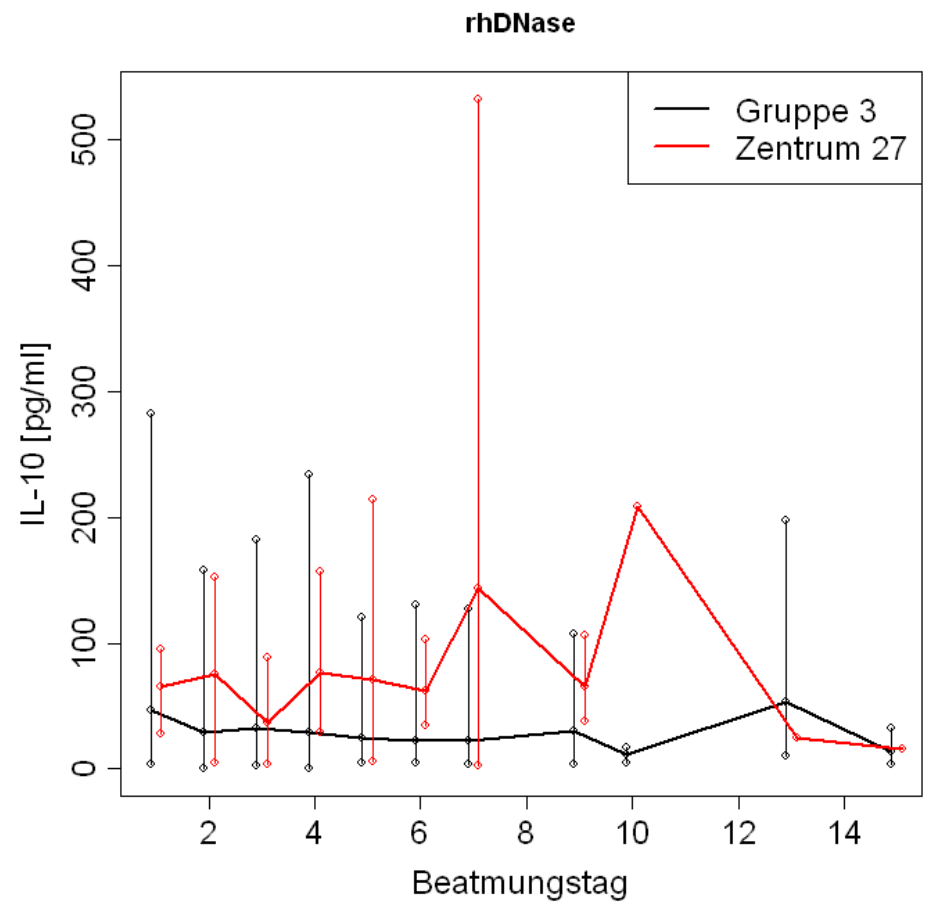

Abbildung 4.5.2.2.4/1.

Vergleich der IL-10-Konzentration im Trachealsekret zwischen den rhDNase-Gruppen des Zentrums 27 und der mod. Gruppe 3 
Die Gegenüberstellung von IL-10-Konzentration der NaCl-Gruppen des Zentrums 27 und der mod. Gruppe 3 ergab, dass sich die IL-10-Konzentration in der mod. Gruppe 3 im Laufe der Studie minimal verringerte. Im Zentrum 27 zeigte die IL-10-Konzentration starke Schwankungen, so dass kein Trend beobachtet werden konnte. Es ließ sich kein Unterschied zwischen den Gruppen feststellen (Gruppeneffekt: $p=0,71$ ) (s. Abb. 4.5.2.2.4/2).

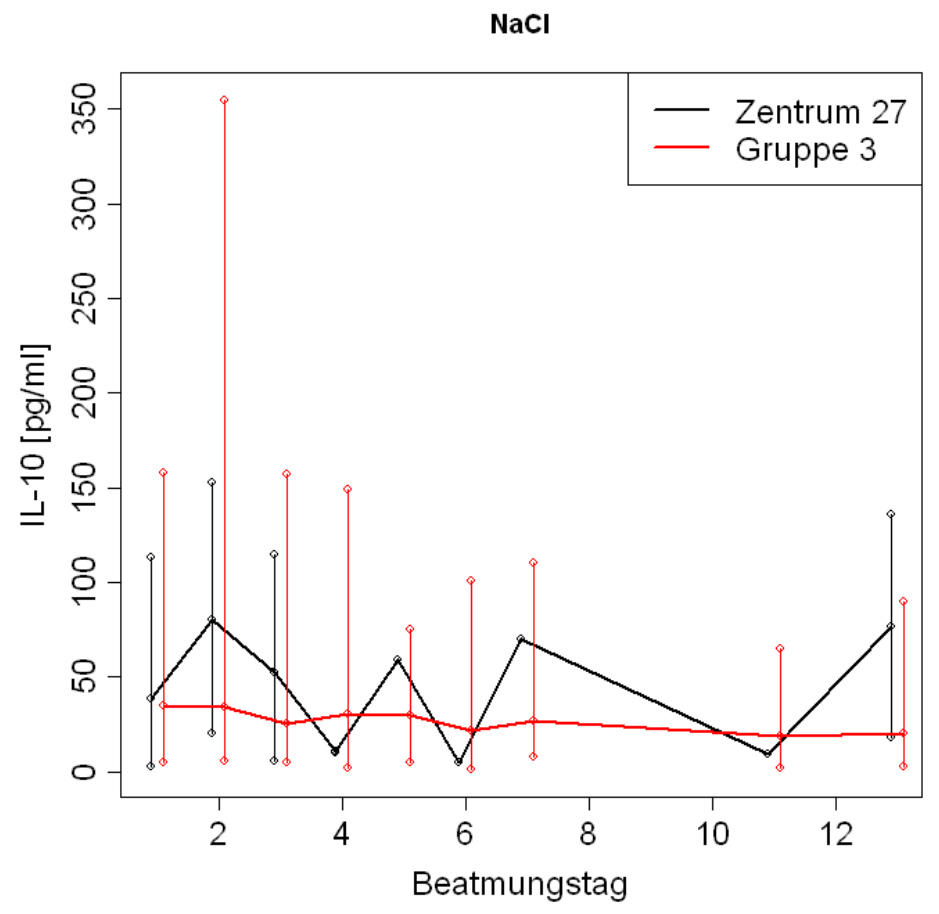

Abbildung 4.5.2.2.4/2.

Vergleich der IL-10-Konzentration im Trachealsekret zwischen den NaCl-Gruppen des Zentrums 27 und der mod. Gruppe 3 


\subsection{Lipopolysaccharidbindendes Protein (LBP)}

Am Studientag 1 unterschieden sich die LBP-Konzentrationen der beiden rhDNase-Gruppen um genau $400 \mathrm{ng} / \mathrm{ml}$ zugunsten der mod. Gruppe 3. In beiden Gruppen verringerte sich, begleitet von Schwankungen, die LBP-Konzentration, wobei sie im Zentrum 27 kontinuierlich mit einzelnen Ausnahmen unter dem Konzentrationsniveau der mod. Gruppe 3 blieb. Der Unterschied im LBP-Spiegel war signifikant (Gruppeneffekt: $p=0,01$ ) (s. Abb. 4.5.2.2.5/1).

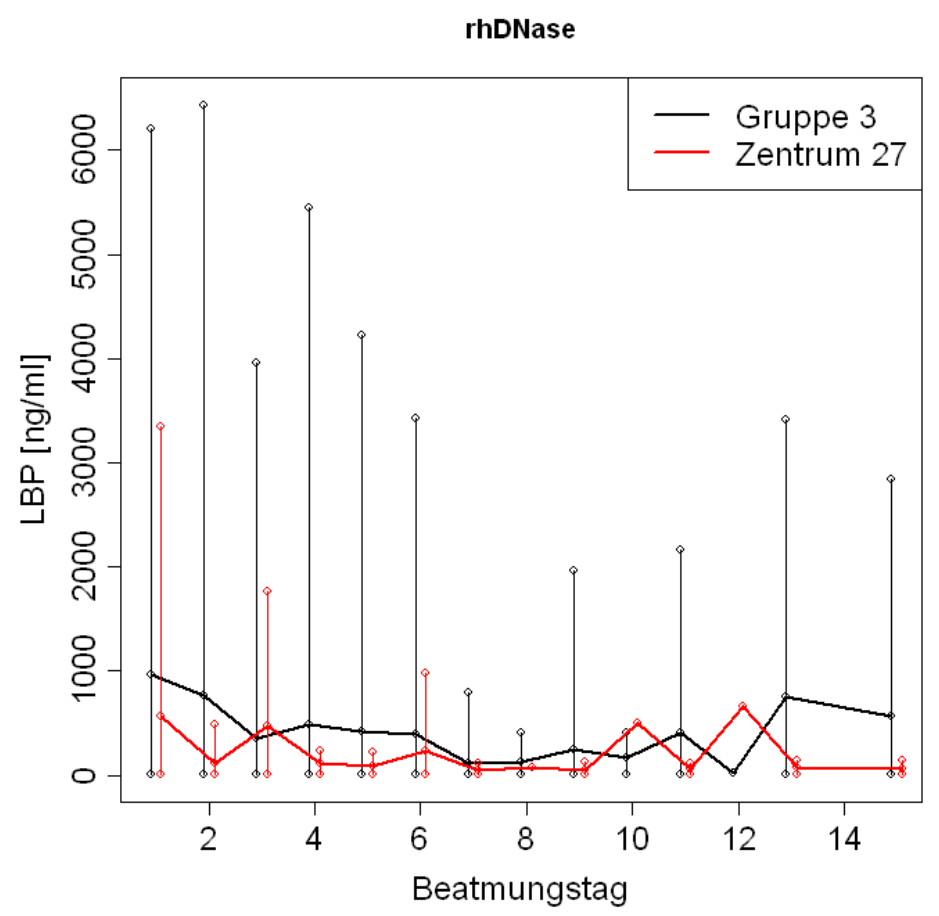

Abbildung 4.5.2.2.5/1.

Vergleich der LBP-Konzentration im Trachealsekret zwischen den rhDNase-Gruppen des Zentrums 27 und der mod. Gruppe 3 
Bei primärer LBP-Konzentration von $1328 \pm 498,86 \mathrm{ng} / \mathrm{ml}$ in der NaCl-Gruppe der mod. Gruppe 3, nahm diese im Studienverlauf ab. Im Trachealsekret des Zentrums 27 nahm die LBP-Konzentration von anfänglichen $40 \pm 20,4 \mathrm{ng} / \mathrm{ml}$ bis zum 8 . Studientag zu, um danach wieder auf ähnlich niedrige Werte abzufallen. Zwischen den Gruppen wurde kein signifikanter Unterschied festgestellt (Gruppeneffekt: $p=0,19$ ) (s. Abb. 4.5.2.2.5/2).

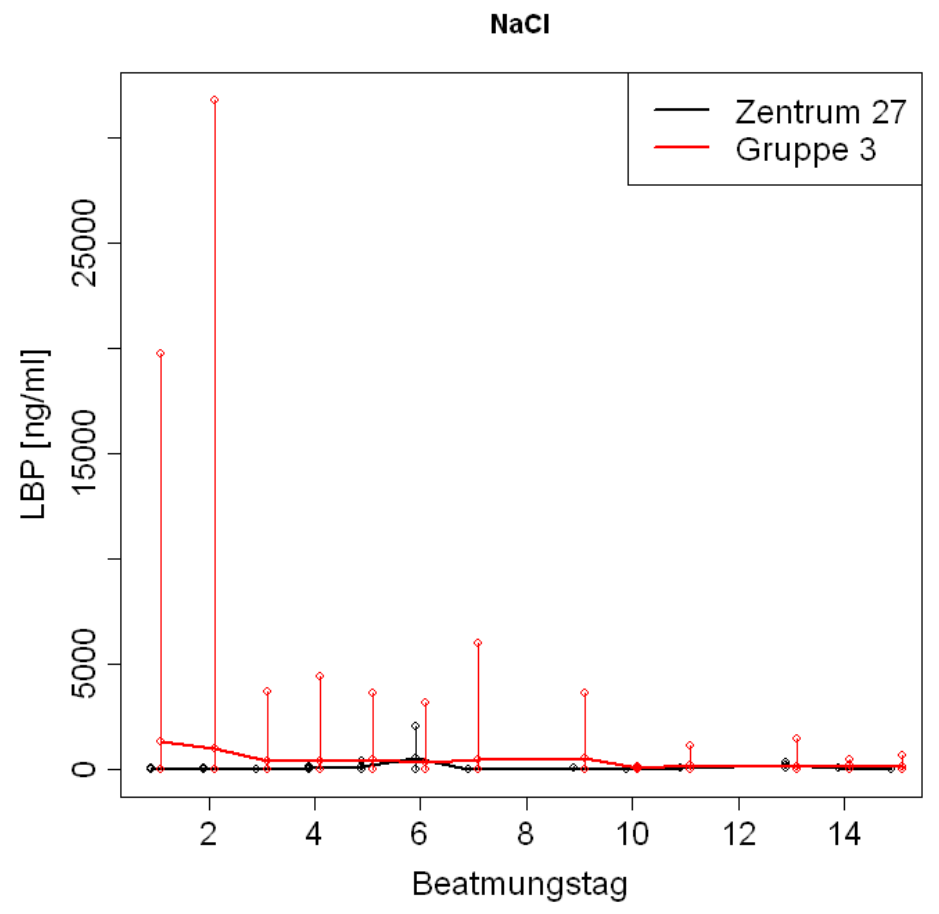

Abbildung 4.5.2.2.5/2.

Vergleich der LBP-Konzentration im Trachealsekret zwischen den NaCl-Gruppen des Zentrums 27 und der mod. Gruppe 3 


\section{$(G M-C S F)$}

In beiden rhDNase-Gruppen herrschte am 1. Studientag im Trachealsekret eine ähnlich hohe GM-CSF-Konzentration von $649 \pm 240,73$ bzw. $589 \pm 268,71$ pg/ml (mod. Gruppe 3 vs. Zentrum 27). Die GM-CSF-Konzentration in beiden Gruppen zeigte einen alternierenden Verlauf, wobei sich die Talkonzentrationen im Verlauf verringerten. Ein Gruppenunterschied konnte nicht festgestellt werden (Gruppeneffekt: $p=0,13$ ) (s. Abb. 4.5.2.2.6/1).

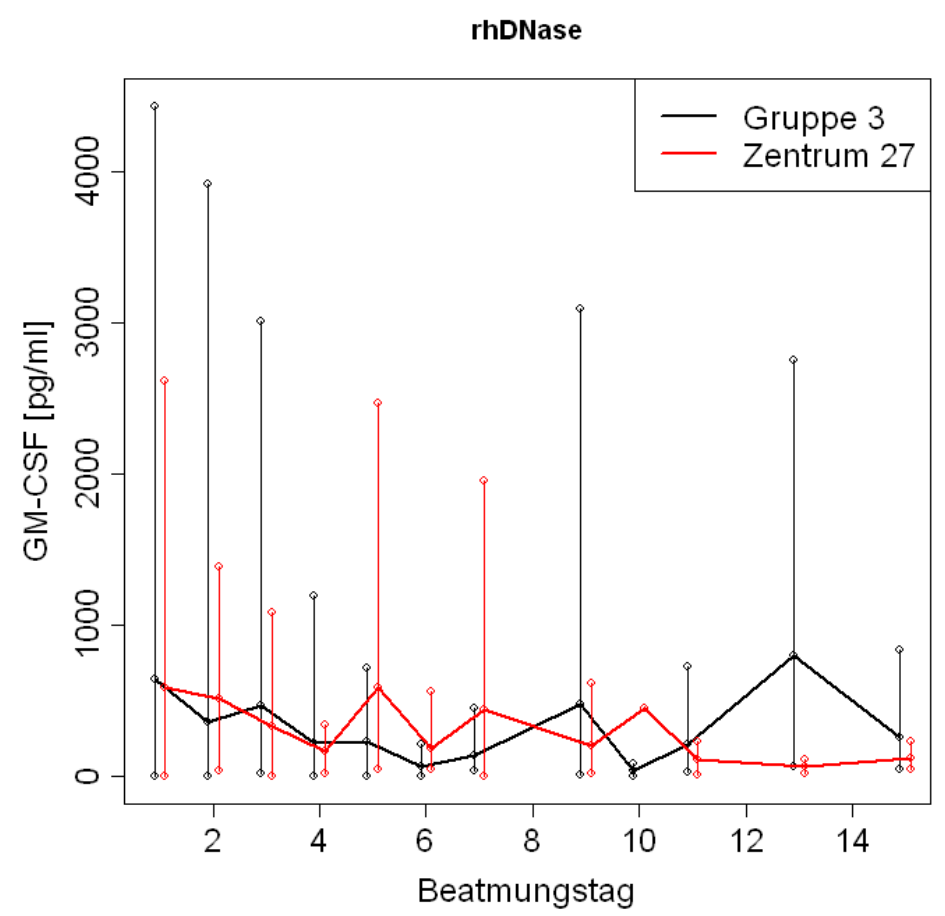

Abbildung 4.5.2.2.6/1.

Vergleich der GM-CSF-Konzentration im Trachealsekret zwischen den rhDNase-Gruppen des Zentrums 27 und der mod. Gruppe 3 
Der Vergleich der GM-CSF-Konzentration der NaCl-Gruppen ergab, dass in beiden Gruppen eine ähnlich hohe GM-CSF-Konzentration in den ersten 2 Studientagen vorlag $(355 \pm 93,18$ pg/ml und $382 \pm 142,04$ pg/ml [mod. Gruppe 3 vs. Zentrum 27]). Ab dem Studientag 3 begann die GM-CSF-Konzentration im Zentrum 27 abzunehmen. In der NaCl-Gruppe der mod. Gruppe 3 stieg die GM-CSF-Konzentration allmählich an. Die Veränderungen der GM-CSFKonzentration ergaben einen signifikanten Unterschied zwischen den Gruppen (Gruppeneffekt: $\mathrm{p}<0,01)$ (s. Abb.4.5.2.2.6/2).

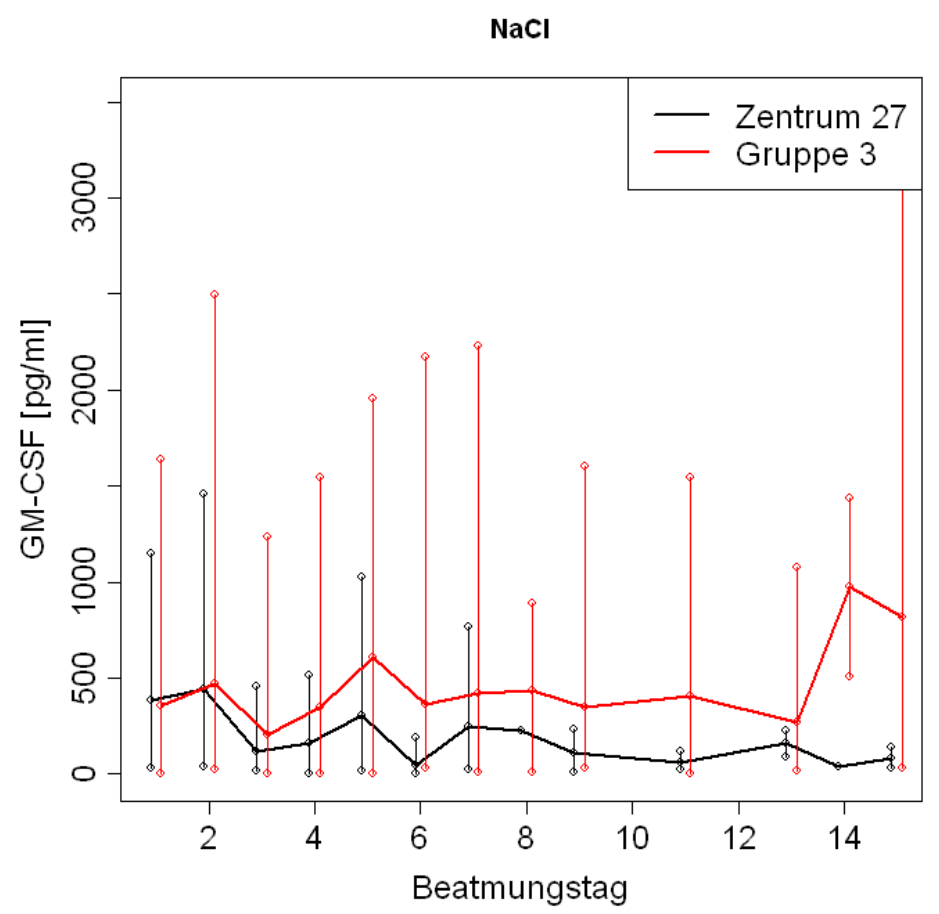

Abbildung 4.5.2.2.6/2.

Vergleich der GM-CSF-Konzentration im Trachealsekret zwischen den NaCl-Gruppen des Zentrums 27 und der mod. Gruppe 3 


\section{Diskussion}

In unserer Arbeit konnte die Verkürzung der DNA-Fragmente und Verminderung der DNAKonzentration im Trachealsekret durch zweimal tägliche intratracheale rhDNase-Applikation bestätigt werden. Dennoch ließ sich keine Verkürzung der Beatmungsdauer bei Patienten unter rhDNase-Therapie im Zentrum 27 (Göttinger Arm der Lufit-Studie) beobachten. Wesentlichen Einfluss auf die Beatmungsdauer und Dauer des Aufenthaltes auf der Intensivstation hatten mit größter Wahrscheinlichkeit die neurologische Grunderkrankung und der mit ihr verbundene ,retikuläre Schock“, d.h. die Auswirkungen des akuten Grundleidens auf die in der Formatio reticularis lokalisierten Atemzentren.

5.1 Basischarakteristika

Das abgebildete Diagramm stellt die Gruppenaufteilung und die vorgenommenen Vergleiche dar.

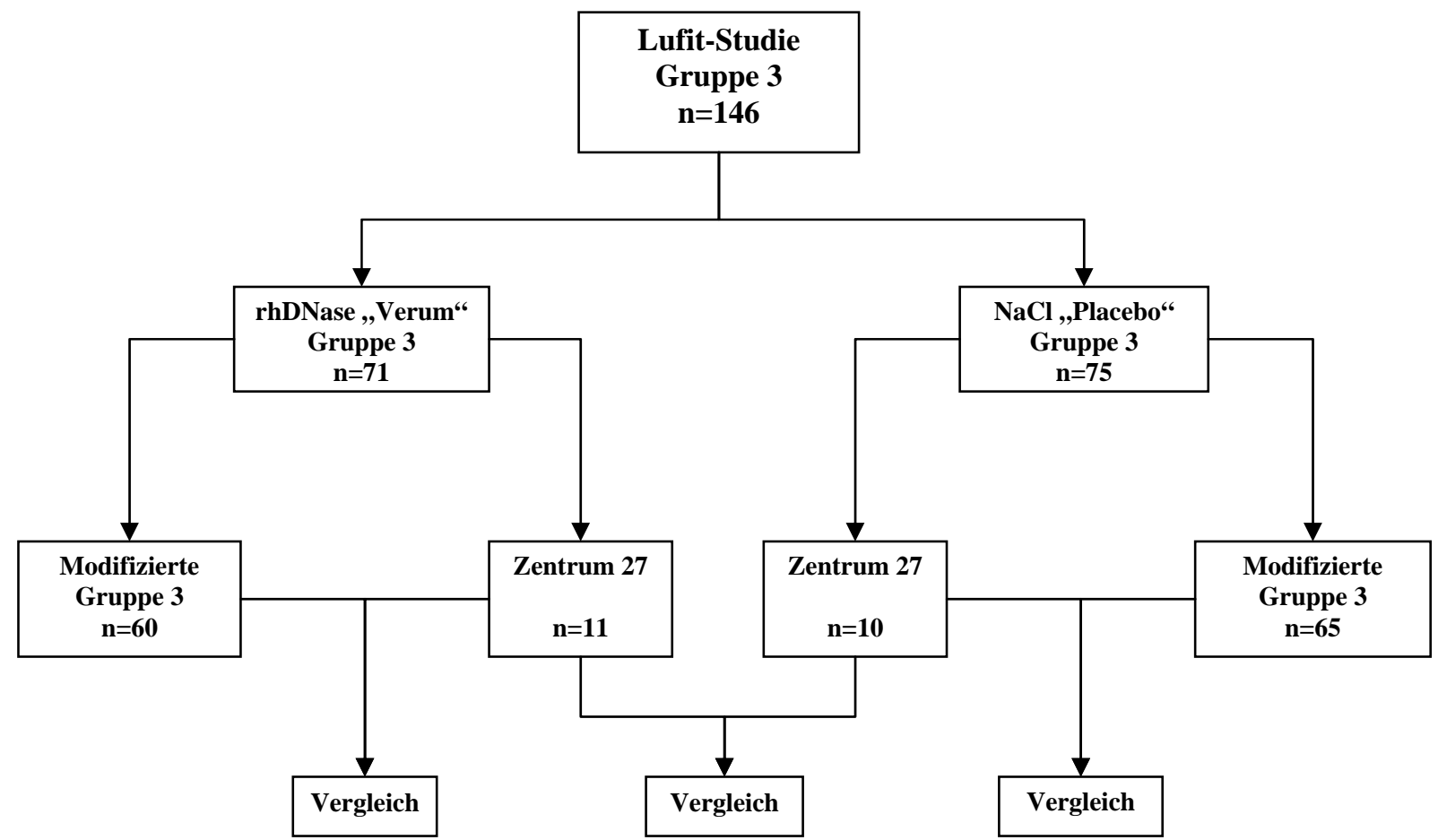

\section{Abbildung 5.1/1:}

Baumdiagramm der Patientenaufteilung und die vorgenommenen Gruppenvergleiche

In den Basischarakteristika unterschieden sich die Patienten des Zentrums 27 (Göttinger Arm) von Patienten der modifizierten Gruppe 3 (mod. Gruppe 3). 
Die Patienten des Zentrums 27 waren im Median 7,2 Jahre in der rhDNase-Gruppe und 6,5 Jahre in der NaCl-Gruppe älter als die Patienten der jeweiligen Gruppen der mod. Gruppe 3. Während Frauen in der rhDNase-Gruppe der mod. Gruppe 3 weniger als ein Drittel des Patientenkollektivs ausmachten, waren sie im Patientenkollektiv des Zentrums 27 mit 46\% repräsentiert.

Mehr als 75\% der Patienten in der rhDNase-Gruppe („Verum“) der mod. Gruppe 3 wiesen nicht neurologische Grunderkrankungen auf. Unter diesen Patienten waren die Kranken mit Pneumonien überrepräsentiert. Im Zentrum 27 mit ausschließlich neurologischen Patienten bot nur knapp die Hälfte der Personen in der Verumgruppe (rhDNase-Gruppe) die typischen Kriterien einer Pneumonie.

In der NaCl-Gruppe („Placebo“) der mod. Gruppe 3 lag der Anteil von Patienten mit nicht neurologischen Grunderkrankungen ebenfalls bei mehr als $75 \%$. Die Patienten mit Pneumonie als Grunderkrankung stellten den Hauptanteil dar. In der NaCl-Gruppe des Zentrums 27 konnten bei 8 Patienten die typischen Kriterien einer Pneumonie festgestellt werden.

\section{2}

\section{Erfassung der klinischen Wirksamkeit}

\section{2 .1}

\section{Beatmungsdauer}

Die Behandlung der neurologischen Patienten im Zentrum 27 mit rhDNase (,Verum“) hat zu keiner signifikanten Verkürzung der Beatmungsdauer geführt. Der Unterschied in der Beatmungsdauer der beiden NaCl-Gruppen („Placebo“-mod. Gruppe 3 vs. Zentrum 27) erwies sich als ebenfalls nicht signifikant.

Im Vergleich der beiden rhDNase-Gruppen („Verum“) zeigte sich eine signifikante Differenz in der Beatmungsdauer. Bei der Auswertung aller in die Gruppe 3 der Lufit-Studie eingeschlossenen Patienten wurde eine Verkürzung der Beatmungsdauer ermittelt, dies traf für die Untergruppe Zentrum 27 nicht zu. Diese Beobachtung impliziert das Vorliegen eines oder mehrerer Mechanismen, die der Verkürzung der Beatmungsdauer unter der rhDNaseTherapie im Zentrum 27 entgegenwirkten.

Zum Ersten konnte das Vorliegen des „retikulären Schocks“* bei den Patienten in der rhDNase-Gruppe des Zentrums 27 zur Verlängerung der Beatmungsbedürftigkeit führen.

\footnotetext{
*Unter „retikulärem Schock“ verstehen wir eine durch das neurologische Akutereignis beeinträchtigte Funktionsstörung der Formatio reticularis, die eine Affektion der Atemfunktion einschließen kann.
} 
Die Dauer des „retikulären Schocks“ ist beim einzelnen Patienten unvorhersehbar und unterscheidet sich interindividuell (Addington et al. 2005).

Zum Zweiten wirkten die begleitende Sepsis mit oder ohne Multiorganversagen bei Patienten im Zentrum 27 und die bei 3 Patienten aufgetretene nosokomiale Pneumonie der Verkürzung der Beatmungsdauer entgegen.

Zum Dritten konnte eine Verbesserung der mukoziliären Clearance trotz der erfolgten Verringerung der DNA-Kettenlängen nicht stattfinden. Die Verbesserung der mukoziliären Clearance durch rhDNase-Therapie ist auf deren direkte Wirkung in der Reduzierung der Mukusoberflächenspannung und der damit verbundenen indirekten Zunahme der Zilienschlagfrequenz zurückzuführen, allerdings bis zu einer bestimmten effektiven rhDNaseKonzentration. Der Zunahme der Zilienschlagfrequenz konnten folgende Faktoren entgegenwirken, welche die Frequenz verlangsamten und einen verlangsamten Abtransport des verflüssigten Trachealsekrets hervorriefen:

\subsubsection{Verlust des kinozilientragenden Epithels}

Die Verminderung der Oberflächenspannung durch rhDNase ist mit gesteigerter Transportkapazität durch Zilienschlag und Husten verbunden (Zahm et al. 1998). Allerdings verbessert die rhDNase-Therapie die Atemwegsclearance durch Husten im stärkeren Maße, als durch ziliäre Aktivität (Zahm et al. 1995, Griese et al. 1997).

Aufgrund des fehlenden Hustenmechanismus bei den beatmeten Patienten wird die Clearance der Atemwege in erster Linie durch Zilienschlagaktivität gewährleistet. Als Folge der häufig auftretenden Aspiration, die zu einem Verlust von kinozilientragenden Epithelzellen führt, kann die Zilienaktivität bei den neurologischen Patienten besonders beeinträchtigt sein (Kidd et al. 1995, Wynne et al. 1981). Die kleinsten Mengen des Aspirats, die nicht ausreichen um eine Pneumonie auszulösen, führen trotzdem zu bedeutenden Trachealepithelschäden (Wynne et al. 1981). Demzufolge wurde möglicherweise das aufgelöste Trachealsekret von einem geschädigten Trachealepithel bei den rhDNase-Patienten des Zentrums 27 nicht in gewünschter Weise abtransportiert. 


\subsubsection{Effekt der Mukusmenge, rhDNase-Dosis und Viskosität auf Sputumtransportrate}

Wills et al. (1996) vermuten, dass die im Vergleich zu Mukoviszidose-Patienten geringere Trachealsekretmenge zur Unwirksamkeit der rhDNase beitragen könne. Dieses Problem lag mutmaßlich auch bei den Patienten des Zentrums 27 vor. Dies könnte als Folge der abweichenden Äthiopathogenese der Aspirationspneumonie, die in den meisten Pneumoniefällen vorlag, sein. Die Aspirationspneumonie führt nämlich zu einem der Schocklunge ähnlichem Krankheitsbild (diffusem Alveolarschaden); das heißt der Prozess spielt sich im Interstitium ab und ein alveoläres Exsudat, wie es für eine „gewöhnliche“ Pneumonie typisch ist, fehlt (Riede und Costabel 2004). In-vitro-Untersuchungen haben gezeigt, dass der Effekt der rhDNase auf Trachealssekrettransport durch Zilienschlag sowohl von der rhDNase-Konzentration, als auch von der intialen Sekrettransportrate abhängt. Liegt die initiale Sekrettransportrate $>0,8$ führt die Inkubation mit hoher rhDNase-Konzentration $(>20 \mu \mathrm{g} / \mathrm{ml}$ der rhDNase per $1 \mathrm{ml}$ des Sekrets) zu einer Verschlechterung der Sekrettransportrate (Zahm et al. 1995). Puchelle et al. (1983) postulierten, dass Sekrettransportraten über 0,7 dem Normbereich entsprechen. Wenn auch die rhDNaseKonzentration $15 \mathrm{~min}$ nach Vernebelung von 2,5 mg rhDNase 2,9 $\mu \mathrm{g} / \mathrm{ml}$ im Trachealsekret beträgt (Sinicropi et al. 1994), könnten die endotracheale Applikation und die geringe Sekretmenge die effektive Konzentration dermaßen erhöhen, dass bei normaler Sekrettransportrate die rhDNase auf sich selbst limitierend wirkte. Diese Hypothese wird durch die Untersuchungen von Kamin et al. (2006) unterstützt; die Autoren konnten durch direkte bronchoskopische Applikation von 2,5 mg rhDNase in einen infolge hoher Trachealsekretmenge atelektatisch gewordenen Lungenlappen das Sekret effektiv beseitigen. Die gleiche wie in unserer Studie, direkt applizierte rhDNase-Dosis hat sich in einer großen Sekretmenge verteilt und damit die effektive Konzentration nicht überschritten.

Die Unteranalyse innerhalb der Gruppe 3 der Lufit-Studie, die einen größeren Vorteil der rhDNase-Therapie in der Untergruppe der Patienten mit Pneumonie gezeigt hat, könnte die aufgestellte Hypothese bestärken. Dieser Vorteil könnte unter anderem durch hohe produzierende Sekretmenge von Patienten mit Pneumonie im Vergleich zu den anderen Patienten mit primär nicht pulmonaler Grunderkrankung bedingt sein. 


\subsubsection{Die Non-Responder}

In der Literatur finden sich einige Studien, welche eine Unwirksamkeit und eine interindividuell unterschiedliche Ansprechbarkeit auf die rhDNase-Therapie sowohl bei Patienten mit Mukoviszidose als auch bei solchen mit idiopathischen Bronchiektasien erbrachten (Robinson et al. 2000, Laube et al. 1996, O'Donnell et al. 1998, Wills et al. 1996, Davies et al. 1997, Suri et al. 2001). Die Unwirksamkeit der rhDNase wurde sowohl als Ausbleiben bzw. nicht signifikante Verbesserung des klinischen Zustandes als auch der beeinträchtigten mukoziliären Clearance beschrieben.

Aufgrund der geringeren Patientenzahl im Zentrum 27 wurde möglicherweise durch die Einbeziehung von Patienten mit fehlender oder schwacher Ansprechbarkeit auf die rhDNaseVerabfolgung das Gesamtergebnis im Zentrum 27 gravierend verändert, sodass schließlich das Resultat (positiver Terapieeffekt) der Gruppe 3 der Lufit-Studie hier nicht erreicht werden konnte.

\subsubsection{Medikamenteneinfluss}

Im Rahmen der Lufit-Studie durften die Patienten neben der rhDNase-Therapie auch Sekretolytika erhalten. N-Acetylcystein war mit Abstand das meist benutzte Sekretolytikum. Dieses Sekretolytikum reduziert die Viskosität des Trachealsekrets, besitzt jedoch eine negative Wirkung auf die Zilienfunktion (Dreisin und Mostow 1979). Bei der internen Auswertung der in den Studienergebnissen nicht aufgeführten Daten stellte sich heraus, dass im Zentrum 27 (Göttinger Arm) N-Acetylcystein häufiger angewandt wurde als in der mod. Gruppe 3. Trotz des in in-vitro-Untersuchungen beschriebenen additiven Effekts von Nacystelyn, einem Derivat vom N-Acetylcystein, (Dasgupta und King 1996) auf Viskoelaszitität ist bei in-vivo-Gabe ein Negativeffekt möglich. Die Viskoelastizität wird möglicherweise durch beide Medikamente (rhDNase und N-Acetylcystein) sehr stark reduziert mit dem Ergebnis einer Verringerung der Sekrettransportrate (Zahm et al. 1995). Die

direkt durch N-Acetylcystein beeinträchtigte Zilienfunktion vermindert die Sekrettransportrate zusätzlich. Demnach wirkte - wie sich nachträglich zeigt - die häufigere Verwendung von N-Acetylcystein im Zentrum 27 wahrscheinlich dem zu erwartenden positiven rhDNase-Effekt entgegen.

Aufgrund des höheren Alters der Studienteilnehmer im Zentrum 27 kann davon ausgegangen werden, dass bei diesen Patienten die notwendige diuretische Therapie mit Furosemid häufig erfolgte, obwohl dies dem Studienprotokoll nicht immer zu entnehmen ist. Begleitend zur 
Verschlechterung des mukoziliären Transports durch Furosemid, löst die durch vorgenanntes Präparat entstehende Hypomagnesiämie eine Wirkungsabschwächung der rhDNase aus (Kondo et al. 2002, RoteListe ${ }^{\circledR} 2008$ b, Sanders et al. 2006). Zudem könnte die induzierte Diuresis zu systemischem Flüssigkeitsverlust und Verschlechterung der Sekrettransportrate führen (Chopra et al. 1977). Damit hätte die Furosemidgabe eine Abschwächung des rhDNase-Effektes zur Folge.

\subsubsection{5 $\quad \mathrm{O}_{2}$-Fraktion}

Laurenzi et al. (1968) machen Sauerstofffraktionen von $40 \%$ und mehr in der Einatemluft $\left(\mathrm{FiO}_{2}\right)$ für die Verlangsamung der Trachealsekrettransportgeschwindigkeit verantwortlich. Die Patienten in der rhDNase-Gruppe im Zentrum 27 benötigten innerhalb des gesamten Beatmungszeitraumes Sauerstoffkonzentrationen über 40\% und lagen damit tendenziell höher als diejenigen der rhDNase-Gruppe der mod. Gruppe 3. Somit könnte auch der erhöhte $\mathrm{FiO}_{2}$ Bedarf im Zentrum 27 dazu beigetragen haben, dass die bezweckte Verbesserung der mukoziliären Clearance abgeschwächt wurde.

\subsubsection{Lokalisation der Trachealsekretansammlung}

Die Verteilung des Sekrets innerhalb der Lunge könnte eventuell eine Rolle dabei spielen, dass der Effekt der rhDNase im Zentrum 27 nicht den Erwartungen entsprach. Wills et al. (1996) vermuten, dass die Lokalisation der Trachealsekretansammlung in der Lunge einen Einfluss auf die Effektivität der rhDNase-Therapie besitzt. Während bei der Mukoviszidose initial die Atemwege der oberen Lungenanteile betroffen sind, fließt das Trachealsekret bei den leicht über der horizontalen Ebene liegenden Oberkörpern der beatmeten Patienten unter der Einwirkung der Schwerkraft aus der Trachea in die basalen Lungenabschnitte ab (Tomashefski et al. 1986, Bassi et al. 2008). Demzufolge konnte diese ungünstige Verteilung des Trachealsekrets im Vergleich zu Mukoviszidose ein Hindernis des rhDNase-Effekts darstellen.

\subsubsection{Zeitpunkt der Applikation}

Eine weitere Erklärung für die unzureichende rhDNase-Wirkung bei unseren Patienten ist der Zeitpunkt der Applikation. Laut Studienprotokoll erfolgte die zweimal tägliche rhDNaseApplikation zu vorgegebener Uhrzeit, jeweils mit erlaubter Abweichung bis zu 2 Std. Die morgendliche Gabe sollte unmittelbar nach der studienbedingten Trachealsekretentnahme im Rahmen der endotrachealen Absaugung des Patienten erfolgen. 
Bei Anwendung einer druckkontrollierten Beatmung, wie es in unserem Zentrum üblich war, induziert die endotracheale Absaugung des Trachealsekrets eine Bronchokonstriktion und Ausbildung von Atelektasen (Lu et al. 2000, Boutros 1970, Almgren et al. 2004). Die vor der endotrachealen Absaugung häufig angewandte Hyperoxygenierung verringert die Bronchokonstriktion, aber nicht die Atelektasenbildung (Lu et al. 2000). Konsequenterweise empfehlen van der Giessen et al. (2007) die rhDNase-Applikation nicht nach der Entfernung des Trachealsekrets aus den Atemwegen sondern davor.

Ihr Wirkungsmaximum erreicht die rhDNase nach 30 min und die Wirkung hält bis zu 2 Std. an (Shak et al. 1990). Auf diese Weise könnten endotracheale Absaugung und starres Applikationszeitfenster ein Hindernis der rhDNase-Wirksamkeit darstellen. Hinzu sollte das Fehlen vom typischen intraalveolären Exsudat bei der Aspirationspneumonie, wie sie häufig im Zentrum 27 vorlag, betont werden. Die rhDNase-Verabfolgung traf somit auf künstlich erzeugte atetelektatische Lungenbereiche und teilweise oder komplett vom Sekret befreite Atemwege. Somit waren möglicherweise das Wirkungsmaximum und die Wirkdauer der rhDNase schon vor ihrer Ausbreitung in die peripheren Atemwegen und dem Anhäufen der großen Trachealsekretmengen abgeklungen.

\subsubsection{Verbesserung der Lungenfunktionsparameter (FiO2, AMV)}

Der Placebo / Verum-Vergleich der $\mathrm{FiO}_{2}$-Einstellungen innerhalb des Zentrums 27 (Göttinger Arm der Lufit-Studie) lieferte keine signifikanten Unterschiede. Diese Beobachtung wird durch die Studie aus der Arbeitsgruppe Boeuf et al. (1998) bestätigt. Die Autoren stellten keine Veränderungen der $\mathrm{FiO}_{2}$ und der Sauerstoffparameter im Blut nach der rhDNaseTherapie fest.

Überraschenderweise war die Differenz der $\mathrm{FiO}_{2}$ zwischen den beiden NaCl-Gruppen, nämlich zwischen mod. Gruppe 3 und Göttinger Arm, signifikant. Dieses Ergebnis könnte aufgrund der unterschiedlichen Äthiopathogenese der Pneumonien in den Gruppen entstanden sein. Eine die neurologische Grunderkrankung begleitende Aspirationspneumonie im Göttinger Arm hat möglicherweise den niedrigeren $\mathrm{FiO}_{2}-\mathrm{Bedarf}$ in der $\mathrm{NaCl}$-Gruppe („Placebo“-Gruppe) des Zentrums 27 bedingt, während die Patienten der NaCl-Gruppe der mod. Gruppe 3 mit primärer Pneumonie anderer Genese höhere Sauerstofffraktion benötigten. 


\subsubsection{Verkürzung des Aufenthaltes auf der Intensivstation}

Die im Rahmen der Studie nachgewiesenen Unterschiede im intensivstionärem Aufenthalt innerhalb der rhDNase-Gruppen und NaCl-Gruppen werden durch den Qualitätsbericht über die neurologischen Intensivstation (UMG) aus dem Jahre 2003, erstellt von der deutschen interdisziplinären Vereinigung der Intensiv- und Notfallmediziner (DIVI), bestätigt (Lefering 2002). Im Schnitt benötigen die neurologischen Patienten eine intensivstationäre Behandlung von 12 Tagen und halten sich damit 3-mal länger auf der Intensivstation auf als beatmete nicht neurologische Intensivpatienten

\subsubsection{Verkürzung der Krankenhausaufenthaltsdauer}

Die Veränderungen in der Krankenhausaufenhaltsdauer sind schwer zu interpretieren, weil hier lokale Gegebenheiten und interindividuellen Entscheidung leitender Ärzte über das weitere Prozedere nach dem intensivstationären Aufenthalt einfließen. Aufgrund des gut ausgebildeten Netzes von neurologischen Rehabilitationseinrichtungen im Südniedersachsen und Nordhessen erfolgte oftmals eine direkte Verlegung der Patienten des Zentrums 27 von der Intensivstation in eine Rehaklinik zur Frührehabilitation. Diese aus der lokalen Situation im Raum Südniedersachsen entstandene arbiträre Verkürzung der Krankenhausaufenthaltsdauer könnte als Erklärung der nicht nachgewiesenen Unterschiede in der Dauer des Krankenhausaufenthalts innerhalb der rhDNase-Gruppen und der NaClGruppen fungieren.

5.3

Erfassung der Wirksamkeit von rhDNase in vitro

Verringerung des DNA-Gehaltes und Verkürzung der DNA-Kettenlängen im Trachealsekret

\subsubsection{DNA-Konzentration im Trachealsekret}

Es ist denkbar, dass die primäre Abnahme der DNA-Konzentration im Trachealsekret der Patienten während des Beobachtungszeitraums Folge der physiologischen Eindämmung der Inflammation und der Restitution ist. Die anfänglichen Differenzen der DNA-Konzentration zwischen den Gruppen könnten auf die unterschiedliche Last der neutrophilen Granulozyten in den Atemwegen zurückzuführen sein (Ratjen et al. 2005).

Die Verabfolgung der rhDNase trug zur additiven Reduktion der DNA-Menge im Trachealsekret bei (Brandt et al. 1995, Ratjen et al. 2005, Riethmüller et al. unveröffentlicht). 
Diese Beobachtung wird eindeutig durch die Ergebnisse des Zentrums 27 bestätigt. Die Tatsache, dass die DNA-Konzentration im Trachealsekret nicht immer mit einem klinischen Effekt nach der rhDNase-Verabfolgung einhergeht (Ratjen und Tummler 1999), könnte eine weitere Erklärung für das Ausbleiben einer signifikanten Verkürzung der Beatmungsdauer in der rhDNase-Gruppe darstellen.

\subsubsection{DNA-Fragmente im Trachealsekret}

Eine Effektivität der rhDNase bei der Spaltung der DNA in kleine Polynukleotide war bei den Patienten des Zentrums 27 gegeben. Die Auswertung des gesamten Studienkollektivs (Gruppe 3 der Lufit-Studie) bestätigte ebenfalls die signifikante Verkürzung der DNA-Kettenlängen durch rhDNase (Riethmüller et al. noch unveröffentlicht).

Die DNA-Kettenverkürzung erlaubt indes - wie schon angedeutet - keine Aussage über die klinische Effektivität der rhDNase-Therapie (Ratjen und Tummler 1999). Trotz der erfolgten Verkürzung der DNA-Fragmente im Trachealsekret der rhDNase-Gruppe („Verum“) des Zentrums 27 (Göttinger Arm) dürfte das Nichterreichen des primären Studienziels bei den Verum-Patienten des Zentrums 27 auch dadurch erklärbar sein, dass Verkürzung der DNAKettenlänge und Therapieeffekt eben nicht immer kongruent sind.

Im menschlichen Körper (Gewebe und Flüssigkeiten) werden 2 Genfamilien der DNase exprimiert (Yasuda et al. 1992). Die DNase-I-Genfamilie wird in unterschiedlichen Geweben exprimiert. Sowohl in der Trachea als auch in den Lungen werden alle 4 Gene der DNase-IGenfamilie exprimiert (Shiokawa und Tanuma 2001). Die physiologische Rolle der DNase-IGenfamilie ist nicht definitiv geklärt. Die DNase-II-Genfamilie wird ebenfalls von diversen Gewebearten exprimiert und lässt sich unter anderem in Leukozyten nachweisen (Yasuda et al. 1992, Krieser et al. 2001). Die DNase IIb, eine der 2 DNase-II-Varianten, kommt seltener vor. Sie wird in geringer Menge in den Lungen exprimiert. Es wird angenommen, dass sie dort für DNA-Clearance der Lungen verantwortlich ist (Krieser et al. 2001). Da die DNase IIa mit den Lysosomen assoziiert ist, übt sie ihre Funktion in der DNA-Fragmentierung phagozytierter Partikel aus (Evans und Aguilera 2003). Somit ist denkbar, dass in den Lungensekreten a priori DNase IIa von den neutrophilen Granulozyten und DNase IIb aus Lungengewebe vorhanden sind und diese die DNA-Fragmentation vorangetrieben haben (Brandt et al. 1995). Im Vergleich zur NaCl-Gruppe („Placebo“) des Zentrums 27 mit Aspirationspneumonie wiesen die Patienten der NaCl-Gruppe der mod. Gruppe 3 äthiopathogenetisch andere Pneumonien auf. Letztere dürfte die DNase-IIb-Synthese in der 
Lunge inhibiert und die physiologische DNA-Clearance beeinträchtigt haben. Es ist denkbar, dass auf diese Weise der Unterschied in der DNA-Fragmentierung zwischen den beiden NaCl-Gruppen zustande kam (Zentrum 27 > mod. Gruppe 3).

\subsection{2}

\section{Verminderung der Entzündungsreaktion}

\subsubsection{Anzahl der Leukozyten im Trachealsekret}

Die Verringerung der Leukozyten im Trachealsekret kann entweder durch verminderte Anschoppung der Leukozyten im Entzündungsgebiet oder durch deren Beseitigung aus dem Entzündungsgebiet erfolgen. Henry et al. (1998) konnten trotz der Sekretverflüssigung durch die rhDNase keine Reduktion der Anzahl von neutrophilen Granulozyten im Sekret beobachten. Zudem vertraten sie die Auffassung, dass die Leukozytenzahl im Sekret die Ansprechbarkeit und den Erfolg der rhDNase-Therapie nicht reflektiert. Diese Annahme wird durch unsere Ergebnisse bestätigt. Im Laufe der Zeit nahm die Leukozytenzahl bei den Patienten aller Gruppen ab. Die Verminderung der neutrophilen Granulozyten im Sputum könnte als Folge der unter der antibiotischen Therapie eingegrenzten Entzündungsreaktion und der physiologischen Clearance im Tracheobronchialbaum entstehen.

\subsubsection{Senkung der Zytokinkonzentration im Trachealsekret}

Die rhDNase entfaltet keinen direkten Effekt auf die Produktion der proinflammatorischen Zytokine, die Chemotaxis der neutrophilen Granulozyten oder die Freisetzung von deren Produkten. Dagegen hemmt sie bei Mukoviszidose-Patienten im Langzeitverlauf die Progression der Entzündungsreaktion in den Atemwegen (Paul et al. 2004). Allerdings zeigten die Studien von Shah et al. (1996b) und Perks und Shute (2000), dass die kurzzeitige rhDNase-Verabfolgung einen Anstieg der freien Konzentration an Neutrophilenelastase und IL-8 bedingt.

Die meisten Daten über die Zytokinkonzentrationen im Trachealsekret nach der rhDNaseTherapie gehen auf die Studien an Mukoviszidose-Patienten zurück. Dies bedeutet: identische Ausgangsdiagnose beim Patientenkollektiv, vergleichbares, wenn auch nicht gleiches Erregerspektrum in den Atemwegen und die Anwendung einer etablierten (standardisierten) Antibiotikatherapie (Uni-duesseldorf 2008). Demgegenüber waren die Patienten in der LufitStudie sehr heterogen bezüglich von Grunderkrankung, Begleiterkrankungen, Erregerspektrum im Trachealsekret, antibiotischer Behandlung und Einstellungen des Beatmungsgerätes. Sie waren älter als die Mukoviszidose-Patienten. Diese Heterogenität lässt 
keinen direkten Vergleich unserer Studiendaten mit den Daten von Mukoviszidose-Patienten $\mathrm{Zu}$.

\subsubsection{1}

\section{Veränderungen der Zytokinbalance durch die jeweilige}

\section{Grunderkrankung}

Ischämische ZNS-Prozesse stellten den überwiegenden Anteil der Grunderkrankungen bei den Patienten der rhDNase-Gruppe des Zentrums 27, wogegen in der mod. Gruppe 3 der Lufit-Studie die Pneumonie dominierte. Daher ist der Vergleich der auftretenden Zytokinveränderungen durch die beiden Erkrankungen aufschlussreich.

Zentrales Nervensystem und Immunsystem sind in ihrer Funktion eng miteinander verknüpft (Blalock 1989, Elenkov et al. 2000). Die Bidirektionalität dieses Verhältnisses wird in der Manifestation der immunologischen Veränderungen als Antwort auf zerebralen Schaden und vice versa evident (Chamorro et al. 2007). Sowohl auf humoralem als auch auf neuronalem Wege moduliert das ZNS die Aktivität des Immunsystems (Elenkov et al. 2000). Die von Meisel et al. (2005) publizierte Graphik stellt die pathophysiologischen Ereignisse, welche zu Infektionen und schlechterem Therapieeregebnis bei neurologischen Patienten führen, sehr deutlich dar.

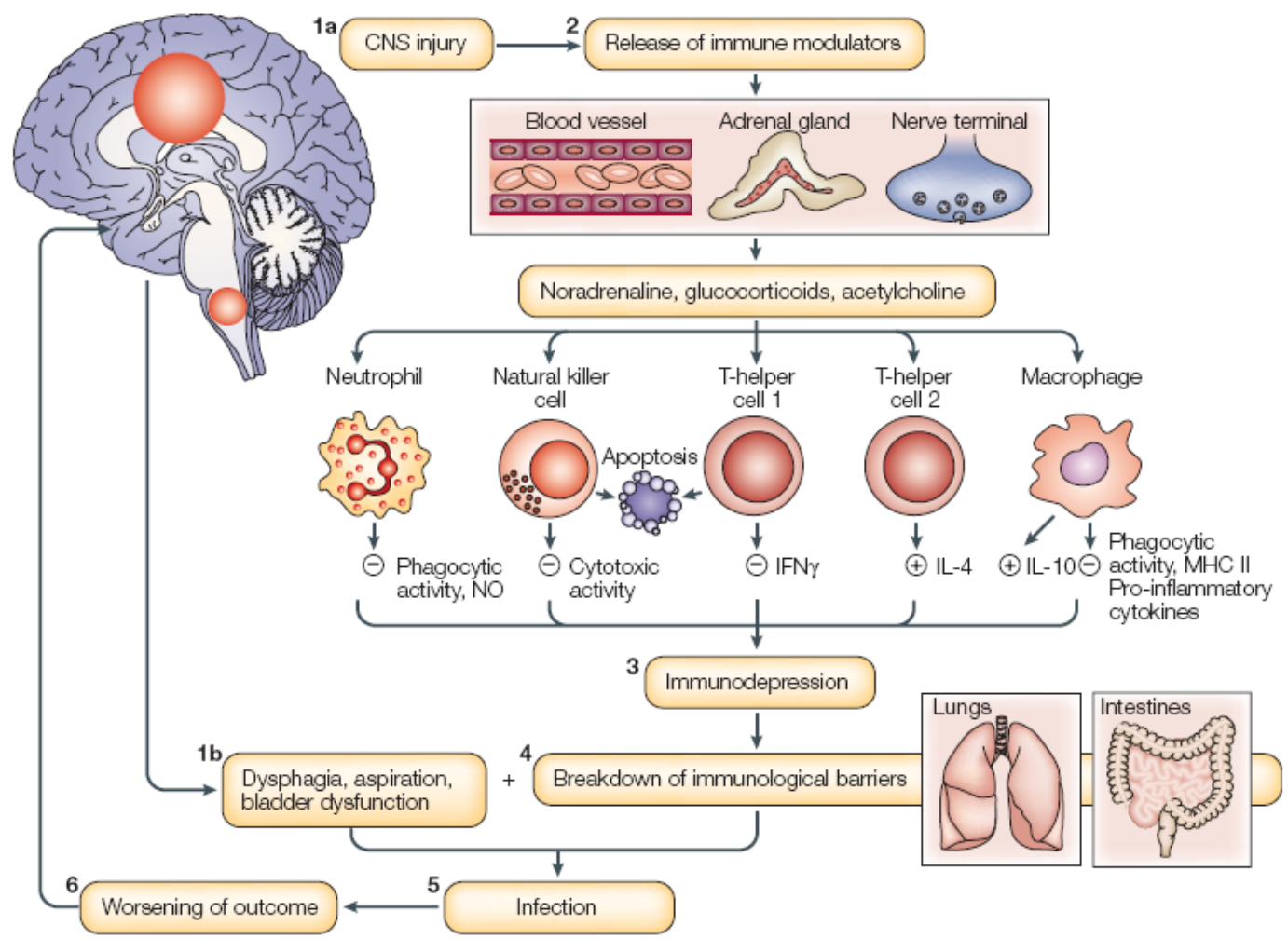

Abbildung 5.3.2.2.1/1:

Schematische Darstellung der pathophysiologischen Veränderungen im Organismus nach ZNS-Trauma (Meisel et al. 2005 S.783) 
Der ischämische Schlaganfall löst bereits nach wenigen Stunden eine Immunsuppression aus, die über mehrere Wochen andauert (Dirnagl et al. 2007). Sie äußert sich in einem schnellen Anstieg der im Plasma zirkulierenden Zytokine mit einem niedrigen Quotienten zwischen proinflammatorischem TNF- $\alpha$ und antiinflammatorischem IL-10 (Chamorro et al. 2007). Die fast ausnahmslos bei allen Patienten der rhDNase-Gruppe des Zentrums 27 auftretende Sepsis dürfte u.a. eine Folge dieser Immunsuppression darstellen.

Seine antiinflammatorische Rolle übt das IL-10 gleichfalls bei der Kontrolle der Entzündungsprozesse in den Atemwegen aus (Tournoy et al. 2000). Ausgehend von seiner synthesehemmenden Wirkung auf IL-1 $\beta$, IL-6, IL-8, GM-CSF (de Waal Malefyt et al.1991) kann man auch deren erniedrigte Spiegel im Trachealsekret erwarten. Zu dieser Reaktion mögen die Leukozyten, die trotz LPS-Stimulation bereits wenige Stunden nach dem Schlaganfall und in der folgenden Woche weniger Zytokine produzieren, beitragen (Emsley et al. 2007). Fünf von unseren Probanden litten an Broncho- bzw. Aspirationspneumonie. Bei ihnen dürfte eine weitere Determinante für die Zytokinbalance in Erscheinung getreten sein, indem die Aspirationspneumonie ein für sie spezifisches Zytokinmuster erzeugt (Rotta et al. 2004, Folkesson et al. 1995).

Eine Pneumonie löst in der betroffenen Lunge einen Anstieg von proinflammatorischen Zytokinen (IL-1 $\beta$, IL-6 und IL-8) und von antiiflammatorischem Zytokin (IL-10) aus (Kolsuz et al. 2003, Wu et al. 2006). Expressionsgrad und Gleichgewicht der Zytokine verändern sich entsprechend der Keimart und Schwere von Pneumonie (Kolsuz et al. 2003, Wu et al. 2006). Zusätzlich greift die immunologische Kompetenz des Patienten in das Gleichgewicht der Zytokine ein.

\subsubsection{2}

\section{Einfluss der Antibiotika und des Erregerspektrums auf den Zytokinspiegel}

In einigen Studien konnte gezeigt werden, dass die gram-negativen und gram-positiven Bakterien unterschiedliche Muster von immunomodulatorischen Zytokinen induzieren (Hessle et al. 2005, Hessle et al. 2000, Jiang et al. 1999). Darüber hinaus führen diverse Antibiotika zu Veränderungen im Zytokinspiegel (Prins et al. 1995, Arditi et al. 1993, Simon et al. 1991). Sogar innerhalb eines mikrobiellen Genus lassen sich ebenfalls gattungsabhängig unterschiedliche Zytokinmuster vorfinden (Jotwani et al. 1994, Zughaier et al. 1999). 
Demzufolge führten möglicherweise der höhere Anteil der gram-negativen Bakterien im Zentrum 27 und die hausspezifischen Richtlinien der antibiotischen Therapien zu einem eigenen Muster in der Zytokinfreisetzung.

\subsection{Einfluss der Beatmung auf den Zytokinspiegel}

Allein die mechanische Dehnung der Lungen im Rahmen der Respiratorbeatmung kann die Produktion und Freisetzung der Entzündungsmediatoren, u. a. des proinflammatorischen IL-8, aus dem Alveolarepithel steigern (Vlahakis et al. 1999). Mit der Freisetzung von IL-6, IL-8, TNF- $\alpha$ reagieren auch die Alveolarmakrophagen auf die Beatmung (Pugin et al. 1998). Bei Vorhandensein von Endotoxin sowohl systemisch als auch intrapulmonal verstärkt die Beatmung die Zytokinantwort und zelluläre Entzündungsreaktion der Lungen (Altemeier et al. 2004, Dhanireddy et al. 2006). Somit wirkte möglicherweise auch die Beatmung der erhofften antiinflammatorischen rhDNase-Wirkung entgegen, was letztlich in unterschiedlicher Ausprägung für alle Verum-Patienten zuträfe.

\subsection{Einfluss des Alters auf den Zytokinspiegel}

Für die Komplexität des proinflammatorischen Bildes trägt noch das höhere Alter der Studienteilnehmer bei. Höheres Alter ist mit einer veränderten Immunregulation und einer persistierenden leichtgradigen Entzündung im Organismus, speziell in den unteren Atemwegen verbunden (Meyer et al. 1996, Pedersen et al. 2000). Die veränderte Immunregulation äußert sich in verlängerter inflammatorischen Aktivität (Bruunsgaard et al. 1999). Aufgrund des höheren Alters der Studienpatienten kann man mit präexistierender leichtgradiger Entzündung, abgesehen von pulmonalen Vor- und Grunderkrankungen, und veränderter Immunregulation rechnen.

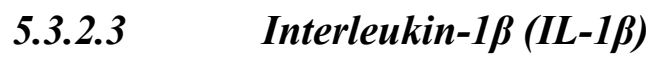

Der IL-1 $\beta$-Spiegel im Trachealsekret reflektiert die Bakterienlast bei einer Pneumonie (Wu et al. 2003). Die Exposition des Atemwegsepithels durch saures Aspirationsmaterial führt

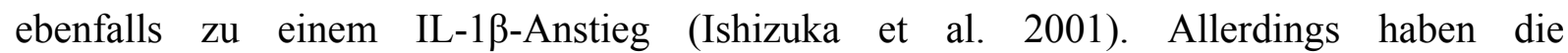
Untersuchungen von Aspirationsschäden und ambulant erworbenen Pneumonien ergeben, dass der IL-1ß-Anstieg transient ist (Rotta et al. 2004, Wu et al. 2003). Dagegen verringert sich die IL-1 $\beta$-Konzentration nicht bei fortbestehender und therapieresistenter Pneumonie (Wu et al. 2003). Pneumonien stellten den Hauptanteil an den Grunderkrankungen in der NaCl-Gruppe („Placebo“) der mod. Gruppe 3 der Lufit-Studie dar. Aufgrund dessen waren 
höhere Konzentrationen an IL-1 $\beta$ im Trachealsekret vorhanden. Als Folge des nur transienten Charakters von IL-1 $\beta$-Anstieg und der Pneumonieart, nämlich Aspirationspneumonie, im Zentrum 27 kam es möglicherweise zur Reduktion des IL-1 $\beta$-Spiegels bei unseren „Placebo“Patienten. Dies wäre eine Erklärung für den signifikanten Unterschied in der IL-1 $\beta$ Konzentration zwischen den NaCl-Gruppen, d.h. der „Placebo“-Gruppe der mod. Gruppe 3 und der „Placebo“-Gruppe im Zentrum 27.

\subsubsection{Interleukin-6 (IL-6)}

Das IL-6 ist eines der Zytokine, die im Rahmen der Pneumonie und nach der Aspiration des Magensaftes ansteigen (Kolsuz et al. 2003, Nishina et al. 1998). Sein Spiegel dient als Marker in der Beurteilung des Schweregrades und der Komplikationen einer Pneumonie (Kolsuz et al. 2003). Der IL-6-Spiegel blieb in der NaCl-Gruppe des Zentrums 27 zu Beginn niedrig und nahm erst mit der Zeit zu. Eine Erklärung hierfür mag die in der NaCl-Gruppe des Zentrums 27 vorhandene schlaganfallbedingte Immunsuppression mit verminderter Produktion der Zytokine durch Leukozyten und angestiegenem Spiegel des antiinflammatorischen IL-10 im Trachealsekret sein (Emsley et al. 2007, Schulte-Herbrüggen et al. 2008). Im Gegensatz dazu nahm die IL-6-Konzentration in der NaCl-Gruppe der mod. Gruppe 3 im Verlauf ab. Diese Reduktion lässt sich durch therapeutischen und physiologischen Effekt auf das entzündliche Geschehen begründen. Auf diese Weise könnte der signifikante Unterschied im IL-6-Spiegel zwischen den beiden „Placebo“-Gruppen erklärbar sein.

\subsubsection{Interleukin-8 (IL-8)}

Die stattgefundene Aspiration, Pneumonie und maschinelle Beatmung haben einen Anstieg der IL-8-Konzentration im Trachealsekret zur Folge (Folkesson et al. 1995, Kolsuz et al. 2003, Vlahakis et al. 1999, Pugin et al. 1998). Konsekutiv kommt es zur Einwanderung der neutrophilen Granulozyten in die Atemwege und Freisetzung ihrer Enzyme, u.a. Elastase (Baggiolini et al. 1989). Das Bronchialepithel reagiert auf die Elastase-Freisetzung mit der vermehrten Expression von IL-8 (Nakamura et al. 1992). Durch Ausbildung von Komplexen zusammen mit DNA und Aktin sinkt die freie IL-8-Konzentration im Trachealsekret ab (Perks und Shute 2000). Daher könnten die täglichen Differenzen von Leukozytenzahlen, freier DNA und Aktin die Schwankungen und keine eruierbare Tendenz der freien IL-8Konzentration in allen Gruppen bedingen. 


\subsubsection{Interleukin-10 (IL-10)}

Der Vergleich der rhDNase-Gruppen („Verum“) erbrachte einen signifikanten Unterschied des IL-10-Spiegels.

IL-10 ist ein antiinflammatorisches Zytokin: es ist, wie schon erwähnt, mit dem Mechanismus der gehirninduzierten Immunsuppression assoziiert (Akdis und Blaser 2001). Durch seinen Anstieg wird - so nimmt man an - der zerebrale Schaden nach Ischämie limitiert, auf Kosten einer systemischen Abwehrschwäche (Spera et al. 1998, Chamorro et al. 2007). Eine Konsequenz ist die Alteration der lokalen pulmonalen Immunität infolge gesteigerter IL-10Produktion durch Alveolarmakrophagen und verminderter Lymphozytenzahl in den Lungen (Schulte-Herbrüggen et al. 2008). Die bei neurologischen Patienten häufig auftretende Aspiration von Magensaft trägt darüber hinaus zu einem Anstieg des IL-10-Spiegels bei (Kidd et al. 1995, Rotta et al. 2004). Zudem beschrieben Meyer et al. (1996) eine altersabhängige Zunahme der IL-10-Konzentration, die auch das Trachealsekret betrifft. Schlaganfallassoziierter Anstieg des IL-10, höheres Alter der Patienten zusammen mit gehäuften Aspirationspneumonien dürften der Grund für hohe IL-10-Konzentrationen bei Patienten der rhDNase-Gruppe des Zentrums 27 sein.

Die Höhe des IL-10-Spiegels im Trachealsekret reflektiert bei Patienten mit Pneumonie außerdem die Bakterienart und den genetischen Polymorphismus der IL-10-Genexpression (Hessle et al. 2000, Wu et al. 2006, Gallagher et al. 2003). Deshalb könnten der Altersunterschied, nämlich die jüngeren Patienten in der rhDNase-Gruppe der mod. Gruppe 3, die Unterschiede im Keimspektrum zwischen den beiden rhDNase-Gruppen (Daten nicht aufgeführt) und der eventuell vorhandene genetische Polymorphismus des IL-10-Gens den niedrigen IL-10-Spiegel in der rhDNase-Gruppe der mod. Gruppe 3 bedingen.

\subsubsection{Lipopolysaccharidbindendes Protein (LBP)}

In unseren Ergebnissen konnten wir einen Unterschied im LBP-Spiegel zwischen den rhDNase-Gruppen feststellen. Die intraalveoläre LBP-Synthese steigt mit zunehmender Lipopolysaccharidmenge an (Knapp et al. 2006). Nicht nur LPS, sondern auch IL-1 $\beta$, IL-6 und Dexamethason führen zu gesteigerter intraalvolärer LBP-Produktion (Dentener et al. 2000, Knapp et al. 2006).

Unter den objektivierbaren Faktoren mit einem Einfluss auf den LBP-Spiegel unterschieden sich die Gruppen im Steroidgebrauch. Die interne Datenanalyse der Steroidanwendung (Daten nicht aufgeführt) ergab einen vermehrten Gebrauch von Steroiden in der rhDNase-Gruppe der 
mod. Gruppe 3 im Vergleich mit der rhDNase-Gruppe des Zentrums 27. Dies könnte eine signifikant erhöhte LBP-Konzentration im Trachealsekret der Patienten der mod. Gruppe 3, verglichen mit Patienten des Zentrums 27, bedingen.

\subsubsection{Granulozyten-Makrophagen-Kolonienstimulierender Faktor (GM-CSF)}

Die GM-CSF-Konzentration wird durch unterschiedliche Parameter beeinflusst.

Die Veränderungen in der GM-CSF-Expression treten in Abhängigkeit vom Pathogen auf. Bei Mischinfektion steigt die GM-CSF-Expression stärker an (Michelow et al. 2007). Zu den die GM-CSF-Freisetzung begünstigenden Faktoren gehören neben Il-1 $\beta$ auch lokale Mediatoren, wie Histamin und Acetylcholin (Klapproth et al. 1998). Dagegen nimmt unter der Therapie mit Steroiden und Makroliden die GM-CSF-Konzentration ab (Papoff et al. 2001, Yamasawa et al. 2004).

Aufgrund der Unterschiede in der Pathogenese von pulmonalen Erkrankungen innerhalb der NaCl-Gruppen („Placebo“-Gruppen) entstanden komplexe Wechselwirkungen in der Zytokinbalance. Höchstwahrscheinlich führte die Dominanz von „gewöhnlichen“ Pneumonien und COPD in der NaCl-Gruppe der mod. Gruppe 3 zu signifikant höherem IL-1 $\beta$-Spiegel als in der NaCl-Gruppe des Zentrums 27 (Göttinger Arm).

Außerdem steigt im Rahmen der Entzündung der Gehalt an nicht neuronalem Acetylcholin an (Reinheimer et al. 1998 a). Das nicht neuronale Acetylcholinsystem ist fast in allen Entzündungszellen der Atemwege vorhanden, am deutlichsten in Lymphozyten und Atemwegsepithelien (Gwilt et al. 2007). Unter Glukokortikosteroidanwendung verringert sich der Acetylcholingehalt in Atemwegsepithelzellen (Reinheimer et al. 1998 b).

Die internen Auswertungen der Studiendaten ergaben die häufigere Anwendung der Steroide in der NaCl-Gruppe des Zentrums 27.

Demzufolge konnten die erhöhten Konzentrationen von IL-1 $\beta$ und Acetylcholin in der NaClGruppe der mod. Gruppe 3 zum signifikant höheren GM-CSF-Spiegel führen. Im Gegensatz hat möglicherweise die gehäufte Steroidanwendung in der NaCl-Gruppe des Zentrums 27 direkt bzw. indirekt durch reduzierten Acetylcholingehalt die Verminderung der GM-CSFKonzentration bewirkt. 


\section{$5.4 \quad$ Schlussfolgerung}

Unsere Arbeit konnte die primäre Wirkung der rhDNase in der Spaltung der freien DNAFragmente in kürzere DNA-Polynukleotidfragmente bestätigen. Dessen ungeachtet führten die kurzkettigen DNA-Fragmente nicht $\mathrm{zu}$ den erhofften antiinflammatorischen Veränderungen im Sinne der Reduktion von Leukozytenzahl und proinflammatorischen Zytokinen im Trachealsekret und damit verbundener verminderter Dauer der Beatmung und des Aufenthaltes auf der Intensivstation bzw. in der Klinik.

Vom großen Interesse sind auch die gefundenen Unterschiede zwischen den Patienten des Zentrums 27 (Göttinger Arm) und der modifizierten Gruppe 3. Der höhere IL-10-Spiegel im Trachealsekret der rhDNase-Gruppe des Zentrums 27 unterschied sich signifikant von dem der rhDNase-Gruppe der modifizierten Gruppe 3. Dieser Unterschied scheint die in der Zwischenzeit bekannte, nach einem zerebralen Ereignis stattfindende globale Immunsuppression bei neurologischen Patienten zu bestätigen. Diese Tatsache unterstreicht die Anfälligkeit eines neurologischen Patienten für nosokomiale Infektionen zum einen und erklärt zum anderen die im Zentrum 27 beobachteten bei nahezu allen Patienten gegebenen septischen Verläufe. Demnach könnte die Immunsuppression einen additiven bzw. synergistischen Einfluss neben der zentralen Ventilationsstörung auf die Beatmungsdauer der Patienten im Zentrum 27 ausüben. Ebenfalls wurden einige Differenzen zwischen den NaClGruppen nachgewiesen. In ihrer Gesamtheit weisen sie auf die Unterschiede in der Äthiopathogenese der Aspirationspneumonie und ,gewöhnlichen“ Pneumonie, welche in der NaCl-Gruppe der modifizierten Gruppe 3 dominierte, hin.

Die Regulation der Mukoviskoelaszitität und mukoziliären Clearance ist ein multikausal abhängiger und störanfälliger Prozess. Damit die Auswirkung der rhDNase-Therapie auf die mukoziliäre Clearance durch diverse in die Regulation eingreifende Faktoren nicht nivelliert wird, ist eine größere Patientenpopulation als im Göttinger Arm der Lufit-Studie notwendig. Bei der kleinen Göttinger Gruppe von 21 Patienten wirkten individuelle, kranheitsbedingte und therapieabhängige Besonderheiten limitierend auf die Studienergebnisse. Dadurch konnten sich die statistisch eindeutigen Ergebnisse der Gruppe 3 der Lufit-Studie nicht im Zentrum 27 abbilden. 


\section{Zusammenfassung}

Nosokomiale Pneumonie stellt laut aktuellen Ergebnissen des Krankenhaus-InfektionsSurveillance-Systems (KISS) die häufigste Hospitalinfektion dar. Bei einem über 48 Std. beatmeten Patienten liegt die Inzidenz einer nosokomialen Pneumonie zwischen 10-20 \%. Die neurologischen Patienten nehmen eine gesonderte Stellung ein, da sie als Folge der zentralen Ventilationsstörungen eine längere Beatmungsdauer aufweisen. Aus diesem Grund kommt dem Versuch, die Beatmungsdauer zu verkürzen, eine besondere Bedeutung zu.

Das primäre Ziel dieser Arbeit war, die rhDNase- Wirkung auf die Gesamtbeatmungsdauer der langzeitbeatmeten ( $>3$ Tagen) erwachsenen neurologischen Patienten im Vergleich zur „Placebo“- Gruppe zu prüfen. Zusätzlich wurden die Folgen der erleichterten Mobilisierung des Bronchial- und Trachealsekrets als sekundäre Ziele verwendet.

Es handelte sich um den Arm einer prospektiven randomisierten placebokontrollierten doppelt-blinden multizentrischen deutschlandweiten Studie bei erwachsenen maschinell beatmeten Patienten (Lufit-Studie). Insgesamt wurden in die 3 Gruppen der Lufit-Studie 262 Patienten eingeschlossen. In der modifizierten Gruppe 3 (ohne Göttinger Arm) konnten 125 Patienten ausgewertet werden. 60 Patienten erhielten rhDNase-Therapie und 65 Patienten eine NaCl-Therapie. Im Göttinger Arm der Studie (Zentrum 27) wurden 22 Patienten rekrutiert. 21 Patienten davon entsprachen den Kriterien der Diagnosegruppe 3 und 1 Patient Kriterien der Diagnosegruppe 1. In der rhDNase-Gruppe befanden sich 11 Patienten und in der NaClGruppe 10 Patienten. Die Applikation von Medikation (rhDNase bzw. NaCl) erfolgte zweimal täglich für min. 3 bis max. 21 Beatmungstage.

Im Göttinger Arm der Lufit-Studie konnte keine Verkürzung der Beatmungsdauer unter Therapie mit rhDNase beobachtet werden. Desgleichen wurde keine Verringerung der Aufenthaltsdauer auf der Intensivstation und im Krankenhaus festgestellt. Ebenfalls keine signifikanten Unterschiede wurden bei dem Vergleich der Beatmungsparameter erreicht. Es konnte nachgewiesen werden, dass durch die Applikation von rhDNase tatsächlich die DNAFragmente im Trachealsekret verkürzt werden und die freie DNA-Konzentration abnimmt, jedoch ohne jeglichen Einfluss auf Leukozytenzahl und Zytokinspiegel.

Der Vergleich von rhDNase-Gruppen des Zentrums 27 und der modifizierten Gruppe 3 ergab eine signifikant kürzere Beatmungsdauer und intensivstationäre Aufenthaltsdauer bei den 
Patienten der modifizierten Gruppe 3. In der Dauer des Krankenhausaufenthaltes unterschieden sich die Gruppen allerdings nicht. Ähnliche Verläufe zeigten die Beatmungsparameter in beiden Gruppen. Des Weiteren wurden keine signifikanten Unterschiede zwischen den beiden rhDNase-Gruppen bezüglich der DNA-Konzentration und DNA-Kettenlänge, Leukozytenzahl und Zytokine, mit Ausnahme von IL-10 und LBP festgestellt.

Bei der Gegenüberstellung der NaCl-Gruppen des Zentrums 27 und der modifizierten Gruppe 3 zeigten sich keine Unterschiede in der Dauer der Beatmung, des Aufenthaltes auf Intensivstation und im Krankenhaus. Bei den Beatmungsparametern unterschieden sich jedoch die Gruppen signifikant hinsichtlich des $\mathrm{FiO}_{2}-$ Bedarfs, jedoch nicht des benötigten Atemminutenvolumens. Überraschenderweise wies die NaCl-Gruppe des Zentrums 27 signifikant kürzere DNA-Fragmente als die NaCl-Gruppe der modifizierten Gruppe 3 auf. Die DNA-Konzentration unterschied sich innerhalb der Gruppen jedoch nicht. Bezüglich Leukozytenzahl und Zytokinen ließen sich, mit Ausnahme von IL-1 $\beta$, IL-6 und GM-CSF, keine signifikanten Unterschiede nachweisen.

In unserem Zentrum führte die rhDNase-Therapie durch DNA-Fragmentierung und Verringerung der DNA-Konzentration zu keiner Verkürzung der Beatmungsdauer im Gegensatz zu den Ergebnissen der Gruppe 3 der Lufit-Studie. Dieses Resultat war höchstwahrscheinlich durch die Komplexität der Krankheitsbilder intensivpflichtiger neurologischer Patienten, die im Vordergrund stehende zentrale Atemstörung und eventuell durch niedrige Patientenzahl im Zentrum 27 bedingt.

Dennoch ist die Therapie mit rhDNase in Anbetracht der Ergebnisse der Gruppe 3 der LufitStudie, in besonderem Maße der Patienten mit nicht zerebraler Grunderkrankung, zu empfehlen.

Die Anwendung der rhDNase bei neurologischen Patienten kann vornehmlich bei Patienten mit starker Produktion von Lungen- und Trachealsekret und damit assoziierten Beatmungsschwierigkeiten in Betracht kommen. Außerdem könnte, um den Erfolg der rhDNase-Therapie $\mathrm{zu}$ steigern, die endotracheale Absaugung erst $30 \mathrm{~min}$. nach der Applikation und nicht davor in Erwägung gezogen werden.

Um genaue Kenntnis über die Effektivität der regelmäßigen rhDNase-Therapie bei neurologischen Patienten zu erhalten, wäre hierfür eine Studie mit statistisch zu berechnender höherer Anzahl ausschließlich neurologischen Patienten wünschenswert. 


\section{Literaturverzeichnis}

Addington, W. R., Stephens, R. E., Widdicombe, J. G., Rekab, K. (2005): Effect of stroke location on the laryngeal cough reflex and pneumonia risk. Cough $\underline{1}, 4$.

Aderka, D., Le, J. M., Vilcek, J. (1989): IL-6 inhibits lipopolysaccharide-induced tumor necrosis factor production in cultured human monocytes, U937 cells, and in mice. $J$ Immunol 143, 3517-23.

Akdis, C. A., Blaser, K. (2001): Mechanisms of interleukin-10-mediated immune suppression. Immunology 103, 131-6.

Almgren, B., Wickerts, C. J., Heinonen, E., Hogman, M. (2004): Side effects of endotracheal suction in pressure- and volume-controlled ventilation. Chest $\underline{125}, 1077-$ 80 .

Altemeier, W. A., Matute-Bello, G., Frevert, C. W., Kawata, Y., Kajikawa, O., Martin, T. R., Glenny, R. W. (2004): Mechanical ventilation with moderate tidal volumes synergistically increases lung cytokine response to systemic endotoxin. Am J Physiol Lung Cell Mol Physiol 287, L533-42.

App, E. M., King, M., Helfesrieder, R., Kohler, D., Matthys, H. (1990): Acute and longterm amiloride inhalation in cystic fibrosis lung disease. A rational approach to cystic fibrosis therapy. Am Rev Respir Dis 141, 605-12.

Arditi, M., Kabat, W., Yogev, R. (1993): Antibiotic-induced bacterial killing stimulates tumor necrosis factor-alpha release in whole blood. $J$ Infect Dis 167, 240-4.

Baggiolini, M., Walz, A., Kunkel, S. L. (1989): Neutrophil-activating peptide-1/interleukin 8, a novel cytokine that activates neutrophils. J Clin Invest 84, 1045-9.

Bassi, G. L., Zanella, A., Cressoni, M., Stylianou, M., Kolobow, T. (2008): Following tracheal intubation, mucus flow is reversed in the semirecumbent position: possible role in the pathogenesis of ventilator-associated pneumonia. Crit Care Med $\underline{36}, 518$ 25.

Baumgartner R: Neurophysiologische Grundlagen des Bewußtseins; in: Der bewußtlose Patient; hrsg. v. Ahnefeld FW, Bergmann H, Burri C u.a.; Springer-Verlag, Berlin 1979, 10-19.

Blalock, J. E. (1989): A molecular basis for bidirectional communication between the immune and neuroendocrine systems. Physiol Rev $\underline{69}, 1-32$.

Boat, T. F., Cheng, P., Leigh, M. W.: Biochemistry of mucus; in :Airway Secretion: Physiological Bases for the Control of Mucuous Hypersecretion. Lung Biology in Helth and Disease; hrsg. v. Takishima T, Shimura S u.a.; Marcel Dekker, New York 1994, Vol. 72, 217-282.

Bodmann, K.-F., Lorenz, J., Bauer, T.T., Ewig, S., Trautmann, M., Vogel, F. (2003): Nosokomiale Pneumonie: Prävention, Diagnostik und Therapie. Chemother J 12, 3344.

Boeuf, B., Prouix, F., Morneau, S., Marton, D., Lacroix, J. (1998): Safety of endotracheal rh DNAse (Pulmozyme) for treatment of pulmonary atelectasis in mechanically ventilated children. Pediatr Pulmonol 26, 147.

Boucher, R. C. (1994): Human airway ion transport. Part one. Am J Respir Crit Care Med $150,271-81$.

Boutros, A. R. (1970): Arterial blood oxygenation during and after endotracheal suctioning in the apneic patient. Anesthesiology $\underline{32}, 114-8$. 
Brandt, T., Breitenstein, S., von der Hardt, H., Tummler, B. (1995): DNA concentration and length in sputum of patients with cystic fibrosis during inhalation with recombinant human DNase. Thorax 50, 880-2.

Brass, D. M., Savov, J. D., Whitehead, G. S., Maxwell, A. B., Schwartz, D. A. (2004): LPS binding protein is important in the airway response to inhaled endotoxin. $J$ Allergy Clin Immunol 114, 586-92.

Bruunsgaard, H., Skinhoj, P., Qvist, J., Pedersen, B. K. (1999): Elderly humans show prolonged in vivo inflammatory activity during pneumococcal infections. $J$ Infect Dis $\underline{180}, 551-4$.

Ceesay, S. M., Melville, G. N., Mills, J. L., Wray, S. R. (1983): Comparative observations of mucus transport velocity in health and disease. Respiration 44, 184-8.

Chamorro, A., Urra, X., Planas, A. M. (2007 ): Infection after acute ischemic stroke: a manifestation of brain-induced immunodepression. Stroke 38, 1097-103.

Chevret, S., Hemmer, M., Carlet, J., Langer, M. (1993): Incidence and risk factors of pneumonia acquired in intensive care units. Results from a multicenter prospective study on 996 patients. European Cooperative Group on Nosocomial Pneumonia. Intensive Care Med 19, 256-64.

Chilvers, M. A., O'Callaghan, C. (2000): Local mucociliary defence mechanisms. Paediatr Respir Rev 1, 27-34.

Chopra, S. K., Taplin, G. V., Simmons, D. H., Robinson, G. D., Jr., Elam, D., Coulson, A. (1977): Effects of hydration and physical therapy on tracheal transport velocity. Am Rev Respir Dis 115, 1009-14.

Cicco, N. A., Lindemann, A., Content, J., Vandenbussche, P., Lubbert, M., Gauss, J., Mertelsmann, R., Herrmann, F. (1990): Inducible production of interleukin-6 by human polymorphonuclear neutrophils: role of granulocyte-macrophage colonystimulating factor and tumor necrosis factor-alpha. Blood $\underline{75}, 2049-52$.

Clamp, J. R. (1978): Chemical aspects of mucus. General considerations. Br Med Bull 34, 257.

Clarke, S. W. (1989): Rationale of airway clearance. Eur Respir J Suppl 7, 599s-603s.

Cliffton, E. E., Grossi, C. E. (1960): Pancreatic dornase aerosol in postoperative atelectasis. Am J Surg 100, 447-54.

Content, J., De Wit, L., Poupart, P., Opdenakker, G., Van Damme, J., Billiau, A. (1985): Induction of a 26-kDa-protein mRNA in human cells treated with an interleukin-1related, leukocyte-derived factor. Eur J Biochem 152, 253-7.

Cook, D., Walter, S. D., Cook, R. J., Griffith, L. E., Guyatt, G. H., Leasa, D., Jaeschke, R. Z., Brun-Buisson, C. (1998a): Incidence of and risk factors for ventilator-associated pneumonia in critically ill patients. Ann Intern Med 129, 433-40.

Cook, D., Guyatt, G., Marshall, J., Leasa, D., Fuller, H., Hall, R., Peters, S., Rutledge, F., Griffith, L., McLellan, A., Wood, G., Kirby, A. (1998b): A comparison of sucralfate and ranitidine for the prevention of upper gastrointestinal bleeding in patients requiring mechanical ventilation. Canadian Critical Care Trials Group. $N$ Engl J Med $\underline{338}, 791-7$.

Copewithcytokines (2008a): http://www.copewithcytokines.de/cope.cgi?key=IL8; (Abruf am 21.02.08).

Copewithcytokines (2008b): http://www.copewithcytokines.de/cope.cgi?key=IL10; (Abruf am 21.02.08).

Copewithcytokines (2008 c): http://www.copewithcytokines.de/cope.cgi?key=GM\%2dCSF; (Abruf am 21.02.2008).

Creeth, J. M. (1978): Constituents of mucus and their separation. Br Med Bull 34, 17-24.

Cromwell, O., Hamid, Q., Corrigan, C. J., Barkans, J., Meng, Q., Collins, P. D., Kay, A. B. (1992): Expression and generation of interleukin-8, IL-6 and granulocyte-macrophage 
colony-stimulating factor by bronchial epithelial cells and enhancement by IL-1 beta and tumour necrosis factor-alpha. Immunology 77, 330-7.

Daniels, S. K., Brailey, K., Priestly, D. H., Herrington, L. R., Weisberg, L. A., Foundas, A. L. (1998): Aspiration in patients with acute stroke. Arch Phys Med Rehabil 79, 14-9.

Dasgupta, B., King, M. (1996): Reduction in viscoelasticity in cystic fibrosis sputum in vitro using combined treatment with nacystelyn and rhDNase. Pediatr Pulmonol 22, 161-6.

Davies, J., Trindade, M. T., Wallis, C., Rosenthal, M., Crawford, O., Bush, A. (1997): Retrospective review of the effects of rhDNase in children with cystic fibrosis. Pediatr Pulmonol 23, 243-8.

Davis, J. C., Jr., Manzi, S., Yarboro, C., Rairie, J., McInnes, I., Averthelyi, D., Sinicropi, D., Hale, V. G., Balow, J., Austin, H., Boumpas, D. T., Klippel, J. H. (1999): Recombinant human Dnase I (rhDNase) in patients with lupus nephritis. Lupus $\underline{8}, 68$ 76.

Defilippi, P., Poupart, P., Tavernier, J., Fiers, W., Content, J. (1987): Induction and regulation of mRNA encoding $26-\mathrm{kDa}$ protein in human cell lines treated with recombinant human tumor necrosis factor. Proc Natl Acad Sci U S A $\underline{84}$, 4557-61.

de Lange, D. W., Bonten, M. J. (2005): Can we predict septic shock in patients with hospitalacquired pneumonia? Crit Care $\underline{9}, 640-1$.

Dentener, M. A., Bazil, V., Von Asmuth, E. J., Ceska, M., Buurman, W. A. (1993): Involvement of CD14 in lipopolysaccharide-induced tumor necrosis factor-alpha, IL-6 and IL-8 release by human monocytes and alveolar macrophages. $J$ Immunol $\underline{150}$, 2885-91.

Dentener, M. A., Vreugdenhil, A. C., Hoet, P. H., Vernooy, J. H., Nieman, F. H., Heumann, D., Janssen, Y. M., Buurman, W. A., Wouters, E. F. (2000): Production of the acute-phase protein lipopolysaccharide-binding protein by respiratory type II epithelial cells: implications for local defense to bacterial endotoxins. Am J Respir Cell Mol Biol 23, 146-53.

Desai, M., Weller, P. H., Spencer, D. A. (1995): Clinical benefit from nebulized human recombinant DNase in Kartagener's syndrome. Pediatr Pulmonol 20, 307-8.

de Waal Malefyt, R., Abrams, J., Bennett, B., Figdor, C. G., de Vries, J. E. (1991): Interleukin 10(IL-10) inhibits cytokine synthesis by human monocytes: an autoregulatory role of IL-10 produced by monocytes. J Exp Med 174, 1209-20.

Dhanireddy, S., Altemeier, W. A., Matute-Bello, G., O'Mahony, D. S., Glenny, R. W., Martin, T. R., Liles, W. C. (2006): Mechanical ventilation induces inflammation, lung injury, and extra-pulmonary organ dysfunction in experimental pneumonia. Lab Invest $\underline{86}, 790-9$.

Dirnagl, U., Klehmet, J., Braun, J. S., Harms, H., Meisel, C., Ziemssen, T., Prass, K., Meisel, A. (2007): Stroke-induced immunodepression: experimental evidence and clinical relevance. Stroke $\underline{38}, 770-3$.

Dormehl, I., Ras, G., Taylor, G., Hugo, N. (1991): Effect of Pseudomonas aeruginosaderived pyocyanin and 1-hydroxyphenazine on pulmonary mucociliary clearance monitored scintigraphically in the baboon model. Int J Rad Appl Instrum B 18, 455-9.

Dreisin, R. B., Mostow, S. R. (1979): Sulfhydryl-mediated depression of ciliary activity: an adverse effect of acetylcysteine. J Lab Clin Med 93, 674-8.

Dubin, W., Martin, T. R., Swoveland, P., Leturcq, D. J., Moriarty, A. M., Tobias, P. S., Bleecker, E. R., Goldblum, S. E., Hasday, J. D. (1996): Asthma and endotoxin: lipopolysaccharide-binding protein and soluble CD14 in bronchoalveolar compartment. Am J Physiol 270, L736-44.

Dubravec, D. B., Spriggs, D. R., Mannick, J. A., Rodrick, M. L. (1990): Circulating human peripheral blood granulocytes synthesize and secrete tumor necrosis factor alpha. Proc Natl Acad Sci U S A $\underline{87}, 6758-61$. 
El Hassan, N. O., Chess, P. R., Huysman, M. W., Merkus, P. J., de Jongste, J. C. (2001): Rescue use of DNase in critical lung atelectasis and mucus retention in premature neonates. Pediatrics $\underline{108}, 468-70$.

Elenkov, I. J., Wilder, R. L., Chrousos, G. P., Vizi, E. S. (2000): The sympathetic nerve--an integrative interface between two supersystems: the brain and the immune system. Pharmacol Rev 52, 595-638.

Emsley, H. C., Smith, C. J., Gavin, C. M., Georgiou, R. F., Vail, A., Barberan, E. M., Illingworth, K., Scarth, S., Wickramasinghe, V., Hoadley, M. E., Rothwell, N. J., Tyrrell, P. J., Hopkins, S. J. (2007): Clinical outcome following acute ischaemic stroke relates to both activation and autoregulatory inhibition of cytokine production. BMC Neurol 7, 5.

Estes, R. J., Meduri, G. U. (1995): The pathogenesis of ventilator-associated pneumonia: I. Mechanisms of bacterial transcolonization and airway inoculation. Intensive Care Med 21, 365-83.

Evans, C. J., Aguilera, R. J. (2003): DNase II: genes, enzymes and function. Gene 322, 1-15.

Ewig, S., Dalhoff, K., Lorenz, J., Schaberg, T., Welte, T., Wilkens, H. (2000): [Nosocomial pneumonia: recommendations on treatment and prevention. German Pneumology Society]. Pneumologie 54, 525-38.

Fagon, J. Y., Chastre, J., Vuagnat, A., Trouillet, J. L., Novara, A., Gibert, C. (1996): Nosocomial pneumonia and mortality among patients in intensive care units. JAMA $\underline{275}, 866-9$.

Folkesson, H. G., Matthay, M. A., Hebert, C. A., Broaddus, V. C. (1995): Acid aspirationinduced lung injury in rabbits is mediated by interleukin-8-dependent mechanisms. $J$ Clin Invest 96, 107-16.

Frederick, D., Pesanti, E. L. (1987): Intrapulmonary growth of Staphylococcus aureus in rats during induced atelectasis. Infect Immun 55, 2747-53.

Fuchs, H. J., Borowitz, D. S., Christiansen, D. H., Morris, E. M., Nash, M. L., Ramsey, B. W., Rosenstein, B. J., Smith, A. L., Wohl, M. E. (1994): Effect of aerosolized recombinant human DNase on exacerbations of respiratory symptoms and on pulmonary function in patients with cystic fibrosis. The Pulmozyme Study Group. $N$ Engl J Med 331, 637-42.

Gallagher, P. M., Lowe, G., Fitzgerald, T., Bella, A., Greene, C. M., McElvaney, N. G., O'Neill, S. J. (2003): Association of IL-10 polymorphism with severity of illness in community acquired pneumonia. Thorax $\underline{58}$, 154-6.

Gastmeier, P., Sohr, D., Geffers, C., Zuschneid, I., Behnke, M., Ruden, H. (2005): [Mortality in German intensive care units: dying from or with a nosocomial infection?]. Anasthesiol Intensivmed Notfallmed Schmerzther 40, 267-72.

Gene (2008): http://www.gene.com/gene/products/information/opportunistic/pulmozyme/insert.jsp\# overdosage; (Abruf am 5.03.2008).

Gershan, W. M., Rusakow, L. S., Chetty, A., Splaingard, M. L. (1994): Resolution of chronic atelectasis in a child with asthma after aerosolized recombinant human DNase. Pediatr Pulmonol 18, 268-9.

Girod, S., Zahm, J. M., Plotkowski, C., Beck, G., Puchelle, E. (1992): Role of the physiochemical properties of mucus in the protection of the respiratory epithelium. Eur Respir J $\underline{5}, 477-87$.

Goodman, R. M., Yergin, B. M., Landa, J. F., Golivanux, M. H., Sackner, M. A. (1978): Relationship of smoking history and pulmonary function tests to tracheal mucous velocity in nonsmokers, young smokers, ex-smokers, and patients with chronic bronchitis. Am Rev Respir Dis 117, 205-14. 
Griese, M., App, E. M., Duroux, A., Burkert, A., Schams, A. (1997): Recombinant human DNase (rhDNase) influences phospholipid composition, surface activity, rheology and consecutively clearance indices of cystic fibrosis sputum. Pulm Pharmacol Ther $\underline{10}$, 21-7.

Gwilt, C. R., Donnelly, L. E., Rogers, D. F. (2007): The non-neuronal cholinergic system in the airways: an unappreciated regulatory role in pulmonary inflammation? Pharmacol Ther 115, 208-22.

Hailman, E., Lichenstein, H. S., Wurfel, M. M., Miller, D. S., Johnson, D. A., Kelley, M., Busse, L. A., Zukowski, M. M., Wright, S. D. (1994): Lipopolysaccharide (LPS)binding protein accelerates the binding of LPS to CD14. J Exp Med 179, 269-77.

Harms, H. K., Matouk, E., Tournier, G., von der Hardt, H., Weller, P. H., Romano, L., Heijerman, H. G., FitzGerald, M. X., Richard, D., Strandvik, B., Kolbe, J., Kraemer, R., Michalsen, H. (1998): Multicenter, open-label study of recombinant human DNase in cystic fibrosis patients with moderate lung disease. DNase International Study Group. Pediatr Pulmonol 26, 155-61.

Hasani, A., Vora, H., Pavia, D., Agnew, J. E., Clarke, S. W. (1994): No effect of gender on lung mucociliary clearance in young healthy adults. Respir Med $\underline{88}, 697-700$.

Heckmann, J. G., Kraus, J., Niedermeier, W., Erbguth, F., Druschky, A., Schoerner, C., Neundorfer, B. (1999): [Nosocomial pneumonias in a neurology intensive care unit]. Dtsch Med Wochenschr 124, 919-24.

Hehlgans, T., Pfeffer, K. (2005): The intriguing biology of the tumour necrosis factor/tumour necrosis factor receptor superfamily: players, rules and the games. Immunology $\underline{115}$, $1-20$.

Hendriks, T., de Hoog, M., Lequin, M. H., Devos, A. S., Merkus, P. J. (2005): DNase and atelectasis in non-cystic fibrosis pediatric patients. Crit Care 9 , R351-6.

Henry, R. L., Gibson, P. G., Carty, K., Cai, Y., Francis, J. L. (1998): Airway inflammation after treatment with aerosolized deoxyribonuclease in cystic fibrosis. Pediatr Pulmonol 26, 97-100.

Hessle, C., Andersson, B., Wold, A. E. (2000): Gram-positive bacteria are potent inducers of monocytic interleukin-12 (IL-12) while gram-negative bacteria preferentially stimulate IL-10 production. Infect Immun $\underline{68}$, 3581-6.

Hessle, C. C., Andersson, B., Wold, A. E. (2005): Gram-positive and Gram-negative bacteria elicit different patterns of pro-inflammatory cytokines in human monocytes. Cytokine 30, 311-8.

Heuschmann, P. U., Kolominsky-Rabas, P. L., Misselwitz, B., Hermanek, P., Leffmann, C., Janzen, R. W., Rother, J., Buecker-Nott, H. J., Berger, K. (2004): Predictors of inhospital mortality and attributable risks of death after ischemic stroke: the German Stroke Registers Study Group. Arch Intern Med 164, 1761-8.

Hilker, R., Poetter, C., Findeisen, N., Sobesky, J., Jacobs, A., Neveling, M., Heiss, W. D. (2003): Nosocomial pneumonia after acute stroke: implications for neurological intensive care medicine. Stroke $\underline{34}$, 975-81.

Houtmeyers, E., Gosselink, R., Gayan-Ramirez, G., Decramer, M. (1999a): Effects of drugs on mucus clearance. Eur Respir J 14, 452-67.

Houtmeyers, E., Gosselink, R., Gayan-Ramirez, G., Decramer, M. (1999b): Regulation of mucociliary clearance in health and disease. Eur Respir J 13, 1177-88.

Ishizuka, S., Yamaya, M., Suzuki, T., Nakayama, K., Kamanaka, M., Ida, S., Sekizawa, K., Sasaki, H. (2001): Acid exposure stimulates the adherence of Streptococcus pneumoniae to cultured human airway epithelial cells: effects on platelet-activating factor receptor expression. Am J Respir Cell Mol Biol 24, 459-68. 
Jenkins, J. K., Malyak, M., Arend, W. P. (1994): The effects of interleukin-10 on interleukin1 receptor antagonist and interleukin-1 beta production in human monocytes and neutrophils. Lymphokine Cytokine Res 13, 47-54.

Jiang, Y., Magli, L., Russo, M. (1999): Bacterium-dependent induction of cytokines in mononuclear cells and their pathologic consequences in vivo. Infect Immun $\underline{67}, 2125-$ 30.

Jotwani, R., Tanaka, Y., Watanabe, K., Tanaka-Bandoh, K., Kato, N., Ueno, K. (1994): Comparison of cytokine induction by lipopolysaccharide of Bacteroides fragilis with Salmonella typhimurium in mice. Microbiol Immunol 38, 763-6.

Kamin, W., Klar-Hlawatsch, B., Truebel, H. (2006): Easy removal of a large mucus plug with a flexible paediatric bronchoscope after administration of rhDNase (Pulmozyme). Klin Padiatr 218, 88-91.

Kampf, G., Wischnewski, N., Schulgen, G., Schumacher, M., Daschner, F. (1998): Prevalence and risk factors for nosocomial lower respiratory tract infections in German hospitals. J Clin Epidemiol 51, 495-502.

Kardos, P., Cegla, U., Gillissen, A., Kirsten, D., Mitfessel, H., Morr, H., SchultzeWerninghaus, G., Sitter, H., Vogelmeier, C., Voshaar, T., Worth, H., Eckardt, V., Klimek, L. (2004): [Guideline of the German respiratory society for diagnosis and treatment of patients suffering from acute or chronic cough]. Pneumologie $\underline{58}, 570-$ 602.

Kawano, T., Mori, S., Cybulsky, M., Burger, R., Ballin, A., Cutz, E., Bryan, A. C. (1987): Effect of granulocyte depletion in a ventilated surfactant-depleted lung. J Appl Physiol 62, 27-33.

Khair, O. A., Davies, R. J., Devalia, J. L. (1996): Bacterial-induced release of inflammatory mediators by bronchial epithelial cells. Eur Respir J 9, 1913-22.

Kidd, D., Lawson, J., Nesbitt, R., MacMahon, J. (1995): The natural history and clinical consequences of aspiration in acute stroke. QJM $\underline{88}, 409-13$.

Kishimoto, T. (1989): The biology of interleukin-6. Blood 74, 1-10.

Klapproth, H., Racke, K., Wessler, I. (1998): Acetylcholine and nicotine stimulate the release of granulocyte-macrophage colony stimulating factor from cultured human bronchial epithelial cells. Naunyn Schmiedebergs Arch Pharmacol 357, 472-5.

Knapp, S., Florquin, S., Golenbock, D. T., van der Poll, T. (2006): Pulmonary lipopolysaccharide (LPS)-binding protein inhibits the LPS-induced lung inflammation in vivo. J Immunol 176, 3189-95.

Knowles, M. R., Stutts, M. J., Yankaskas, J. R., Gatzy, J. T., Boucher, R. C., Jr. (1986): Abnormal respiratory epithelial ion transport in cystic fibrosis. Clin Chest Med $\underline{7}, 285-$ 97.

Kolsuz, M., Erginel, S., Alatas, O., Alatas, F., Metintas, M., Ucgun, I., Harmanci, E., Colak, O. (2003): Acute phase reactants and cytokine levels in unilateral communityacquired pneumonia. Respiration $\underline{70}, 615-22$.

Kondo, C. S., Macchionne, M., Nakagawa, N. K., de Carvalho, C. R., King, M., Saldiva, P. H., Lorenzi-Filho, G. (2002): Effects of intravenous furosemide on mucociliary transport and rheological properties of patients under mechanical ventilation. Crit Care $\underline{6}, 81-7$.

Konrad, F., Schreiber, T., Brecht-Kraus, D., Georgieff, M. (1993): Bronchial mucus transport in chronic smokers and nonsmokers during general anesthesia. $J$ Clin Anesth $\underline{5}, 375-80$.

Konrad, F., Schreiber, T., Brecht-Kraus, D., Georgieff, M. (1994): Mucociliary transport in ICU patients. Chest $\underline{105}, 237-41$. 
Konrad, F., Schiener, R., Marx, T., Georgieff, M. (1995): Ultrastructure and mucociliary transport of bronchial respiratory epithelium in intubated patients. Intensive Care Med $\underline{21}, 482-9$.

Konrad, F., Schraag, S., Marx, T., Kilian, J., Goertz, A. (1998): [The effect of total intravenous anesthesia with propofol, alfentanil and vecuronium (TIVA) on bronchial mucosal transport]. Anasthesiol Intensivmed Notfallmed Schmerzther 33, 171-6.

Kraus, J., Heckmann J.G., Erbguth, F., Jauß, M., Neundörfer, B. (2002): Risikofaktoren für die Entwicklung einer nosokomialen Pneumonie bei Patienten einer neurologischen Intensivstation bezogen auf neurologische und internistische Grunderkrankungen. Intensivmed 39: 537-543.

Krieser, R. J., MacLea, K. S., Park, J. P., Eastman, A. (2001): The cloning, genomic structure, localization, and expression of human deoxyribonuclease IIbeta. Gene $\underline{269}$, 205-16.

Küpeli, S., Teksam, O., Dogru, D., Yurdakok, M. (2003): Use of recombinant human DNase in a premature infant with recurrent atelectasis. Pediatr Int $\underline{45}$, 584-6.

Landa, J. F., Kwoka, M. A., Chapman, G. A., Brito, M., Sackner, M. A. (1980): Effects of suctioning on mucociliary transport. Chest 77, 202-7.

Laube, B. L., Auci, R. M., Shields, D. E., Christiansen, D. H., Lucas, M. K., Fuchs, H. J., Rosenstein, B. J. (1996): Effect of rhDNase on airflow obstruction and mucociliary clearance in cystic fibrosis. Am J Respir Crit Care Med 153, 752-60.

Laurenzi, G. A., Yin, S., Guarneri, J. J. (1968): Adverse effect of oxygen on tracheal mucus flow. N Engl J Med 279, 333-9.

Le, J. M., Vilcek, J. (1989): Interleukin 6: a multifunctional cytokine regulating immune reactions and the acute phase protein response. Lab Invest $\underline{61}$, 588-602.

Ledowski, T., Paech, M. J., Patel, B., Schug, S. A. (2006): Bronchial mucus transport velocity in patients receiving propofol and remifentanil versus sevoflurane and remifentanil anesthesia. Anesth Analg 102, 1427-30.

Lefering, R. (2002): Erste Ergebnisse des nationalen Registers zum externen Qualitätsvergleich der Intensivmedizin. Intensivmed 39, 334-40.

Leith, D. E. (1968): Cough. Phys Ther $\underline{48}, 439-47$.

Lethem, M. I., James, S. L., Marriott, C., Burke, J. F. (1990): The origin of DNA associated with mucus glycoproteins in cystic fibrosis sputum. Eur Respir $J \underline{3}, 19-23$.

Lindemann, A., Riedel, D., Oster, W., Ziegler-Heitbrock, H. W., Mertelsmann, R., Herrmann, F. (1989): Granulocyte-macrophage colony-stimulating factor induces cytokine secretion by human polymorphonuclear leukocytes. J Clin Invest $\underline{83}, 1308$ 12.

Lord, P. C., Wilmoth, L. M., Mizel, S. B., McCall, C. E. (1991): Expression of interleukin-1 alpha and beta genes by human blood polymorphonuclear leukocytes. J Clin Invest $\underline{87}$, 1312-21.

Lu, Q., Capderou, A., Cluzel, P., Mourgeon, E., Abdennour, L., Law-Koune, J. D., Straus, C., Grenier, P., Zelter, M., Rouby, J. J. (2000): A computed tomographic scan assessment of endotracheal suctioning-induced bronchoconstriction in ventilated sheep. Am J Respir Crit Care Med 162, 1898-904.

Lundgren, R., Horstedt, P., Winblad, B. (1983): Respiratory mucosal damage by flexible fiberoptic bronchoscopy in pigs. Eur J Respir Dis 64, 24-32.

Lundy, D. S., Smith, C., Colangelo, L., Sullivan, P. A., Logemann, J. A., Lazarus, C. L., Newman, L. A., Murry, T., Lombard, L., Gaziano, J. (1999): Aspiration: cause and implications. Otolaryngol Head Neck Surg 120, 474-8.

Manna, S. S., Shaw, J., Tibby, S. M., Durward, A. (2003): Treatment of plastic bronchitis in acute chest syndrome of sickle cell disease with intratracheal rhDNase. Arch Dis Child $\underline{88}, 626-7$. 
Meisel, C., Schwab, J. M., Prass, K., Meisel, A., Dirnagl, U. (2005): Central nervous system injury-induced immune deficiency syndrome. Nat Rev Neurosci $\underline{6}, 775-86$.

Meyer, K. C., Ershler, W., Rosenthal, N. S., Lu, X. G., Peterson, K. (1996): Immune dysregulation in the aging human lung. Am J Respir Crit Care Med 153, 1072-9.

Michelow, I. C., Katz, K., McCracken, G. H., Hardy, R. D. (2007): Systemic cytokine profile in children with community-acquired pneumonia. Pediatr Pulmonol $\underline{42}, 640-5$.

Morar, P., Singh, V., Zvoru, M., Jones, A., Baines, P., Seiby, A., Sarginson, R., Hughes J., van Saene, R. (2002): Differing pathways of lower airway colonisation and infection according to mode of ventilation (endotracheal vs tracheotomy). Arch Otolaryngol Head Neck Surg 128, 1061-6.

Mortensen, J., Lange, P., Nyboe, J., Groth, S. (1994): Lung mucociliary clearance. Eur J Nucl Med 21, 953-61.

Mosconi, P., Langer, M., Cigada, M., Mandelli, M. (1991): Epidemiology and risk factors of pneumonia in critically ill patients. Intensive Care Unit Group for Infection Control. Eur J Epidemiol 7, 320-7.

Munro, N. C., Barker, A., Rutman, A., Taylor, G., Watson, D., McDonald-Gibson, W. J., Towart, R., Taylor, W. A., Wilson, R., Cole, P. J. (1989): Effect of pyocyanin and 1hydroxyphenazine on in vivo tracheal mucus velocity. J Appl Physiol 67, 316-23.

Nahori, M. A., Renesto, P., Vargaftig, B. B., Chignard, M. (1992): Activation and damage of cultured airway epithelial cells by human elastase and cathepsin G. Eur J Pharmacol $\underline{228}, 213-8$.

Nakamura, H., Yoshimura, K., McElvaney, N. G., Crystal, R. G. (1992): Neutrophil elastase in respiratory epithelial lining fluid of individuals with cystic fibrosis induces interleukin-8 gene expression in a human bronchial epithelial cell line. J Clin Invest $\underline{89}, 1478-84$.

Nakos, G., Tsangaris, H., Liokatis, S., Kitsiouli, E., Lekka, M. E. (2003): Ventilatorassociated pneumonia and atelectasis: evaluation through bronchoalveolar lavage fluid analysis. Intensive Care Med 29, 555-63.

Nasr, S. Z., Strouse, P. J., Soskolne, E., Maxvold, N. J., Garver, K. A., Rubin, B. K., Moler, F. W. (2001): Efficacy of recombinant human deoxyribonuclease I in the hospital management of respiratory syncytial virus bronchiolitis. Chest $120,203-8$.

Nishimoto, N., Kishimoto, T. (2006): Interleukin 6: from bench to bedside. Nat Clin Pract Rheumatol 2, 619-26.

Nishina, K., Mikawa, K., Takao, Y., Shiga, M., Maekawa, N., Obara, H. (1998): Intravenous lidocaine attenuates acute lung injury induced by hydrochloric acid aspiration in rabbits. Anesthesiology $\underline{88}, 1300-9$.

O'Donnell, A. E., Barker, A. F., Ilowite, J. S., Fick, R. B. (1998): Treatment of idiopathic bronchiectasis with aerosolized recombinant human DNase I. rhDNase Study Group. Chest 113, 1329-34.

Papoff, P., Christensen, R. D., Calhoun, D. A., Juul, S. E. (2001): Granulocyte colonystimulating factor, granulocyte macrophage colony-stimulating factor and neutrophils in the bronchoalveolar lavage fluid of premature infants with respiratory distress syndrome. Biol Neonate $\underline{80}$, 133-41.

Patel, A., Harrison, E., Durward, A., Murdoch, I. A. (2000): Intratracheal recombinant human deoxyribonuclease in acute life-threatening asthma refractory to conventional treatment. Br J Anaesth 84, 505-7.

Patrick, G., Stirling, C. (1977): Measurement of mucociliary clearance from the trachea of conscious and anesthetized rats. J Appl Physiol $\underline{42}, 451-5$.

Paul, K., Rietschel, E., Ballmann, M., Griese, M., Worlitzsch, D., Shute, J., Chen, C., Schink, T., Doring, G., van Koningsbruggen, S., Wahn, U., Ratjen, F. (2004): Effect 
of treatment with dornase alpha on airway inflammation in patients with cystic fibrosis. Am J Respir Crit Care Med 169, 719-25.

Pavia, D. (1987): Acute respiratory infections and mucociliary clearance. Eur J Respir Dis $\underline{71}$, 219-26.

Pedersen, B. K., Bruunsgaard, H., Ostrowski, K., Krabbe, K., Hansen, H., Krzywkowski, K., Toft, A., Sondergaard, S. R., Petersen, E. W., Ibfelt, T., Schjerling, P. (2000): Cytokines in aging and exercise. Int J Sports Med 21 Suppl 1, S4-9.

Perks, B., Shute, J. K. (2000): DNA and actin bind and inhibit interleukin-8 function in cystic fibrosis sputa: in vitro effects of mucolytics. Am J Respir Crit Care Med 162, 176772.

Peveri, P., Walz, A., Dewald, B., Baggiolini, M. (1988): A novel neutrophil-activating factor produced by human mononuclear phagocytes. J Exp Med 167, 1547-59.

Prins, J. M., Kuijper, E. J., Mevissen, M. L., Speelman, P., van Deventer, S. J. (1995): Release of tumor necrosis factor alpha and interleukin 6 during antibiotic killing of Escherichia coli in whole blood: influence of antibiotic class, antibiotic concentration, and presence of septic serum. Infect Immun 63, 2236-42.

Prod'hom, G., Leuenberger, P., Koerfer, J., Blum, A., Chiolero, R., Schaller, M. D., Perret, C., Spinnler, O., Blondel, J., Siegrist, H., Saghafi, L., Blanc, D., Francioli, P. (1994): Nosocomial pneumonia in mechanically ventilated patients receiving antacid, ranitidine, or sucralfate as prophylaxis for stress ulcer. A randomized controlled trial. Ann Intern Med 120, 653-62.

Puchelle, E., Tournier, J. M., Petit, A., Zahm, J. M., Lauque, D., Vidailhet, M., Sadoul, P. (1983): The frog palate for studying mucus transport velocity and mucociliary frequency. Eur J Respir Dis Suppl 128 (Pt 1), 293-303.

Pugin, J., Dunn, I., Jolliet, P., Tassaux, D., Magnenat, J. L., Nicod, L. P., Chevrolet, J. C. (1998): Activation of human macrophages by mechanical ventilation in vitro. Am J Physiol 275, L1040-50.

Pulmozyme ${ }^{\circledR} 2002$ a: Product Monograph Update 2, produced by Gardiner-Caldwell Communications Ltd for F. Hoffmann-La Roche Ltd Basel, 2002, Seite(n) 10-12.

Pulmozyme ${ }^{\circledR} 2002$ b: Product Monograph Update 2, produced by Gardiner-Caldwell Communications Ltd for F. Hoffmann-La Roche Ltd Basel, 2002, Seite 14.

Pulmozyme ${ }^{\circledR} 2002$ c: Product Monograph Update 2, produced by Gardiner-Caldwell Communications Ltd for F. Hoffmann-La Roche Ltd Basel, 2002, Seite 61.

Ratjen, F., Tummler, B. (1999): Comparison of the in vitro and in vivo response to inhaled DNase in patients with cystic fibrosis. Thorax 54, 91.

Ratjen, F., Paul, K., van Koningsbruggen, S., Breitenstein, S., Rietschel, E., Nikolaizik, W. (2005): DNA concentrations in BAL fluid of cystic fibrosis patients with early lung disease: influence of treatment with dornase alpha. Pediatr Pulmonol $\underline{39}, 1-4$.

Read, R. C., Roberts, P., Munro, N., Rutman, A., Hastie, A., Shryock, T., Hall, R., McDonald-Gibson, W., Lund, V., Taylor, G., et al. (1992): Effect of Pseudomonas aeruginosa rhamnolipids on mucociliary transport and ciliary beating. $J$ Appl Physiol 72, 2271-7.

Reinheimer, T., Vogel, P., Racke, K., Bittinger, F., Kirkpatrick, C. J., Saloga, J., Knop, J., Wessler, I. (1998 a): Non-neuronal acetylcholine is increased in chronic inflammation like atopic dermatitis. Naunyn-Schmiedberg's Arch Pharmacol (Suppl) 358, R87.

Reinheimer, T., Munch, M., Bittinger, F., Racke, K., Kirkpatrick, C. J., Wessler, I. (1998 b): Glucocorticoids mediate reduction of epithelial acetylcholine content in the airways of rats and humans. Eur J Pharmacol 349, 277-84.

Reiter, P. D., Townsend, S. F., Velasquez, R. (2000): Dornase alfa in premature infants with severe respiratory distress and early bronchopulmonary dysplasia. J Perinatol $\underline{20}, 530$ 4. 
Riede UN, Costabel U: Respiratorisches system; in: Allgemeine und spezielle Pathologie; hrsg. v. Riede UN, Werner M, Schaefer HE; Georg Thieme Verlag, Stuttgart 2004, 622.

Riethmueller, J., Borth-Bruhns, T., Kumpf, M., Vonthein, R., Wiskirchen, J., Stern, M., Hofbeck, M., Baden, W. (2006): Recombinant human deoxyribonuclease shortens ventilation time in young, mechanically ventilated children. Pediatr Pulmonol $\underline{41}, 61-$ 6.

Robinson, M., Hemming, A. L., Moriarty, C., Eberl, S., Bye, P. T. (2000): Effect of a short course of rhDNase on cough and mucociliary clearance in patients with cystic fibrosis. Pediatr Pulmonol 30, 16-24.

Rosenwasser, L. J. (1998): Biologic activities of IL-1 and its role in human disease. J Allergy Clin Immunol 102, 344-50.

RoteListe ${ }^{\circledR}$ (2008a): http://www.rote-liste.de/Online/jumpsearch: Pulmozyme; (Abruf am 1.03.2008).

RoteListe ${ }^{\circledR}$ (2008 b): http://www.rote-liste.de/Online/jsearch_signaturen,S 12; (Abruf am 30.04.2008).

Roth, Y., Aharonson, E. F., Teichtahl, H., Baum, G. L., Priel, Z., Modan, M. (1991): Human in vitro nasal and tracheal ciliary beat frequencies: comparison of sampling sites, combined effect of medication, and demographic relationships. Ann Otol Rhinol Laryngol 100, 378-84.

Rotta, A. T., Shiley, K. T., Davidson, B. A., Helinski, J. D., Russo, T. A., Knight, P. R. (2004): Gastric acid and particulate aspiration injury inhibits pulmonary bacterial clearance. Crit Care Med 32, 747-54.

Sackner, M. A., Hirsch, J., Epstein, S. (1975): Effect of cuffed endotracheal tubes on tracheal mucous velocity. Chest $\underline{68}, 774-7$.

Safdar, N., Dezfulian, C., Collard, H. R., Saint, S. (2005): Clinical and economic consequences of ventilator-associated pneumonia: a systematic review. Crit Care Med 33, 2184-93.

Salemi, C., Morgan, J. W., Kelleghan, S. I., Hiebert-Crape, B. (1993): Severity of illness classification for infection control departments: a study in nosocomial pneumonia. Am J Infect Control 21, 117-26.

Sanders, N. N., Franckx, H., De Boeck, K., Haustraete, J., De Smedt, S. C., Demeester, J. (2006): Role of magnesium in the failure of rhDNase therapy in patients with cystic fibrosis. Thorax $61,962-8$.

Schmidt, J., Holas, M., Halvorson, K., Reding, M. (1994): Videofluoroscopic evidence of aspiration predicts pneumonia and death but not dehydration following stroke. Dysphagia $\underline{9}, 7-11$.

Schröder, N. W., Heine, H., Alexander, C., Manukyan, M., Eckert, J., Hamann, L., Gobel, U. B., Schumann, R. R. (2004): Lipopolysaccharide binding protein binds to triacylated and diacylated lipopeptides and mediates innate immune responses. $J$ Immunol 173, 2683-91.

Schulte-Herbruggen, O., Quarcoo, D., Brzoska, T., Klehmet, J., Meisel, A., Meisel, C. (2008): Alpha-MSH promotes spontaneous post-ischemic pneumonia in mice via melanocortin-receptor-1. Exp Neurol 210, 731-9.

Schumacher M, Olschewski M: Analyse von Ereigniszeiten - Teil I.; in: Methodik klinischer Studien; hrsg. v. Schumacher M, Schulgen G; Springer, Berlin. 2002, 71-88.

Shah, P. L., Scott, S. F., Knight, R. A., Marriott, C., Ranasinha, C., Hodson, M. E. (1996 a): In vivo effects of recombinant human DNase I on sputum in patients with cystic fibrosis. Thorax $\underline{51}, 119-25$. 
Shah, P. L., Scott, S. F., Knight, R. A., Hodson, M. E. (1996 b): The effects of recombinant human DNase on neutrophil elastase activity and interleukin-8 levels in the sputum of patients with cystic fibrosis. Eur Respir J $\underline{9}, 531-4$.

Shah, P. L., Conway, S., Scott, S. F., Rainisio, M., Wildman, M., Stableforth, D., Hodson, M. E. (2001): A case-controlled study with dornase alfa to evaluate impact on disease progression over a 4-year period. Respiration $\underline{68}, 160-4$.

Shak, S., Capon, D. J., Hellmiss, R., Marsters, S. A., Baker, C. L. (1990): Recombinant human DNase I reduces the viscosity of cystic fibrosis sputum. Proc Natl Acad Sci $U$ $S$ A $\underline{87}, 9188-92$.

Shennib, H., Mulder, D. S., Chiu, R. C. (1984): The effects of pulmonary atelectasis and reexpansion on lung cellular immune defenses. Arch Surg 119, 274-7.

Shiokawa, D., Tanuma, S. (2001): Characterization of human DNase I family endonucleases and activation of DNase gamma during apoptosis. Biochemistry $\underline{40}, 143-52$.

Shirafuji, N., Matsuda, S., Ogura, H., Tani, K., Kodo, H., Ozawa, K., Nagata, S., Asano, S., Takaku, F. (1990): Granulocyte colony-stimulating factor stimulates human mature neutrophilic granulocytes to produce interferon-alpha. Blood 75, 17-9.

Simon, D. M., Koenig, G., Trenholme, G. M. (1991): Differences in release of tumor necrosis factor from THP-1 cells stimulated by filtrates of antibiotic-killed Escherichia coli. J Infect Dis 164, 800-2.

Simpson, G., Roomes, D., Reeves, B. (2003): Successful treatment of empyema thoracis with human recombinant deoxyribonuclease. Thorax $\underline{58}$, 365-6.

Sinicropi, D.V., Williams, M., Prince, W.S., Lofgren J.A., Lucas, M., Devault, A., Baugham, S., Nash, M., Fuchs H., Shak S. (1994): Sputum pharmacodynamics and pharmacokinetics of recombinant human DNase I in cystic fibrosis. [Abstract] Am J Respir Crit Care Med 149, A671.

Smallman, L. A., Hill, S. L., Stockley, R. A. (1984): Reduction of ciliary beat frequency in vitro by sputum from patients with bronchiectasis: a serine proteinase effect. Thorax $\underline{39}, 663-7$.

Spera, P. A., Ellison, J. A., Feuerstein, G. Z., Barone, F. C. (1998): IL-10 reduces rat brain injury following focal stroke. Neurosci Lett 251, 189-92.

Standiford, T. J., Kunkel, S. L., Basha, M. A., Chensue, S. W., Lynch, J. P., 3rd, Toews, G. B., Westwick, J., Strieter, R. M. (1990): Interleukin-8 gene expression by a pulmonary epithelial cell line. A model for cytokine networks in the lung. J Clin Invest $\underline{86}, 1945-53$.

Strieter, R. M., Wiggins, R., Phan, S. H., Wharram, B. L., Showell, H. J., Remick, D. G., Chensue, S. W., Kunkel, S. L. (1989): Monocyte chemotactic protein gene expression by cytokine-treated human fibroblasts and endothelial cells. Biochem Biophys Res Commun 162, 694-700.

Strieter, R. M., Kasahara, K., Allen, R. M., Standiford, T. J., Rolfe, M. W., Becker, F. S., Chensue, S. W., Kunkel, S. L. (1992): Cytokine-induced neutrophil-derived interleukin-8. Am J Pathol 141, 397-407.

Suri, R., Metcalfe, C., Lees, B., Grieve, R., Flather, M., Normand, C., Thompson, S., Bush, A., Wallis, C. (2001): Comparison of hypertonic saline and alternate-day or daily recombinant human deoxyribonuclease in children with cystic fibrosis: a randomised trial. Lancet $358,1316-21$.

Svartengren, M., Mossberg, B., Philipson, K., Camner, P. (1986): Mucociliary clearance in relation to clinical features in patients with bronchiectasis. Eur J Respir Dis $\underline{68}, 267-$ 78.

Svartengren, M., Falk, R., Philipson, K. (2005): Long-term clearance from small airways decreases with age. Eur Respir J 26, 609-15. 
Thornton, A. J., Strieter, R. M., Lindley, I., Baggiolini, M., Kunkel, S. L. (1990): Cytokineinduced gene expression of a neutrophil chemotactic factor/IL-8 in human hepatocytes. J Immunol 144, 2609-13.

Tiku, K., Tiku, M. L., Skosey, J. L. (1986): Interleukin 1 production by human polymorphonuclear neutrophils. J Immunol 136, 3677-85.

Tobias, P. S., Soldau, K., Gegner, J. A., Mintz, D., Ulevitch, R. J. (1995): Lipopolysaccharide binding protein-mediated complexation of lipopolysaccharide with soluble CD14. J Biol Chem 270, 10482-8.

Tomashefski, J. F., Jr., Bruce, M., Goldberg, H. I., Dearborn, D. G. (1986): Regional distribution of macroscopic lung disease in cystic fibrosis. Am Rev Respir Dis $\underline{133}$, 535-40.

Tournoy, K. G., Kips, J. C., Pauwels, R. A. (2000): Endogenous interleukin-10 suppresses allergen-induced airway inflammation and nonspecific airway responsiveness. Clin Exp Allergy $\underline{30}, 775-83$.

Tsuchida, S., Engelberts, D., Peltekova, V., Hopkins, N., Frndova, H., Babyn, P., McKerlie, C., Post, M., McLoughlin, P., Kavanagh, B. P. (2006): Atelectasis causes alveolar injury in nonatelectatic lung regions. Am J Respir Crit Care Med 174, 279-89.

Tsuda, T., Noguchi, H., Takumi, Y., Aochi, O. (1977): Optimum humidification of air administered to a tracheostomy in dogs. Scanning electron microscopy and surfactant studies. Br J Anaesth 49, 965-77.

Uni-duesseldorf (2008): http://www.uni-duesseldorf.de/AWMF/11-na/026-014.htm;(Abruf am 04.05.2008).

van der Giessen, L. J., de Jongste, J. C., Gosselink, R., Hop, W. C., Tiddens, H. A. (2007): $\mathrm{RhDNase}$ before airway clearance therapy improves airway patency in children with CF. Pediatr Pulmonol 42, 624-30.

van Kaam, A. H., Lachmann, R. A., Herting, E., De Jaegere, A., van Iwaarden, F., Noorduyn, L. A., Kok, J. H., Haitsma, J. J., Lachmann, B. (2004): Reducing atelectasis attenuates bacterial growth and translocation in experimental pneumonia. Am J Respir Crit Care Med 169, 1046-53.

Verdugo, P. (1991): Mucin exocytosis. Am Rev Respir Dis 144, S33-7.

Vincent, J. L., Bihari, D. J., Suter, P. M., Bruining, H. A., White, J., Nicolas-Chanoin, M. H., Wolff, M., Spencer, R. C., Hemmer, M. (1995): The prevalence of nosocomial infection in intensive care units in Europe. Results of the European Prevalence of Infection in Intensive Care (EPIC) Study. EPIC International Advisory Committee. JAMA 274, 639-44.

Vlahakis, N. E., Schroeder, M. A., Limper, A. H., Hubmayr, R. D. (1999): Stretch induces cytokine release by alveolar epithelial cells in vitro. Am J Physiol 277, L167-73.

Voelker, K. G., Chetty, K. G., Mahutte, C. K. (1996): Resolution of recurrent atelectasis in spinal cord injury patients with administration of recombinant human DNase. Intensive Care Med 22, 582-4.

Vreugdenhil, A. C., Dentener, M. A., Snoek, A. M., Greve, J. W., Buurman, W. A. (1999): Lipopolysaccharide binding protein and serum amyloid A secretion by human intestinal epithelial cells during the acute phase response. J Immunol 163 , 2792-8.

Wills, P. J., Wodehouse, T., Corkery, K., Mallon, K., Wilson, R., Cole, P. J. (1996): Shortterm recombinant human DNase in bronchiectasis. Effect on clinical state and in vitro sputum transportability. Am J Respir Crit Care Med 154, 413-7.

Wilson, R., Roberts, D., Cole, P. (1985): Effect of bacterial products on human ciliary function in vitro. Thorax $\underline{40}, 125-31$.

Woloski, B. M., Smith, E. M., Meyer, W. J., 3rd, Fuller, G. M., Blalock, J. E. (1985): Corticotropin-releasing activity of monokines. Science 230, 1035-7. 
Wong, J. W., Keens, T. G., Wannamaker, E. M., Crozier, D. N., Levison, H., Aspin, N. (1977): Effects of gravity on tracheal mucus transport rates in normal subjects and in patients with cystic fibrosis. Pediatrics $\underline{60}, 146-52$

Worth, H., Goeckenjan, G., Hagedorn, H. J., Pfitzer, P. (1982): [Effects of long-term ventilation on the bronchial system. Bronchoscopic, cytologic and microbiological findings]. Dtsch Med Wochenschr 107, 1747-50.

Wu, C. L., Lee, Y. L., Chang, K. M., Chang, G. C., King, S. L., Chiang, C. D., Niederman, M. S. (2003): Bronchoalveolar interleukin-1 beta: a marker of bacterial burden in mechanically ventilated patients with community-acquired pneumonia. Crit Care Med $\underline{31}, 812-7$.

Wu, C. L., Chan, M. C., Chang, G. C., Lee, Y. L., Chin, C. S., Chang, K. M., Hsu, J. Y. (2006): Etiology and cytokine expression in patients requiring mechanical ventilation due to severe community-acquired pneumonia. J Formos Med Assoc 105, 49-55.

Wynne, J. W., Ramphal, R., Hood, C. I. (1981): Tracheal mucosal damage after aspiration. A scanning electron Microscope study. Am Rev Respir Dis 124, 728-32.

Yager, J., Chen, T. M., Dulfano, M. J. (1978): Measurement of frequency of ciliary beats of human respiratory epithelium. Chest $\underline{73}$, 627-33.

Yamasawa, H., Oshikawa, K., Ohno, S., Sugiyama, Y. (2004): Macrolides inhibit epithelial cell-mediated neutrophil survival by modulating granulocyte macrophage colonystimulating factor release. Am J Respir Cell Mol Biol 30, 569-75.

Yasuda, T., Nadano, D., Awazu, S., Kishi, K. (1992): Human urine deoxyribonuclease II (DNase II) isoenzymes: a novel immunoaffinity purification, biochemical multiplicity, genetic heterogeneity and broad distribution among tissues and body fluids. Biochim Biophys Acta 1119, 185-93.

Zahm, J. M., Girod de Bentzmann, S., Deneuville, E., Perrot-Minnot, C., Dabadie, A., Pennaforte, F., Roussey, M., Shak, S., Puchelle, E. (1995): Dose-dependent in vitro effect of recombinant human DNase on rheological and transport properties of cystic fibrosis respiratory mucus. Eur Respir $J \underline{8}, 381-6$.

Zahm, J. M., Galabert, C., Chaffin, A., Chazalette, J. P., Grosskopf, C., Puchelle, E. (1998): Improvement of cystic fibrosis airway mucus transportability by recombinant human DNase is related to changes in phospholipid profile. Am J Respir Crit Care Med 157, 1779-84.

Zolldann, D., Spitzer, C., Hafner, H., Waitschies, B., Klein, W., Sohr, D., Block, F., Lutticken, R., Lemmen, S. W. (2005): Surveillance of nosocomial infections in a neurologic intensive care unit. Infect Control Hosp Epidemiol 26, 726-31.

Zughaier, S. M., Ryley, H. C., Jackson, S. K. (1999): Lipopolysaccharide (LPS) from Burkholderia cepacia is more active than LPS from Pseudomonas aeruginosa and Stenotrophomonas maltophilia in stimulating tumor necrosis factor alpha from human monocytes. Infect Immun $\underline{67}, 1505-7$. 


\section{Publikationen im Rahmen der Lufit-Studie}

1. Deschner, N., Riethmüller, J.: Influence of rhDNAse on the duration of mechanical ventilation in intensive care patients. 9/07 HAI, Berlin

2. Deschner, N., Riethmüller, J.(2008): Influence of rhDNAse on the duration of mechanical ventilation in intensive care patients. European Journal of Anaesthesiology Supp 44, 25.

3. Riessen, R., Deschner, N., Brehm, W., Vonthein, R., Riethmüller, J. (2008):

Einfluss

von rhDNase auf die Dauer der künstlichen Beatmung bei

Intensivpatienten. Intensivmed $\underline{45}, 222-50$.

4. Deschner, N., Brehm, W., Vonthein, R., Lorenz, J., Unertl, K., Riethmueller, J.: Recombinant human DNase reduces duration of ventilation in non-surgical but not in surgical mechanically ventilated intensive care patients.

AJRCCM eingereicht 12/2008 


\section{Danksagung}

Mein großer Dank gilt Herrn Prof. Dr. med. Hilmar Prange, der mir vorliegendes hochinteressante Thema zur Bearbeitung zur Verfügung stellte. Seine Betreuung war außergewöhnlich, stand er mir doch jederzeit mit konstruktiver Kritik zur Seite, begleitete mich mit Sorgfalt und erschloss mir, nicht zuletzt durch stets geführte, lehrreiche und anregende Diskussionen, die große Freude und den Erfolg am wissenschaftlichen Arbeiten.

Allen Prüfärzten von der Station 1013 des Universitätsklinikums Göttingen, besonders Herrn Dr. med. Peter Ratzka, bin ich zu großem Dank für die Hilfe bei der Organisation des Studienzentrums verpflichtet.

Des Weiteren danke ich dem Pflegepersonal der Station 1013 für die tägliche Unterstützung und das Entgegenkommen bei der Durchführung der Studie.

Herrn Dr. Klaus Jung möchte ich für die statistische Ausarbeitung von Ergebnissen des Göttinger Studienzentrums danken.

Mein besonderer Dank gilt Herrn Prof. Dr. med. László Füzesi: Sein ganz persönlicher Einsatz für Studenten, der auch mir zuteil wurde, seine Begeisterungsfähigkeit für die Medizin, die einen immer wieder mitriss und zu Neuem motivierte, seine Prägungen und Hilfestellungen in diesem zeitlich enorm wichtigen Abschnitt meines Lebens, derer ich mich sicherlich immer und gerne erinnern werde, sollen hier nochmals Erwähnung finden.

Nicht zuletzt danke ich meiner Familie, die mir während des Studiums der Medizin mit großer Geduld, Hilfsbereitschaft und Liebe zur Seite stand und hierdurch vieles ermöglichte. 


\section{Lebenslauf}

Am 10.08.1983 wurde ich, Maria Grigoryev, als Tochter des Radiologenehepaares

Dr. Yuriy Volfson und Dr. Nadejda Grigoryev, in Charkow, Ukraine, geboren.

Dort besuchte ich von 1990 bis 1995 die Grundschule Nr. 51.

Im Jahre 1995 wanderte ich mit meiner Familie nach Petah-Tiqwa, Israel, aus.

Nach dem Besuch der Mittelschule „Ehad Haam“ von 1995 bis 1997 erlangte ich am Gymnasium „Ehad Haam“ im Jahre 2000 den Hochschulabschluss.

Am Goethe-Institut in Bremen erlernte ich die ersten Kenntnisse der deutschen Sprache und bestand in Göttingen im April 2001 die DSH-Prüfung.

Von 2001 bis 2007 absolvierte ich mein Studium der Humanmedizin an der GeorgAugust-Universität Göttingen. Mein Praktisches Jahr vom Februar 2006 bis Januar 2007 verbrachte ich am Universitätsklinikum Göttingen mit Wahlfach Pathologie.

Seit August 2008 bin ich als Assistenzärztin am Institut für Radiologie an der CharitéUniversitätsmedizin Berlin tätig. 